\title{
Peripheral pharmacological targets to modify bladder contractility
}

Citation for published version (APA):

Hohnen, R. (2016). Peripheral pharmacological targets to modify bladder contractility. [Doctoral Thesis, Maastricht University]. Maastricht University. https://doi.org/10.26481/dis.20160225rh

Document status and date:

Published: 01/01/2016

DOI:

10.26481/dis.20160225rh

Document Version:

Publisher's PDF, also known as Version of record

\section{Please check the document version of this publication:}

- A submitted manuscript is the version of the article upon submission and before peer-review. There can be important differences between the submitted version and the official published version of record.

People interested in the research are advised to contact the author for the final version of the publication, or visit the DOI to the publisher's website.

- The final author version and the galley proof are versions of the publication after peer review.

- The final published version features the final layout of the paper including the volume, issue and page numbers.

Link to publication

\footnotetext{
General rights rights.

- You may freely distribute the URL identifying the publication in the public portal. please follow below link for the End User Agreement:

www.umlib.nl/taverne-license

Take down policy

If you believe that this document breaches copyright please contact us at:

repository@maastrichtuniversity.nl

providing details and we will investigate your claim.
}

Copyright and moral rights for the publications made accessible in the public portal are retained by the authors and/or other copyright owners and it is a condition of accessing publications that users recognise and abide by the legal requirements associated with these

- Users may download and print one copy of any publication from the public portal for the purpose of private study or research.

- You may not further distribute the material or use it for any profit-making activity or commercial gain

If the publication is distributed under the terms of Article $25 \mathrm{fa}$ of the Dutch Copyright Act, indicated by the "Taverne" license above, 


\section{Peripheral Pharmacological Targets to Modify Bladder Contractility}

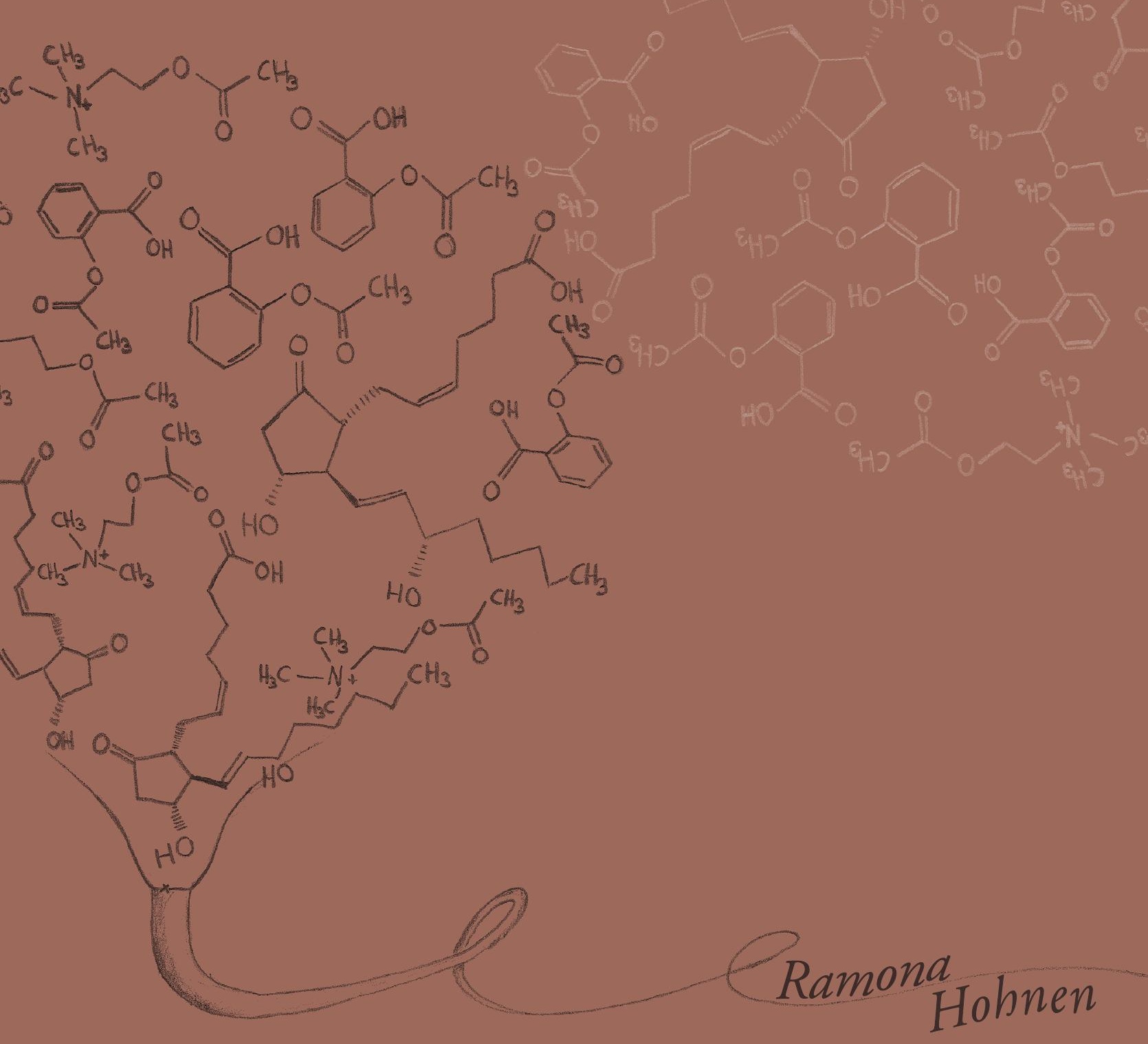




\section{Peripheral Pharmacological Targets to Modify Bladder Contractility}

Ramona Hohnen 
Peripheral Pharmacological Targets to Modify Bladder Contractility - Ramona Hohnen (C) 2015 Ramona Hohnen

ISBN 978-90-9029491-9

Cover Design: Alexandra Hohnen, Jean Blom \& Ramona Hohnen

Design: Ramona Hohnen

Printing \& Binding: 5nul8 Grafische Producties, Valkenburg a/d Geul, The Netherlands - info@5nul8.nl

Sponsors: Society of Urological Research and Education (SURE), Stichting Wetenschappelijke Activiteiten Maastrichtse Urologie (WAMU), Sanofi, Astellas Pharma.

All rights reserved. No part of this thesis may be reproduced, stored in a retrieval center of any nature, or transmitted, in any form or by any means, electronic, mechanical, photocopying, recording or otherwise, without permission of the author. 


\title{
Peripheral Pharmacological Targets to Modify Bladder Contractility
}

\author{
PROEFSCHRIFT
}

Ter verkrijging van de graad van doctor aan de Universiteit Maastricht, op gezag van de Rector Magnificus, Prof. Dr. L.L.G. Soete, volgens het besluit van het College van Decanen, in het openbaar te verdedigen op donderdag 25 februari 2016 om 14:00 uur

door

Ramona Hohnen 


\section{PROMOTOR}

Prof. Dr. G.A. van Koeveringe

Prof. Dr. Ph.E.V. van Kerrebroeck

CO-PROMOTORES

Dr. M.S. Rahnama'i

Dr. C. Meriaux (Université de Lille)

BEOORDELINGSCOMMISSIE

Prof. Dr. H. Steinbusch (voorzitter)

Prof. Dr. F. van der Aa (Katholieke Universiteit Leuven)

Prof. Dr. A.A.M. Masclee

Prof. Dr. M.A.M.J. van Zandvoort

Dr. J.S. Young (University of Portsmouth) 
"The length of a film should be directly related to the endurance of the human bladder."

-Alfred Hitchcock 



\section{Contents}

$\begin{array}{lll}\text { Chapter } 1 & \text { General Introduction } & 9\end{array}$

Chapter 2 Phosphodiesterase Type 2 Distribution in the Guinea

Pig Urinary Bladder 31

Chapter 3 Evidence for Prostaglandin E2 Receptor Expression in the Intramural Ganglia of the Guinea Pig Urinary Bladder

Chapter 4 Ex Vivo Modulation of Muscarinically Induced Contractions by $\mathrm{PGE}_{2}$ and an EP1 Receptor Antagonist in the Guinea Pig Urinary Bladder

Chapter 5 Distribution and Function of the EP3 Receptor in the Guinea Pig Urinary Bladder

Chapter 6 Regulatory Pathways Involved in Detrusor Underactivity - Potential Therapeutic Targets

Chapter 7

General Discussion

Summary

Samenvatting

Valorisation

Abbreviations

List of Publications

151

Acknowledgements

Curriculum Vitae 



The importance of the urinary bladder is often underestimated and the bladder is seen as a mere passive organ. However, the regulatory systems are immensely complex, as we are still unravelling physiological and pathological mechanisms. The bladder is regulated both peripherally and centrally by local reflexes and the central nervous system. Complex interactions of regulators at these levels enable the bladder to store urine and expel it at an appropriate time and place. The pressure within the bladder (intravesical pressure) remains relatively constant at a low level throughout the filling process. During the filling phase, the produced urine is stored in a low pressure reservoir, maintained by partial uninhibited normal distension of the bladder. The pressure in the urethra needs to exceed the intravesical pressure in order to maintain continence. Local regulatory mechanisms, at a bladder level, sense the degree of filling of the bladder and ensure that continence is maintained. This sensory information is subsequently sent to the central nervous system, where the decision is made whether voiding is necessary and if time and place to void are convenient. A great variety of interacting signalling systems at several levels are involved in these processes. Changes at any level in these regulating mechanisms (central and peripheral) can result in functional changes of the lower urinary tract, leading to bladder or sphincter dysfunction, subdivided in storage and voiding problems. Two important bladder dysfunctions are introduced in this chapter: The overactive bladder $(O A B)$ syndrome, which has been already a research focus for a long time, and detrusor underactivity, which was reintroduced as an exciting research topic a few years ago. To be able to identify optimal treatment modalities for both types of dysfunctions, it is of utmost importance to understand the physiological processes which are involved in the control of micturition. In this introduction, a description of the histology of the bladder wall is given. Furthermore, bladder sensation and the contractile mechanism are explained. Subsequently, central and peripheral mechanisms involved in bladder regulation are presented. Also the role of phosphodiesterases (PDEs), the prostanoid and the cholinergic systems are discussed in more detail.

\section{The overactive bladder syndrome}

The overactive bladder syndrome has been defined by the International Continence Society (ICS) as urinary urgency, usually with urinary frequency and nocturia, with or without urgency urinary incontinence ${ }^{1,2}$. Urgency urinary incontinence (UUI) is a sudden and compelling desire to pass urine. It can be accompanied by the involuntary leakage of urine ${ }^{3}$. OAB is characterised by an increased voiding frequency (more than eight voiding episodes during daytime) ${ }^{3}$. 
The impact on patients' quality of live is higher than in patients who suffer from diabetes ${ }^{4-7}$. Economic costs and burden of $O A B$ are comparable to rheumatoid arthritis and asthma ${ }^{8}$. Almost 100 million people suffer from $O A B$ in the western world, 33 million in the United States ${ }^{9}$ and 66 million in the European Union ${ }^{3}$. Due to the multifactorial pathophysiology and the heterogeneity of the patient population, optimal therapy remains challenging. In $O A B$, the detrusor muscle can contract inappropriately regardless of the filling state of the bladder, called detrusor overactivity (DO). An additional aspect of $O A B$ is inappropriate bladder filling sensation without detrusor contractions, meaning that patients suffer from symptoms belonging to the $\mathrm{OAB}$ symptom complex, without detectable DO. Therefore, potential treatment targets need to influence regulation of bladder contraction. Currently, antimuscarinic drugs serve as the first line treatment. However, due to a poor effect size and high prevalence of side effects, treatment compliance is not optimal ${ }^{10}$. Even if initial response rates are good, adverse effects and decreasing efficacy cause poor long-term compliance ${ }^{11}$. To investigate the causes of DO and identify new treatment targets, a variety of animal models are used. Bladder outlet obstruction and diabetes models are two frequently used examples. It is of great importance to characterise the patient population in detail so that appropriate animal models can be designed.

\section{Detrusor underactivity}

The International Continence Society defined detrusor underactivity (DU) as a contraction of reduced strength and/or duration, resulting in prolonged bladder emptying and/or failure to achieve complete bladder emptying ${ }^{1}$.

Adequate bladder emptying requires a coordinated contraction of the bladder and relaxation of the urethra. Failure of this mechanism at any level in the 'brain - bladder' tract may result in complaints of a weak stream, recurrent urinary tract infections or post void residual. In general, these symptoms are considered as possible signs of an underactive bladder in humans.

Detrusor underactivity is thought to be the main factor reducing the evacuation ability of the bladder $^{12}$. DU can be identified as a likely cause of voiding dysfunction and retention in older women. Earlier urodynamic data already suggested that DU and post-voiding residuals are associated with aging ${ }^{13-15}$. However, the exact incidence and prevalence of DU is highly dependent on definition as well as available diagnostic tests.

Detrusor underactivity is thought to be hidden behind other age related conditions, such as bladder outlet obstruction (BOO). In animals, prolonged outlet obstruction increasingly leads to bladder wall hypertrophy, limitation of angiogenesis and blood flow to the smooth muscle cell 
layer, resulting in cyclic ischemia/reperfusion, and eventually muscle layer fibrosis ${ }^{16,17}$. In both, animals and humans, these alterations in the chronic 'end stage' of BOO clinically present as either a thick walled, fibrous, low capacity, poor contractile bladder or a high capacity, poor contractile bladder with a thin fibrous bladder wall ${ }^{18}$.

Knowledge about the pathophysiological and molecular background of DU is limited. Aberrations in regulation of bladder contraction leading to DU can occur at several levels: 1. urethral sensation, 2. sensation at bladder level, 3. within the central nervous system, 4. efferent processing/ bladder contractility. Amongst others, promising and novel targets for treatment are two prostaglandin $E 2\left(\mathrm{PGE}_{2}\right)$ specific receptors, prostaglandin $\mathrm{E}$ receptor type 2 (EP2) and 3 (EP3). A combined EP2/EP3 agonist led to contraction of the bladder and relaxation of the urethra ex vivo ${ }^{19}$ and improved bladder function in a monkey model for DU by increasing the voided volume per micturition and the maximum flow rate ${ }^{19}$. It is important to elucidate the mechanisms leading to DU further and subsequently identify new targets which can be used to treat DU.

\section{Bladder histology}

The urinary bladder is composed of three layers (Figure 1). The urothelium, which is the epithelium of the urinary bladder, faces the lumen of the bladder and consists of three to five cell layers. The outer cell layer of the urothelium consists of big umbrella cells.

The lamina propria is located directly beneath the urothelium and consists of suburothelial interstitial cells, nerves and blood vessels, embedded in extracellular matrix with a high amount of collagen. It can be subdivided into the suburothelium (a dense layer composed of suburothelial interstitial cells and nerves) and a diffuse cell layer containing microvasculature and nerves in which high amounts of collagen can be found.

The detrusor muscle is located adjacent to the lamina propria. The detrusor muscle is composed of an inner and an outer muscle layer. Within the muscle bundles as well as in between individual muscle bundles, interstitial cells can be found. These interstitial cells are known as intra muscle interstitial cells and surface muscle interstitial cells, respectively. The outer layer of the detrusor muscle is covered by the serosa. 


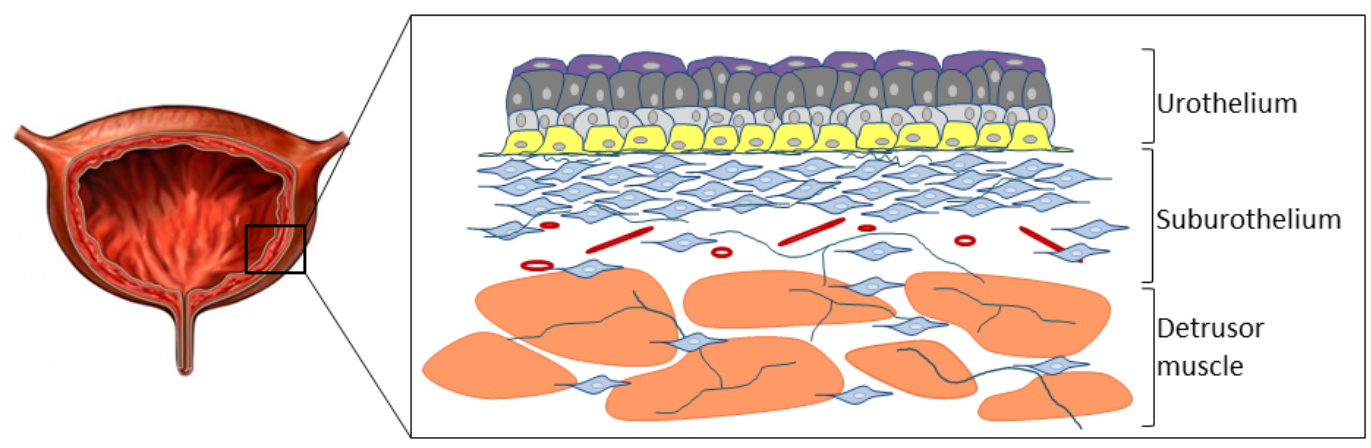

Figure 1. Histology of bladder wall

\section{Bladder sensation}

A sensation can be defined as a perception or physical feeling that is evoked by a stimulus occurring in the body. Bladder sensation is the sensation of fullness or pressure in the urinary bladder. During filling of the bladder, afferent signals are produced and sent through the afferent nervous system to the central nervous system, where further processing takes place. In addition, sensory information is generated within the urethra and sent directly to the bladder (guarding reflex) or to the central nervous system. The urethra contains different sorts of sensors. Next to tension receptors ${ }^{20}$, measuring muscle tension, receptors have been found that are intensively stimulated by flow of fluid along the urethra ${ }^{21}$. These receptors are activated as long as fluid passes the urethra. Thus, types of urethral sensations are of importance for bladder sensation: 1 . pressure, 2. volume and 3. flow sensation. In addition, temperature has been shown to modulate bladder contraction after urethral sensation ${ }^{22}$.

Sensations during the filling phase have been categorised into three sensations; first sensation of filling followed by a first desire to void and a strong desire to void ${ }^{23,24}$. However, it is not clear where these sensations are originated and which sensors detect the filling state of the bladder.

It is well known that the urothelium secretes several substances such as nitric oxide (NO), adenosine triphosphate (ATP), substance $P$, acetylcholine (ACh) and $P G E_{2}$ in response to chemical and mechanical stimuli ${ }^{25}$. Bladder stretch, due to filling, could be such a mechanical stimulus. Once released by the urothelium, ATP can stimulate underlying cells within the bladder wall, such as nerves and interstitial cells ${ }^{26-29}$. Furthermore, ATP can bind to urothelial purinergic cell surface receptors and thereby modulate membrane traffic ${ }^{30}$. This membrane traffic leads, together with unfolding of superficial or umbrella cell membrane to expansion of 
the bladder in response to filling ${ }^{26,31-33}$. It has been hypothesised that urothelium derived chemical mediators are probably able to reduce the threshold for activation of nearby afferents $^{34}$. By this, the urothelium would be able to amplify signals within the urothelium and bladder wall, which could be of interest in sensory processing ${ }^{34}$.

Signal transfer within the bladder wall propagates from the urothelial/suburothelial layer towards the detrusor muscle ${ }^{35,36}$. This propagation could be enhanced by mechanical stretch as it goes along with bladder filling ${ }^{36}$. A promising candidate to be mainly responsible for this propagation are interstitial cells. Interstitial cells respond to exogenous applied NO with increased levels of cyclic guanosine monophosphate (cGMP) ${ }^{37}$. Phosphodiesterases degrade cGMP to GMP and thereby terminate its effect. This enables a short and specific response to NO, which is important for propagation of a signal.

Moreover, bladder filling results in an increased afferent potential rate. This phenomenon is volume-dependent. After voiding has taken place, this neural activity weakens again until baseline values are present ${ }^{38-43}$.

\section{Contractile mechanism of the urinary bladder}

To be able to expel urine, a contraction of the detrusor muscle is necessary. In addition to general modulatory proteins that are found in all muscle types, a great variety of signalling substances and their receptors are present in the urinary bladder. These signalling substances modulate contraction and act on general modulatory proteins. An overview of regulation of the contractile mechanism is given in Figure 2.

Three enzymes are involved in the regulation of the contractile mechanism. These are myosin light chain kinase (MLCK), myosin light chain phosphatase (MLCP) and the cross-bridge ATPase. While MLCP and MLCK are involved in the initiation of the contraction, cross-bridge ATPase has its main function in the prolongation. While ATPase activity can be influenced in an indirect way, making use of the two modulatory proteins caldesmon and calponin, MLCP and MLCK activity can be modulated directly. A great variety of kinases modulate the activity of MLCP, MLCK, caldesmon or calponin via phosphorylation. Those include microtubule-associated protein (MAP) kinase, Ca2+/calmodulin-dependent protein (CaM) kinase II, p21-activated kinase (PAK), protein kinase C (PKC), protein kinase N (PKN) and Rho kinase (ROK). 
Table 1. Individual receptors and their primary effect

\begin{tabular}{|c|c|c|c|c|c|c|c|}
\hline & \multirow[b]{2}{*}{ Target } & \multicolumn{5}{|c|}{ Primary effect } & \multirow{2}{*}{$\begin{array}{l}\text { Theoretical } \\
\text { effect on } \\
\text { contraction }\end{array}$} \\
\hline & & $\mathrm{Ca}^{2+}$ entry & IP3 & $\begin{array}{c}\text { PKA } \\
\text { (cAMP dependent) }\end{array}$ & $\begin{array}{c}\text { PKG } \\
\text { (cGMP dependent) }\end{array}$ & MAP kinases & \\
\hline \multirow{5}{*}{$\begin{array}{l}\text { Adrenergic } \\
\text { System }\end{array}$} & $\alpha_{1}$ receptor & & $\uparrow$ & & & & $\uparrow$ \\
\hline & $\alpha_{2}$ receptor & & & $\downarrow$ & & & $\uparrow$ \\
\hline & $\beta_{1}$ receptor & & & $\uparrow$ & & & $\downarrow$ \\
\hline & $\beta_{2}$ receptor & & & $\uparrow$ & & & $\downarrow$ \\
\hline & $\beta_{3}$ receptor & & & $\uparrow$ & & & $\downarrow$ \\
\hline \multirow{6}{*}{$\begin{array}{l}\text { Cholinergic } \\
\text { System }\end{array}$} & Nicotinic receptors & $\uparrow$ & & & & & $\uparrow$ \\
\hline & Muscarinic receptor $M_{1}$ & & $\uparrow$ & & & & $\uparrow$ \\
\hline & Muscarinic receptor $M_{2}$ & & & $\downarrow$ & & & $\uparrow$ \\
\hline & Muscarinic receptor $M_{3}$ & & $\uparrow$ & & & & $\uparrow$ \\
\hline & Muscarinic receptor $\mathrm{M}_{4}$ & & & $\downarrow$ & & & $\uparrow$ \\
\hline & Muscarinic receptor $M_{5}$ & & $\uparrow$ & & & & $\uparrow$ \\
\hline \multirow{4}{*}{$\begin{array}{l}\text { Prostanoid } \\
\text { System }\end{array}$} & $\mathrm{EP}_{1}$ receptor & & & $\downarrow$ & & & $\uparrow$ \\
\hline & $\mathrm{EP}_{2}$ receptor & & & $\uparrow$ & & & $\downarrow$ \\
\hline & $\mathrm{EP}_{3}$ receptor & & & $\downarrow$ & & & $\uparrow$ \\
\hline & $\mathrm{EP}_{4}$ receptor & & & $\downarrow$ & & & $\uparrow$ \\
\hline \multirow{4}{*}{$\begin{array}{l}\text { Purinergic } \\
\text { System }\end{array}$} & $\mathrm{P} 2 \mathrm{X}_{2}$ receptor & $\uparrow$ & & & & & $\uparrow$ \\
\hline & $\mathrm{P} 2 \mathrm{X}_{5}$ receptor & $\uparrow$ & & & & & $\uparrow$ \\
\hline & $\mathrm{P} 2 \mathrm{X}_{7}$ receptor & $\uparrow$ & & & & & $\uparrow$ \\
\hline & $\mathrm{P}_{2} \mathrm{Y}_{4}$ receptor & & $\uparrow$ & & & & $\uparrow$ \\
\hline \multirow{2}{*}{$\begin{array}{l}\text { Cyclic } \\
\text { Nucleotides }\end{array}$} & CAMP & & & $\uparrow$ & & & $\downarrow$ \\
\hline & cGMP & & & & $\uparrow$ & & $\downarrow$ \\
\hline \multirow{2}{*}{$\begin{array}{l}\text { Cannabinoid } \\
\text { System }\end{array}$} & CB1 receptor & & & $\downarrow$ & & $\uparrow$ & $\uparrow$ \\
\hline & CB2 receptor & & & $\downarrow$ & & $\uparrow$ & $\uparrow$ \\
\hline \multirow{3}{*}{ Bombesines } & BB1 receptor & & $\uparrow$ & & & & $\uparrow$ \\
\hline & BB2 receptor & & $\uparrow$ & & & & $\uparrow$ \\
\hline & BB3 receptor & & $\uparrow$ & & & & $\uparrow$ \\
\hline
\end{tabular}

In the urinary bladder, a great variety of receptors is expressed throughout the different layers. The effect that a substance evokes when binding to its receptor is dependent on the second messenger system the receptor is coupled to. Furthermore, interactions between the different signalling systems present in the urinary bladder modulate the theoretically evoked effect on contraction. Five different second messenger systems play a role in signal transmission within the bladder wall. These are protein kinase A (PKA), protein kinase G (PKG), MAP kinase, inositol triphosphate (IP3) and Calcium (Table 1). 


\section{Central regulation and bladder autonomy}

The urinary bladder has two functions: 1 . storage of urine, which is continuously produced by the kidneys, and 2. emptying of the bladder at an appropriate time and place. To expel urine only at an appropriate time and place is of utmost social importance for humans. In animals this allows territorial carving behaviour. Without influence of the central nervous system, the storage and emptying of the urinary bladder are entirely dependent on the reflex mechanisms in the bladder itself. Reflex micturition, which happens in young children, is involuntary and part of autonomous bladder activity. During the early postnatal development, the central nervous system gains more and more influence on bladder activity and voiding becomes voluntary as a child ages. To be able to void at an appropriate time and place, afferent sensory signals from the bladder containing information, such as the degree of filling, are received by higher brain regions and processed further.

When an appropriate time and place to void is given, signals are sent towards the bladder via efferent pathways (Figure 3). The urinary bladder (and urethra) is innervated by three nerves: the pelvic nerve, the hypogastric nerve and the pudendal nerve. The pudendal nerve contains somatic fibres and innervates the striated urethral sphincter. The hypogastric nerve belongs to the sympathetic system and innervates bladder wall and the urethra, while the pelvic nerve is a parasympathetic structure and innervates the bladder wall.

Thus, micturition involves a complex coordination between the central, autonomic and somatic nervous system to enable social continence.

In order to initiate micturition, in general, two mechanisms are thought to play an important role in detrusor contraction ${ }^{44}$. The first mechanism involves motor nerves, with acetylcholine as a neurotransmitter and finally activation of the detrusor.

In contrast to the mechanism described above, which has its origin in the central nervous system, a second control mechanism originates in the bladder wall itself. The bladder is able to generate phasic increases in intra-vesical pressure, such as localised contractions, propagating waves of contractions and passive stretches of the bladder wall ${ }^{45}$. This activity can be modulated by neuronal input. This autonomous activity has been hypothesised to occur via interstitial cells, similar to the interstitial cells of Cajal in the gut, and intramural nerves ${ }^{44}$. 


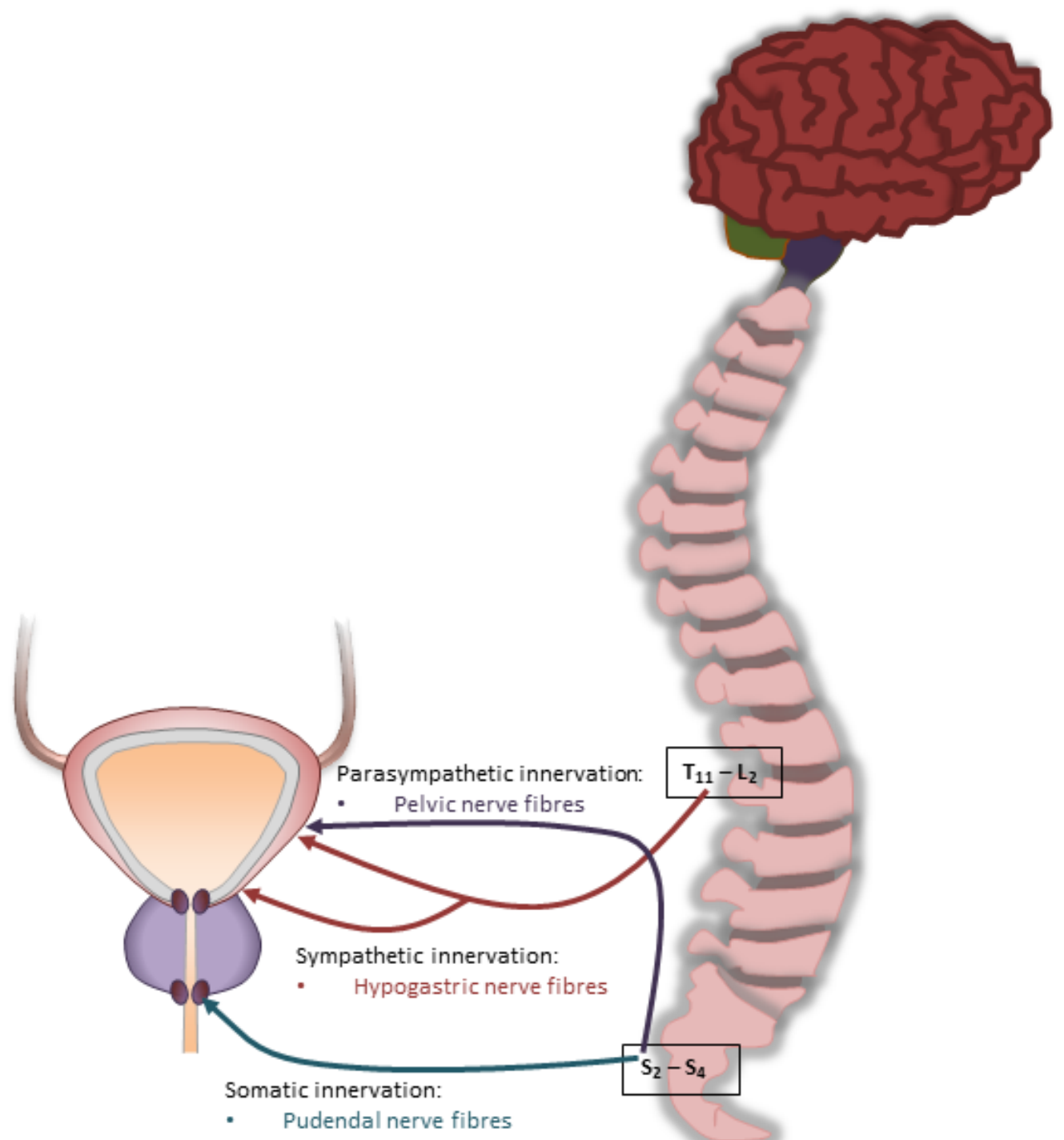

Figure 3. Different levels of bladder innervation 
A great variety of signalling molecules and receptors are involved in signalling processes leading to accurate bladder function. In general, five main signalling systems are present in the urinary bladder: namely, 1 . the noradrenergic system, 2 . the cyclic nucleotide-nitric oxide system, 3 . the prostanoid system, 4 . the purinergic system and 5 . the cholinergic system. These signalling systems of the urinary bladder are in interaction with each other (Figure 4).

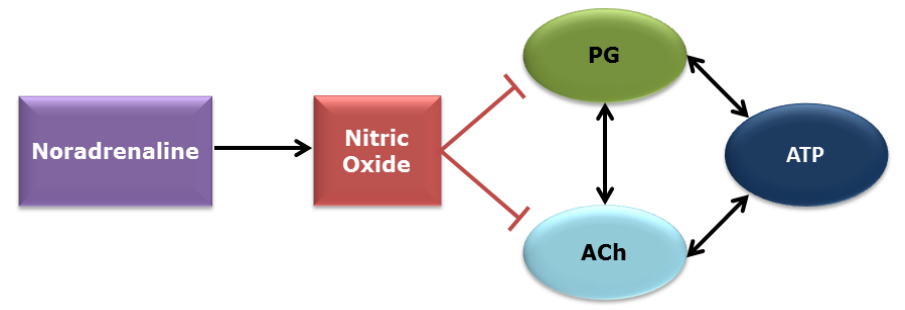

Figure 4. Main signalling systems of the urinary bladder and their interaction

\section{Local regulatory mechanisms}

In response to chemical or mechanical stimuli, substances such as NO, ATP, substance $P, A C h$ and $\mathrm{PGE}_{2}$ are secreted by the urothelium ${ }^{25}$. In addition, urothelial cells express a great diversity of receptors, such as receptors for noradrenaline $(\alpha$ and $\beta$ ) and receptors for PGE2, EP1 and $E P 2^{46,47}$. Activation of the noradrenergic system can induce the production and release of NO by the urothelium ${ }^{48,49}$. NO has been shown to have a short-term inhibitory effect on the production of $\mathrm{PGE}_{2}{ }^{50}$. This is most probably due to the adjacent location of cyclooxygenase type 1 (COX-1) expressing cells to cells which express neuronal nitric oxide synthase (nNOS). Therefore, NO production by urothelial cells could likely affect $\mathrm{PGE}_{2}$ production in basal urothelial cells in a direct or indirect way ${ }^{50}$. While NO has an inhibitory effect on the prostanoid system, the purinergic system can induce $\mathrm{PGE}_{2}$ production via a complex mechanism in which $\mathrm{P} 2 \mathrm{X}$ and $\mathrm{P} 2 \mathrm{Y}$ receptors are involved as well as the $\mathrm{PGE}_{2}$ producing enzyme COX-1 ${ }^{50}$. Furthermore, activation of the PGE2-specific receptor EP1 evokes ATP release in cultured urothelium cells ${ }^{51}$. At a molecular level, $\mathrm{PGE}_{2}$ has been shown to induce the release of $\mathrm{ACh}^{52}$. On the other hand, stimulation with the muscarinic agonist arecaidine evoked $\mathrm{PGE}_{2}$ release ${ }^{52}$, indicating that a positive feedback is active between the prostanoid and the cholinergic system. Stimulation of the $\alpha 7$ nicotinic receptor causes a decrease in ATP release in an in vitro cell culture setting, suggesting that there is an interaction between the cholinergic and purinergic system as well ${ }^{53}$. However, the general effect of interactions between the purinergic and 
cholinergic system cannot be concluded from this single study, since only a single receptor was stimulated ex vivo.

Combining all these findings, a complex mechanism seems to exist in the urinary bladder urothelium. Stimulation with noradrenaline, which binds to both, $\alpha$ and $\beta$ adrenergic receptors, stimulates $\mathrm{NO}$ production in urothelial cells. NO itself has an inhibitory effect on $\mathrm{PGE}_{2}$ production. Furthermore, ATP can activate PGE2 production and activation of the PGE2-receptor EP1 in turn evokes ATP release. Since ACh is expressed by the urothelium as well and stimulation of the nicotinic receptor subtype $\alpha 7$ results in decreased ATP release, it is likely that $\mathrm{ACh}$ also plays a role in the signalling processes of the urothelial layer (Figure 4).

\section{Cholinergic control of the urinary bladder}

In the urinary bladder, ACh has been shown to be released by the urothelium in response to chemical or mechanical stimulation in addition to the neuronal release as a (motor) nerve neurotransmitter. Thus, both neuronal and non-neuronal Ach play a role in urinary bladder signalling. Both, sensory and motor functions of the urinary bladder involve cholinergic signalling. Intravesical administration of muscarinic or nicotinic receptor agonists or anticholinesterase agents that increase the levels of endogenous $\mathrm{ACh}$, have been shown to facilitate reflex bladder activity in rats and cats ${ }^{54}$. ACh exerts its effects by binding to one of its several receptors e.g. muscarinic and nicotinic receptor subgroups. Each subgroup contains several receptors. Nicotinic acetylcholine receptors are ionotropic receptors, which are directly linked to ion channels. These channels are in general permeable for sodium and potassium.

It is generally thought that the muscarinic receptor $\mathrm{M} 3$ is mainly responsible for normal micturition contractions ${ }^{55-58}$. The functions of muscarinic receptors may be changed in different urological disorders such as bladder outlet obstruction, neurogenic bladder, or DO without neurogenic causes.

\section{Phosphodiesterases and bladder control}

Phosphodiesterases (PDEs) are involved in the cyclic nucleotide metabolism and catalyse the reaction from cyclic adenosine monophosphate (cAMP) and cyclic guanosine monophosphate (cGMP) to AMP and GMP. Both cAMP and cGMP are important second messenger molecules playing a role in the regulation of bladder contraction. These second messengers are formed by activation of adenylate cyclase or guanylate cyclase and degraded by PDEs. 
The superfamily of PDEs exists of 14 subtypes and more than 50 distinct isoforms ${ }^{59}$. PDE1-5 and 7-9 have been shown to be expressed in urinary bladder structures ${ }^{60-65}$. PDE1 is present in urothelial cells of the human urinary bladder ${ }^{60}$ and PDE5 expression has been shown in guinea pig urothelium, suburothelial interstitial cells and bladder blood vessels of the guinea pig urinary bladder ${ }^{63}$.

Furthermore, both substrates of phosphodiesterases, cAMP and CGMP, play a role in nonmicturition activity. CGMP stimulates phasic activity and is regulated in part by PDE $10^{66}$. Interstitial cells respond to exogenous applied NO with a rise in $\mathrm{CGMP}^{37}$. It has been shown, in isolated mouse bladders, that these interstitial cells inhibit phasic activity after stimulation with $\mathrm{NO}^{67}$. In these preparations, phasic activity was induced by a muscarinic agonist. Subsequent application of NO inhibited the induced bladder activity ${ }^{67}$. This implicates that the NO-cGMP system within the urinary bladder is a complex regulator of bladder activity and that several factors can alter its effect on bladder activity. CAMP, regulated by PDE4, inhibits phasic activity $^{68}$. It has been hypothesised that inappropriate regulation of autonomous activity leads to bladder overactivity ${ }^{69}$. PDE1 and PDE5 inhibitors have been used as a treatment for bladder overactivity. However, the reported success was limited. The PDE1 inhibitor vinpocetin relaxed pre-contracted strips of human detrusor muscle ${ }^{70,71}$, and reduced clinical symptoms in patients with urgency and urgency incontinence ${ }^{72}$. Inhibition of PDE5 by zaprinast had minor effects on human bladder smooth muscle tone ${ }^{70}$ and high doses of several PDE5 inhibitors were able to relax precontracted bladder strips ${ }^{73-77}$. PDE5 inhibition had no effect on contractile responses to electric field stimulation, ATP and potassium chloride, but supresses contractions induced by carbachol administration ${ }^{78}$. This suggests that PDE5 may be involved in regulation of muscarinically induced contractions. In anaesthetised rats, PDE5 inhibition prolonged the intermicturition interval ${ }^{74}$ and chronic treatment reduced non-voiding contractions in a bladder outlet obstruction model ${ }^{73}$. Thus, PDE inhibitors are involved in the regulation of bladder contraction via several mechanisms and could therefore play a role in the development of new, more specific treatments for DO. In this thesis, a study concerning the expression of PDE2 in the urinary bladder of the guinea pig is presented. PDE2 is both CAMP- and CGMP-dependent.

\section{The role of prostaglandin E2 in bladder control}

$\mathrm{PGE}_{2}$ is released by the urothelium in response to mechanical and chemical stimuli ${ }^{25}$. PGE2specific receptors are expressed by different structures throughout the bladder wall ${ }^{46,79}$. Prostaglandins (PGs) are widely known as substances playing a key role in inflammation ${ }^{80}$. Based on their chemical structure, PGs can be divided into several subtypes, PG $A-I^{81}$. PGE2 evokes its 
effects by binding to one of its specific receptors, which are classified into four subtypes (EP1 EP4) $)^{81}$.

Under healthy conditions, such as normal distension of the bladder, PGs are produced by COX$1^{82}$. Another PG producing enzyme, which is also a member of the COX family, is cyclooxygenase enzyme type 2 (COX-2) and, is mostly active in pathological conditions ${ }^{83}$. In the urinary bladder, different subclasses of prostaglandins (PGs) are present ${ }^{84-88}$.

Several studies showed that PGs play an important role in physiological processes in the bladder in both healthy and pathological conditions. Intravesical administration of PGE2 results in micturition and increased baseline intravesical pressure in anaesthetised rats ${ }^{89}$. Furthermore, administration of $\mathrm{PGE}_{2}$ directly into the human urinary bladder caused strong sensations of urgency ${ }^{90}$. PGE 2 directly affects bladder smooth muscle and is able to activate capsaicinsensitive bladder afferents ${ }^{91,92}$. Moreover, in a murine model it was shown that $\mathrm{PGE}_{2}$ instillation increased the number and amplitude of non-voiding contractions ${ }^{93}$. Urinary $\mathrm{PGE}_{2}$ levels were increased in three studies. In patients with suprapontine brain disease, increased $P G_{2}$ levels in urine were found. Urinary levels of $\mathrm{PGE}_{2}$ were significantly increased in male and female subjects suffering from $O A B^{94,95}$ and in patients with suprapontine brain disease ${ }^{96}$.

In summary, there is ample evidence that $\mathrm{PGE}_{2}$ plays a role in bladder signalling and regulation of micturition in physiological and pathological conditions.

\section{Research question and outline of this thesis}

The development of satisfactory treatments for patients suffering from OAB remains challenging. This is based on a lack of well characterised patient subgroups, but also on a lack of knowledge how and via which regulatory systems bladder contractions can be modulated. Until now, antimuscarinic drugs have been used as a first line treatment for OAB. However, due to a poor effect size and high prevalence of side effects, treatment compliance is bad ${ }^{10}$. Therefore, new treatment targets which influence bladder contractions either via modulation of muscarinically induced contractions or in an ACh-independent manner are needed. The research question on which this thesis is based was how peripheral pharmacological targets can be used to modulate bladder function.

The distribution of PDE2 in the guinea pig bladder is described in chapter 2. PDEs are involved in the cyclic nucleotide metabolism. Both, CAMP and CGMP are able to modulate bladder 
contraction. Via this mechanism, PDE2 might be able to modulate bladder contractility and is therefore a promising target to investigate.

In chapter 3, the expression pattern of two PGE2-specific receptors, EP1 and EP2 in the intramural ganglia of the guinea pig bladder is presented. Elevated levels of $\mathrm{PGE}_{2}$ have been detected in patients suffering from OAB. It has been suggested that there is a network of intramural ganglia in the bladder that may be part of a motor-sensory system and receive afferent input and prostaglandins have been suggested to play a role in this afferent signalling mechanism. To investigate this further, the analysis in this chapter concentrated on the presence of EP1 and EP2 in intramural ganglia.

The results of an ex vivo study on the modulatory role of PGE 2 and an EP1 receptor antagonist on muscarinically induced contractions are displayed in chapter 4. EP1 has been shown to be partly responsible for the stimulating effect $\mathrm{PGE}_{2}$ exerts on bladder activity. Moreover, $\mathrm{PGE}_{2}$ and ACh have been shown to work in a feedback loop on molecular basis. Therefore, this interaction and the role of EP1 were tested in a whole bladder organ bath setting.

The distribution and function of another $\mathrm{PGE}_{2}$-specific receptor, the EP3 receptor is described in chapter 5. EP3 has been shown to have effects on micturition, within the central nervous system. However, as $\mathrm{PGE}_{2}$ has been shown to have an effect ex vivo on muscarinically induced contractions, it was of interest to investigate the peripheral role of EP3 within the urinary bladder in an ex vivo setting.

In chapter 6, various targets involved in modulation of bladder contraction are reviewed, in regards to potential treatment targets for DU. So far, little is known about the pathophysiological and molecular background of DU. It is important to elucidate the mechanisms leading to DU and subsequently identify new targets which can be used to treat DU.

A general discussion of all studies presented in this thesis is given in chapter 7. 


\section{References}

1. Abrams P, Cardozo L, Fall M, Griffiths D, Rosier P, Ulmsten U, et al. The standardisation of terminology in lower urinary tract function: report from the standardisation sub-committee of the International Continence Society. Urology. 2003 Jan;61(1):37-49.

2. Haylen BT, de Ridder D, Freeman RM, Swift SE, Berghmans B, Lee J, et al. An International Urogynecological Association (IUGA)/International Continence Society (ICS) joint report on the terminology for female pelvic floor dysfunction. Neurourol Urodyn. 2010;29(1):4-20.

3. Milsom I, Abrams P, Cardozo L, Roberts RG, Thuroff J, Wein AJ. How widespread are the symptoms of an overactive bladder and how are they managed? A population-based prevalence study. BJU Int. 2001 Jun;87(9):760-6.

4. Abrams P, Kelleher CJ, Kerr LA, Rogers RG. Overactive bladder significantly affects quality of life. The American journal of managed care. 2000 Jul;6(11 Suppl):S580-90.

5. Hashim H, Abrams P. Overactive bladder: an update. Curr Opin Urol. 2007 Jul;17(4):231-6.

6. Komaroff AL, Fagioli LR, Doolittle TH, Gandek B, Gleit MA, Guerriero RT, et al. Health status in patients with chronic fatigue syndrome and in general population and disease comparison groups. Am J Med. 1996 Sep;101(3):281-90.

7. Liberman JN, Hunt TL, Stewart WF, Wein A, Zhou Z, Herzog AR, et al. Health-related quality of life among adults with symptoms of overactive bladder: results from a U.S. community-based survey. Urology. 2001 Jun;57(6):1044-50.

8. Coyne KS, Sexton CC, Thompson CL, Clemens JQ, Chen Cl, Bavendam T, et al. Impact of overactive bladder on work productivity. Urology. 2012 Jul;80(1):97-103.

9. Hu TW, Wagner TH, Bentkover JD, Leblanc K, Zhou SZ, Hunt T. Costs of urinary incontinence and overactive bladder in the United States: a comparative study. Urology. 2004 Mar;63(3):461-5.

10. Cardozo L. The overactive bladder syndrome: treating patients on an individual basis. BJU Int. 2007 Jun;99 Suppl 3:1-7.

11. Andersson KE. Drugs and future candidates. Canadian Urological Association journal = Journal de I'Association des urologues du Canada. 2011 Oct;5(5 Suppl 2):S131-3.

12. Holm NR, Horn T, Smedts F, Nordling J, de la Rossette J. The detrusor muscle cell in bladder outlet obstruction--ultrastructural and morphometric findings. Scand J Urol Nephrol. 2003;37(4):309-15.

13. Bosch JL, Kranse R, van Mastrigt R, Schroder FH. Dependence of male voiding efficiency on age, bladder contractility and urethral resistance: development of a voiding efficiency nomogram. J Urol. 1995 Jul;154(1):190-4.

14. Pfisterer MH, Griffiths DJ, Schaefer W, Resnick NM. The effect of age on lower urinary tract function: a study in women. Journal of the American Geriatrics Society. 2006 Mar;54(3):405-12.

15. Malone-Lee J, Wahedna I. Characterisation of detrusor contractile function in relation to old age. $\mathrm{Br} \mathrm{J} U \mathrm{Urol}$. 1993 Dec;72(6):873-80.

16. Gosling JA, Kung LS, Dixon JS, Horan P, Whitbeck C, Levin RM. Correlation between the structure and function of the rabbit urinary bladder following partial outlet obstruction. J Urol. 2000 Apr;163(4):1349-56.

17. Schroder A, Chichester P, Kogan BA, Longhurst PA, Lieb J, Das AK, et al. Effect of chronic bladder outlet obstruction on blood flow of the rabbit bladder. J Urol. 2001 Feb;165(2):640-6.

18. Levin RM, Haugaard N, O'Connor L, Buttyan R, Das A, Dixon JS, et al. Obstructive response of human bladder to $\mathrm{BPH}$ vs. rabbit bladder response to partial outlet obstruction: a direct comparison. Neurourol Urodyn. 2000;19(5):609-29.

19. Matsuya H, Otsuki T, Kida J, Wakamatsu D, Okada H, Sekido N. ONO-8055, a novel and potent prostanoid EP2 and EP3 receptor dual agonist, improves voiding dysfunction in a monkey underactive bladder model, Abstract PD7-01, AUA Annual Meeting; New Orleans, LA, USA 2015.

20. Lassmann G. Muskelspindeln und sensible Endkorper im Harnrohrenschliessmuskel. Acta neuropathologica. 1984;63(4):344-6.

21. Todd JK. Afferent Impulses in the Pudendal Nerves of the Cat. Quarterly journal of experimental physiology and cognate medical sciences. 1964 Jul;49:258-67. 
22. Combrisson H, Allix S, Robain G. Influence of temperature on urethra to bladder micturition reflex in the awake ewe. Neurourol Urodyn. 2007;26(2):290-5.

23. Wyndaele JJ. The normal pattern of perception of bladder filling during cystometry studied in 38 young healthy volunteers. J Urol. 1998 Aug;160(2):479-81.

24. Wyndaele JJ, De Wachter S. Cystometrical sensory data from a normal population: comparison of two groups of young healthy volunteers examined with 5 years interval. Eur Urol. 2002 Jul;42(1):34-8.

25. Birder LA. More than just a barrier: urothelium as a drug target for urinary bladder pain. Am J Physiol Renal Physiol. 2005 Sep;289(3):F489-95.

26. Apodaca G, Balestreire E, Birder LA. The uroepithelial-associated sensory web. Kidney Int. 2007 Nov;72(9):1057-64.

27. Birder LA, de Groat WC. Mechanisms of disease: involvement of the urothelium in bladder dysfunction. Nat Clin Pract Urol. 2007 Jan;4(1):46-54.

28. Burnstock G. Purine-mediated signalling in pain and visceral perception. Trends Pharmacol Sci. 2001 Apr;22(4):182-8.

29. Ruggieri MR, Sr. Mechanisms of disease: role of purinergic signaling in the pathophysiology of bladder dysfunction. Nat Clin Pract Urol. 2006 Apr;3(4):206-15.

30. Wang EC, Lee JM, Ruiz WG, Balestreire EM, von Bodungen M, Barrick S, et al. ATP and purinergic receptordependent membrane traffic in bladder umbrella cells. J Clin Invest. 2005 Sep;115(9):2412-22.

31. Born M, Pahner I, Ahnert-Hilger G, Jons T. The maintenance of the permeability barrier of bladder facet cells requires a continuous fusion of discoid vesicles with the apical plasma membrane. European journal of cell biology. 2003 Jul;82(7):343-50.

32. Kreft ME, Jezernik K, Kreft M, Romih R. Apical plasma membrane traffic in superficial cells of bladder urothelium. Ann N Y Acad Sci. 2009 Jan;1152:18-29.

33. Truschel ST, Wang E, Ruiz WG, Leung SM, Rojas R, Lavelle J, et al. Stretch-regulated exocytosis/endocytosis in bladder umbrella cells. Molecular biology of the cell. 2002 Mar;13(3):830-46.

34. Birder L, Wyndaele JJ. From urothelial signalling to experiencing a sensation related to the urinary bladder. Acta physiologica. 2013 Jan;207(1):34-9.

35. Ikeda Y, Kanai A. Urotheliogenic modulation of intrinsic activity in spinal cord-transected rat bladders: role of mucosal muscarinic receptors. Am J Physiol Renal Physiol. 2008 Aug;295(2):F454-61.

36. Kanai A, Roppolo J, Ikeda Y, Zabbarova I, Tai C, Birder L, et al. Origin of spontaneous activity in neonatal and adult rat bladders and its enhancement by stretch and muscarinic agonists. Am J Physiol Renal Physiol. 2007 Mar;292(3):F1065-72.

37. Smet PJ, Jonavicius J, Marshall VR, de Vente J. Distribution of nitric oxide synthase-immunoreactive nerves and identification of the cellular targets of nitric oxide in guinea-pig and human urinary bladder by cGMP immunohistochemistry. Neuroscience. 1996 Mar;71(2):337-48.

38. Aizawa N, Igawa Y, Andersson KE, lijima K, Nishizawa O, Wyndaele JJ. Effects of intravesical instillation of ATP on rat bladder primary afferent activity and its relationship with capsaicin-sensitivity. Neurourol Urodyn. 2011 Jan;30(1):163-8.

39. Aizawa N, Igawa Y, Nishizawa O, Wyndaele JJ. Effects of CL316,243, a beta 3-adrenoceptor agonist, and intravesical prostaglandin E2 on the primary bladder afferent activity of the rat. Neurourol Urodyn. 2010 Jun;29(5):771-6.

40. Aizawa N, lijima K, Rosenbaum JS, Downs TR, Igawa Y, Andersson KE, et al. Comparison of the effects of oestrogen deficiency and old age on primary bladder afferent activity and voiding behaviour in the ageing female rat. BJU Int. 2011 Jul;108(2 Pt 2):E10-6.

41. Aizawa N, Wyndaele JJ. Effects of phenazopyridine on rat bladder primary afferent activity, and comparison with lidocaine and acetaminophen. Neurourol Urodyn. 2010 Nov;29(8):1445-50.

42. De Laet K, De Wachter S, Wyndaele JJ. Systemic oxybutynin decreases afferent activity of the pelvic nerve of the rat: new insights into the working mechanism of antimuscarinics. Neurourol Urodyn. 2006;25(2):156-61.

43. De Wachter S, Wyndaele JJ. Intravesical oxybutynin: a local anesthetic effect on bladder C afferents. J Urol. 2003 May;169(5):1892-5.

44. Gillespie JI, Harvey IJ, Drake MJ. Agonist- and nerve-induced phasic activity in the isolated whole bladder of the guinea pig: evidence for two types of bladder activity. Exp Physiol. 2003 May;88(3):343-57. 
45. Drake MJ, Harvey IJ, Gillespie JI. Autonomous activity in the isolated guinea pig bladder. Exp Physiol. 2003 Jan;88(1):19-30.

46. Rahnama'i MS, van Koeveringe GA, Essers PB, de Wachter SG, de Vente J, van Kerrebroeck PE, et al. Prostaglandin receptor EP1 and EP2 site in guinea pig bladder urothelium and lamina propria. J Urol. 2010 Mar;183(3):1241-7.

47. Moro C, Tajouri L, Chess-Williams R. Adrenoceptor function and expression in bladder urothelium and lamina propria. Urology. 2013 Jan;81(1):211 e1-7.

48. Birder LA, Apodaca G, De Groat WC, Kanai AJ. Adrenergic- and capsaicin-evoked nitric oxide release from urothelium and afferent nerves in urinary bladder. Am J Physiol. 1998 Aug;275(2 Pt 2):F226-9.

49. Birder LA, Nealen ML, Kiss S, de Groat WC, Caterina MJ, Wang E, et al. Beta-adrenoceptor agonists stimulate endothelial nitric oxide synthase in rat urinary bladder urothelial cells. J Neurosci. 2002 Sep 15;22(18):806370.

50. Nile CJ, de Vente J, Gillespie JI. Stretch independent regulation of prostaglandin E(2) production within the isolated guinea-pig lamina propria. BJU Int. $2010 \mathrm{Feb}$;105(4):540-8.

51. Wang X, Momota Y, Yanase H, Narumiya S, Maruyama T, Kawatani M. Urothelium EP1 receptor facilitates the micturition reflex in mice. Biomed Res. 2008 Apr;29(2):105-11.

52. Nile CJ, Gillespie JI. Interactions between cholinergic and prostaglandin signaling elements in the urothelium: role for muscarinic type 2 receptors. Urology. 2012 Jan;79(1):240 e17-23.

53. Beckel JM, Birder LA. Differential expression and function of nicotinic acetylcholine receptors in the urinary bladder epithelium of the rat. J Physiol. 2012 Mar 15;590(Pt 6):1465-80.

54. Hawthorn $\mathrm{MH}$, Chapple CR, Cock M, Chess-Williams R. Urothelium-derived inhibitory factor(s) influences on detrusor muscle contractility in vitro. Br J Pharmacol. 2000 Feb;129(3):416-9.

55. Chess-Williams R. Muscarinic receptors of the urinary bladder: detrusor, urothelial and prejunctional. Autonomic \& autacoid pharmacology. 2002 Jun;22(3):133-45.

56. Choppin A. Muscarinic receptors in isolated urinary bladder smooth muscle from different mouse strains. $\mathrm{Br} \mathrm{J}$ Pharmacol. 2002 Oct;137(4):522-8.

57. Fetscher C, Fleichman M, Schmidt M, Krege S, Michel MC. M(3) muscarinic receptors mediate contraction of human urinary bladder. Br J Pharmacol. 2002 Jul;136(5):641-3.

58. Hegde SS, Eglen RM. Muscarinic receptor subtypes modulating smooth muscle contractility in the urinary bladder. Life Sci. 1999;64(6-7):419-28.

59. Essayan DM. Cyclic nucleotide phosphodiesterase (PDE) inhibitors and immunomodulation. Biochem Pharmacol. 1999 May 1;57(9):965-73.

60. Morley DJ, Hawley DM, Ulbright TM, Butler LG, Culp JS, Hodes ME. Distribution of phosphodiesterase I in normal human tissues. The journal of histochemistry and cytochemistry : official journal of the Histochemistry Society. 1987 Jan;35(1):75-82.

61. Nagasaki S, Nakano Y, Masuda M, Ono K, Miki Y, Shibahara Y, et al. Phosphodiesterase type 9 (PDE9) in the human lower urinary tract: an immunohistochemical study. BJU Int. 2012 Mar;109(6):934-40.

62. Rahnama'i MS, Hohnen R, Van Kerrebroeck PE, van Koeveringe GA. Phosphodiesterase type 2 distribution in the guinea pig urinary bladder. World J Urol. 2015 Oct;33(10):1623-33.

63. Rahnama'i MS, van Koeveringe GA, Hohnen R, Ona S, van Kerrebroeck PE, de Wachter SG. Distribution of phosphodiesterase type 5 (PDE5) in the lateral wall of the guinea pig urinary bladder. BJU Int. 2013 Jul;112(2):246-57.

64. Uckert S, Sigl K, Waldkirch ES, Sandner P, Ulbrich E, Oelke $M$, et al. Bedeutung von Phosphodiesteraseisoenzymen in der Kontrolle der humanen Detrusormuskulatur. Eine immunhistochemische und funktionelle In-vitro-Studie. Der Urologe Ausg A. 2009 Jul;48(7):764-9.

65. Uckert S, Stief CG, Mayer M, Jonas U, Hedlund P. Distribution and functional significance of phosphodiesterase isoenzymes in the human lower urinary tract. World J Urol. 2005 Dec;23(6):368-73.

66. Gillespie JI, Drake MJ. The actions of sodium nitroprusside and the phosphodiesterase inhibitor dipyridamole on phasic activity in the isolated guinea-pig bladder. BJU Int. 2004 Apr;93(6):851-8.

67. Lagou M, Gillespie J, Kirkwood T, Harvey I, Drake MJ. Muscarinic stimulation of the mouse isolated whole bladder: physiological responses in young and ageing mice. Autonomic \& autacoid pharmacology. 2006 Jul;26(3):253-60. 
68. Gillespie Jl. Phosphodiesterase-linked inhibition of nonmicturition activity in the isolated bladder. BJU Int. 2004 Jun;93(9):1325-32.

69. Gillespie Jl. The autonomous bladder: a view of the origin of bladder overactivity and sensory urge. BJU Int. 2004 Mar;93(4):478-83.

70. Truss MC, Uckert S, Stief CG, Forssmann WG, Jonas U. Cyclic nucleotide phosphodiesterase (PDE) isoenzymes in the human detrusor smooth muscle. II. Effect of various PDE inhibitors on smooth muscle tone and cyclic nucleotide levels in vitro. Urol Res. 1996;24(3):129-34.

71. Truss MC, Uckert S, Stief CG, Kuczyk M, Jonas U. Cyclic nucleotide phosphodiesterase (PDE) isoenzymes in the human detrusor smooth muscle. I. Identification and characterization. Urol Res. 1996;24(3):123-8.

72. Truss MC, Stief CG, Uckert S, Becker AJ, Schultheiss D, Machtens S, et al. Initial clinical experience with the selective phosphodiesterase-I isoenzyme inhibitor vinpocetine in the treatment of urge incontinence and low compliance bladder. World J Urol. 2000 Dec;18(6):439-43.

73. Filippi S, Morelli A, Sandner P, Fibbi B, Mancina R, Marini M, et al. Characterization and functional role of androgen-dependent PDE5 activity in the bladder. Endocrinology. 2007 Mar;148(3):1019-29.

74. Lee JG, Moon du G, Kang SH, Cho DY, Park HS, Bae JH. Relaxation effect of phosphodiesterase-5 inhibitor on the animal bladder and prostatic urethra: in vitro and in vivo study. Urol Int. 2010;84(2):231-5.

75. Tinel H, Stelte-Ludwig B, Hutter J, Sandner P. Pre-clinical evidence for the use of phosphodiesterase-5 inhibitors for treating benign prostatic hyperplasia and lower urinary tract symptoms. BJU Int. 2006 Dec;98(6):1259-63.

76. Werkstrom V, Hedlund P, Lee T, Andersson KE. Vardenafil-induced relaxation and cyclic nucleotide levels in normal and obstructed rat urinary bladder. BJU Int. 2009 Dec;104(11):1740-5.

77. Yanai Y, Hashitani H, Hayase M, Sasaki S, Suzuki H, Kohri K. Role of nitric oxide/cyclic GMP pathway in regulating spontaneous excitations in detrusor smooth muscle of the guinea-pig bladder. Neurourol Urodyn. 2008;27(5):446-53.

78. Longhurst PA, Briscoe JA, Rosenberg DJ, Leggett RE. The role of cyclic nucleotides in guinea-pig bladder contractility. Br J Pharmacol. 1997 Aug;121(8):1665-72.

79. Rahnama'i MS, de Wachter SG, van Koeveringe GA, van Kerrebroeck PE, de Vente J, Gillespie JI. The relationship between prostaglandin E receptor 1 and cyclooxygenase I expression in guinea pig bladder interstitial cells: proposition of a signal propagation system. J Urol. 2011 Jan;185(1):315-22.

80. Ricciotti E, FitzGerald GA. Prostaglandins and inflammation. Arterioscler Thromb Vasc Biol. 2011 May;31(5):986-1000.

81. Narumiya S, Sugimoto Y, Ushikubi F. Prostanoid receptors: structures, properties, and functions. Physiol Rev. 1999 Oct;79(4):1193-226.

82. Poggesi L, Nicita G, Castellani S, Selli C, Galanti G, Turini D, et al. The role of prostaglandins in the maintenance of the tone of the rabbit urinary bladder. Invest Urol. 1980 May;17(6):454-8.

83. Frolich JC. A classification of NSAIDs according to the relative inhibition of cyclooxygenase isoenzymes. Trends Pharmacol Sci. 1997 Jan;18(1):30-4.

84. Abrams PH, Sykes JA, Rose AJ, Rogers AF. The synthesis and release of prostaglandins by human urinary bladder muscle in vitro. Invest Urol. 1979 Mar;16(5):346-8.

85. Alkondon M, Ganguly DK. Release of prostaglandin E from the isolated urinary bladder of the guinea-pig. Br J Pharmacol. 1980 Aug;69(4):573-7.

86. Brown WW, Zenser TV, Davis BB. Prostaglandin E2 production by rabbit urinary bladder. Am J Physiol. 1980 Nov;239(5):F452-8.

87. Jeremy JY, Mikhailidis DP, Dandona P. The rat urinary bladder produces prostacyclin as well as other prostaglandins. Prostaglandins Leukot Med. 1984 Nov;16(2):235-48.

88. Leslie CA, Pavlakis AJ, Wheeler JS, Jr., Siroky MB, Krane RJ. Release of arachidonate cascade products by the rabbit bladder; neurophysiological significance? J Urol. 1984 Aug;132(2):376-9.

89. Ishizuka O, Mattiasson A, Andersson KE. Prostaglandin E2-induced bladder hyperactivity in normal, conscious rats: involvement of tachykinins? J Urol. 1995 Jun;153(6):2034-8.

90. Schussler B. Comparison of the mode of action of prostaglandin E2 (PGE2) and sulprostone, a PGE2derivative, on the lower urinary tract in healthy women. A urodynamic study. Urol Res. 1990;18(5):349-52.

91. Maggi CA. Prostanoids as local modulators of reflex micturition. Pharmacol Res. 1992 Jan;25(1):13-20. 
92. Maggi CA, Giuliani S, Conte B, Furio M, Santicioli P, Meli P, et al. Prostanoids modulate reflex micturition by acting through capsaicin-sensitive afferents. Eur J Pharmacol. 1988 Jan 12;145(2):105-12.

93. Schroder A, Newgreen D, Andersson KE. Detrusor responses to prostaglandin E2 and bladder outlet obstruction in wild-type and Ep1 receptor knockout mice. J Urol. 2004 Sep;172(3):1166-70.

94. Kim JC, Park EY, Hong SH, Seo SI, Park YH, Hwang TK. Changes of urinary nerve growth factor and prostaglandins in male patients with overactive bladder symptom. Int J Urol. 2005 Oct;12(10):875-80.

95. Kim JC, Park EY, Seo SI, Park YH, Hwang TK. Nerve growth factor and prostaglandins in the urine of female patients with overactive bladder. J Urol. 2006 May;175(5):1773-6; discussion 6.

96. Yamauchi H, Akino H, Ito H, Aoki Y, Nomura T, Yokoyama O. Urinary prostaglandin E was increased in patients with suprapontine brain diseases, and associated with overactive bladder syndrome. Urology. 2010 Nov;76(5):1267 e13-9. 



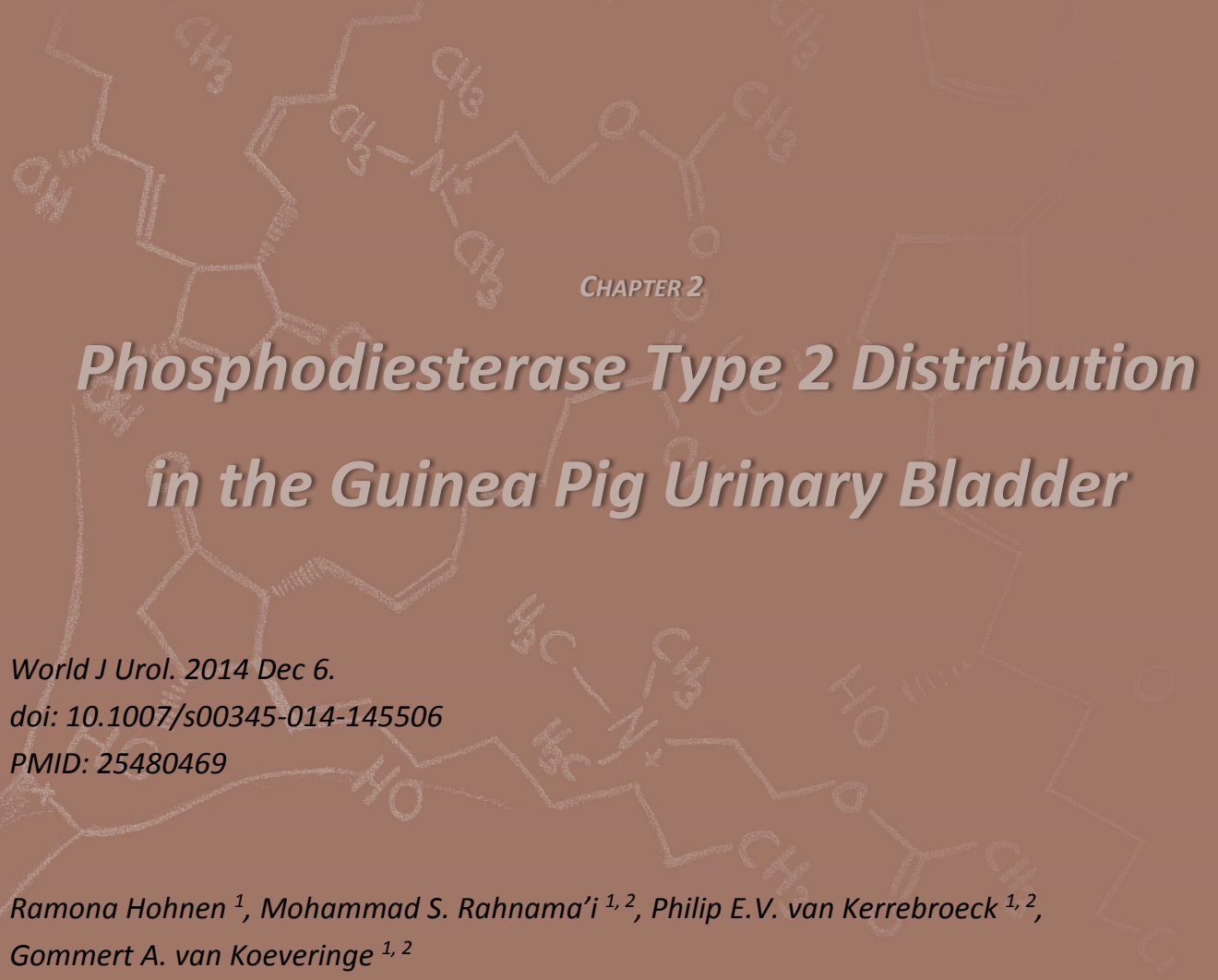

Gommert A. van Koeveringe ${ }^{1,2}$

${ }^{1}$ European Graduate School of Neuroscience (EURON), Maastricht University P.O. Box 616, 6200 MD Maastricht, The Netherlands

${ }^{2}$ Maastricht University Medical Centre $\left(\mathrm{MUMC}^{+}\right)$, Urology department, P.O. Box 5800, 6202 AZ Maastricht, The Netherlands 


\section{Abstract}

Nitric oxide-stimulated cGMP synthesis represents an important signalling pathway in the urinary bladder. Inhibitors of PDE1 and PDE5 enzymes have been studied to treat storage and voiding disorders in clinical settings. The distribution of PDE2 in the bladder is unknown. This study focuses on the distribution and site of action of PDE2 within the guinea pig urinary bladder wall.

In order to investigate the distribution of PDE2 in the guinea pig urinary bladder, six male guinea pig bladders were dissected and treated in $2 \mathrm{ml}$ Krebs solution and $10 \mu \mathrm{M}$ of the specific PDE2 inhibitor, Bay $60-7550$ at $36^{\circ} \mathrm{C}$ for 30 minutes. After stimulating tissues with $100 \mu \mathrm{M}$ of diethylamine-NONOate for 10 minutes, the tissues were snap frozen and cut in $10 \mu \mathrm{m}$ sections which were examined for cGMP immune-reactivity, co-stained with either vimentin, synaptic vesicle protein 2 , calcitonin gene-related protein and protein gene product 9.5 .

The PDE2 inhibitor Bay 60-7550 inhibits cGMP breakdown the most in the urothelial and suburothelial layers, as well as on the nerve fibres. After inhibition by Bay 60-7550, cGMP was mainly expressed in the intermuscle interstitial cells and the nerve fibres of the outer muscle layers of lateral wall, indicating the presence of PDE2 activity.

Our study is the first to show the distribution of PDE2 in the bladder, which was shown to be present in the urothelium, mainly umbrella cells, the interstitial cells of the suburothelium and the outer muscle, as well as in nerve fibres. 


\section{Introduction}

Nitric oxide (NO)-stimulated cGMP synthesis represents an important signalling pathway in the bladder of the guinea pig and the human ${ }^{1-6}$. To terminate NO-cGMP signalling, cGMP is hydrolysed to $5^{\prime}-G M P$ by a number of phosphodiesterases (PDEs) ${ }^{7}$. The superfamily of PDEs has burgeoned into 14 families and more than 50 distinct isoforms have been characterised ${ }^{5}$. Some of these PDE isoforms identified are shown to be highly selective for cGMP with little or no affinity for $\mathrm{CAMP}^{7,8}$. In the clinic, PDE inhibitors are used as therapeutic agents in different areas such as pulmonary arterial hypertension ${ }^{9,10}$, coronary heart disease ${ }^{11}$, dementia ${ }^{12}$, depression ${ }^{12}$, erectile dysfunction ${ }^{13}$, intermittent claudication ${ }^{14}$ and schizophrenia ${ }^{12}$.

In the recent years, a lot of research has concentrated on development of new drug treatment for the overactive bladder syndrome (OAB) with or without demonstrable detrusor overactivity (DO). In this light, among other agents, PDE inhibitors have been a promising focus of research ${ }^{15,16}$. PDE isoenzymes 1-5 and 7-9 have been shown to be expressed in the human urinary bladder ${ }^{15}$. Consequently, there is a rationale for the use of selective PDE inhibitors in the lower urinary tract dysfunction such as DO and OAB. Up until today, only inhibitors of the PDE1 and PDE5 have been studied in clinical setting for the treatment of storage and voiding disorders. PDE1 inhibition has been shown to relax detrusor smooth muscle and exert beneficial clinical effects in patients with $\mathrm{OAB}$ and low-compliance bladder ${ }^{15}$. In addition, PDE5 inhibitors have now been recommended by the most recent European Association of Urology (EAU) guidelines as a possible treatment for nonneurogenic male lower urinary tract symptoms ${ }^{17}$.

There is little known about the distribution and possible role of PDE2 in the urinary bladder. The functional role of PDE2 inhibition has been studied in the context of frog bladders ${ }^{18}$. Furthermore, in a recent study in neonatal rat bladder, the PDE2 inhibitor Bay 60-7550 was shown not to effect the carbachol-enhanced phasic contractions of bladder strips ${ }^{19}$. However, a sensory effect of PDE2 inhibition in the bladder has not yet been studied. In the human bladder, PDE2 has been shown to be present $^{20,21}$. However, its exact site of action remains unknown.

In the current study, we have intended to pinpoint the exact site of action of PDE2 in the bladder. The technique of cGMP detection using highly selective cGMP antibodies in combination with immunofluorescence has been used to indicate the localisation of PDE2 activity. 


\section{Methods}

Six male guinea pigs weighing 220-300 g were killed by cervical dislocation. All procedures were done in agreement with Maastricht University ethical committee guidelines. The bladder was immediately removed from each animal and placed in ice-cold Krebs solution composed of $121.1 \mathrm{mM} \mathrm{NaCl}, 1.87 \mathrm{mM} \mathrm{KCl}, 1.2 \mathrm{mM} \mathrm{CaCl}, 1.15 \mathrm{mM} \mathrm{MgSO}_{4}, 25 \mathrm{mM} \mathrm{NaHCO}$, $1.17 \mathrm{mM} \mathrm{KH}_{2} \mathrm{PO}_{4}$ and $11.0 \mathrm{mM}$ glucose bubbled with $5 \% \mathrm{CO}_{2}$ and $95 \% \mathrm{O}_{2}(\mathrm{pH}$ 7.4). Strips were cut from the lateral wall and maintained in Krebs solution containing one of the two phosphodiesterase inhibitors isobutylmethylxanthine (Sigma-Aldrich ${ }^{\circledR}$ ) and the PDE2 inhibitor Bay $60-7550$, at $36{ }^{\circ} \mathrm{C}$ for 30 minutes. Isobutylmethylxanthine is a general PDE inhibitor and functions as a positive control. To stimulate the production of cGMP, the tissue was also stimulated with NO. Stimulation with NO was achieved by adding freshly prepared, NO donor diethylamine-NONOate to a final concentration of $100 \mu \mathrm{M}$ for 10 minutes. Incubation was terminated by immersing bladder pieces in ice-cold fixative solution of $4 \%$ freshly prepared depolymerized paraformaldehyde for 2 hours at $4{ }^{\circ} \mathrm{C}$. Tissues were then fixed in three steps of two overnight and one daytime incubation at $4{ }^{\circ} \mathrm{C}$ in $0.1 \mathrm{M}$ phosphate buffer with 10,20 and 30 $\%$ sucrose, respectively. On day 3 , the tissues were placed in Tissue-Tek ${ }^{\circledR}$ O.C.T. ${ }^{\text {тм }}$ compound to $^{\circ}$ form a single block, snap frozen in isopentane and cooled in liquid nitrogen. Cryostat sections (9-10 $\mu \mathrm{m})$ were cut such that each section was perpendicular to the urothelial surface. Sections were thawed on chrome alum-gelatin coated slides and processed for immunohistochemistry.

\section{PDE2 detection}

The first specific inhibitor developed for PDE2 was EHNA (erythro-9-(2-hydroxy-3nonyl)adenine $)^{22}$. Bay $60-7550$ is an analogue of EHNA, which is more than 100 -fold more potent and is highly selective for PDE2A, an iso form of PDE2 ${ }^{23}$.

In our study, PDE2 was detected by incubation of the bladder tissue with Bay 60-7550, where after, the tissue was stimulated with NO. This resulted in an increased cGMP concentration at sites where PDE2 is present compared to the negative control.

\section{Antibodies}

Six different primary antibodies were used to study the PDE2 location in the bladder wall in relationship to various nerve fibres. To detect PDE2 site of action, we used sheep antiformaldehyde fixed cGMP (1:4000). The specificity of this antibody has been studied and described before ${ }^{1,24-26}$. In order to identify the nerves in the tissue, the sections were co-stained 
with the antibodies polyclonal chicken anti-PGP 9.5 (1:3000, Abcam), mouse anti-synaptic vesicle protein 2 (SV2) (1:500; DS Hybridoma Bank, USA) and monoclonal anti-vimentin (1:1000, Biogenex), monoclonal rabbit anti-neurofilament (1:1000, Epitomics) and polyclonal rabbit antiCGRP (calcitonin gene-related peptide) (1:1000, Calbiochem). Vimentin was used to detect interstitial cells.

\section{Immunohistochemistry}

The sections were prepared for immunohistochemistry by drying for 20 minutes at room temperature followed by three washes with Tris-buffered saline (TBS; $\mathrm{pH}$ 7.4). The slides were then incubated overnight with primary antibodies at $4{ }^{\circ} \mathrm{C}$. After overnight incubation with the primary antibodies diluted in TBS containing $0.3 \%$ (v/v) Triton X-100 (TBS-T), sections were washed in TBS-T, TBS and TBS- T; each wash step lasted 15 minutes. Rabbit primary antibodies were visualised using Alexa Fluor 488 donkey anti-rabbit IgG $(\mathrm{H}+\mathrm{L})$ conjugate (Molecular Probes, Invitrogen Ltd, Paisley, UK), diluted 1:100 in TBS-T. Mouse primary antibodies were visualised with Alexa Fluor 488 donkey anti-mouse IgG conjugate (Molecular Probes, Invitrogen Ltd, Paisley, UK), diluted 1:100 in TBS-T. Chicken primary antibodies were visualised with Alexa 488 goat anti-chicken. Sheep primary antibodies were visualised with two different antibodies, Alexa Fluor 594 donkey anti-sheep IgG conjugate (Molecular Probes, Invitrogen Ltd, Paisley, UK) and Alexa Fluor 546 donkey anti-sheep, both diluted 1:100. Sections were incubated with the secondary antibodies for 1 hour at room temperature in the dark. After washing with TBS-T, cell nuclei were visualised by Hoechst staining, diluted 1:1000 in TBS-T and incubated for 10 minutes at room temperature. After washing with TBS-T and TBS, sections were mounted with TBS-glycerol. Sections were analysed and photographed using an Olympus AX70 microscope using a 10x, 20x, 40x and 100x objectives. For the detection of Alexa 488 fluorescence and the detection of Alexa 594 and 546, a narrow band-pass MNIBA-filter and a filter with a narrow excitation band, the U-M41007A filter (both filters from Chroma Technologies, Rockingham, VT, USA) were used, respectively. The microscope was equipped with a cooled CCD Olympus digital video camera F-view. Images were stored digitally as 8-bits images and analysed using ImageJ software.

\section{Results}

Guinea pig urinary bladder tissue incubated in vitro as described in the methods section without any addition of PDE inhibitor or NO, will not show a significant accumulation of CGMP in any cell type or cellular structure present (Figures $1 \mathrm{~A}-\mathrm{C}$ ). Inhibition of cGMP breakdown using non- 
selective PDE inhibitor IBMX results, after addition of NO to the incubation medium in accumulation of cGMP in a number of (sub)cellular structures like umbrella cells, suburothelial interstitial cells and cells associated with the outer muscle layers located on the serosal surface, on the surface of the muscle bundles and within the muscle bundle. This has been documented several times ${ }^{1,4}$. From the present series of experiments, we have seen cGMP accumulation in the suburothelial layers of the lateral wall of the guinea pig bladder after incubation of tissue in the presence of $1 \mathrm{mM}$ IBMX and $100 \mu \mathrm{M}$ DEANO (Figures 1D-F). PDE2 presence in the guinea pig urinary bladder tissue is shown, using an indirect immunohistochemical technique, because no reliable antibodies are available for PDE2 enzyme. By adding a NO donor, cGMP production is stimulated while we inhibit its breakdown via specific PDE2 inhibition, through incubation with the PDE2 inhibitor Bay 60-7550. The result of these steps is a cGMP elevation at sites where PDE2 enzyme is active in the tissue (Figures 1G-I).

In Figures 1G-I, it can be noted that the umbrella cells of the urothelium stain positive for cGMP. Furthermore, the vimentin-positive interstitial cells are also cGMP-positive. Moreover, endothelium of the blood vessels is strongly positive for cGMP. These signals were specific to the tissue which was inhibited by the PDE2 inhibitor Bay 60-7550. However, a much weaker signal can also be detected under the condition without any PDE inhibition (Figures $1 \mathrm{~A}-\mathrm{C}$ ). This is due to stimulation with NO, which was done with all samples. Therefore, in absence of any PDE inhibition, a low amount of cGMP is also present in the tissue, which causes a low signal of cGMP.

PDE2 distribution in the urothelium is shown in more detail in Figure 2. Different layers of the urothelium can be noted and it is clearly shown that the outer layer stains strongly positive for cGMP. Moreover, in Figure 2, details of PDE2 activity in the interstitial cells of the suburothelium can be noted. These interstitial cells are clearly cGMP-positive. Besides the presence of PDE2 in the urothelium and suburothelium, which was detected by an increase in cGMP compared to the negative control, cGMP also stains positive in the nerves and blood vessels, which are present in the muscle layer.

The positive signals of cGMP in the inner muscle layer of the lateral wall of the guinea pig bladder are shown further in Figure 3. cGMP-positive interstitial cells can be noted. In Figure 4, the distribution of cGMP and vimentin after PDE2 inhibition in the outer muscle layer is shown where also cGMP-positive interstitial cells can be noted. 

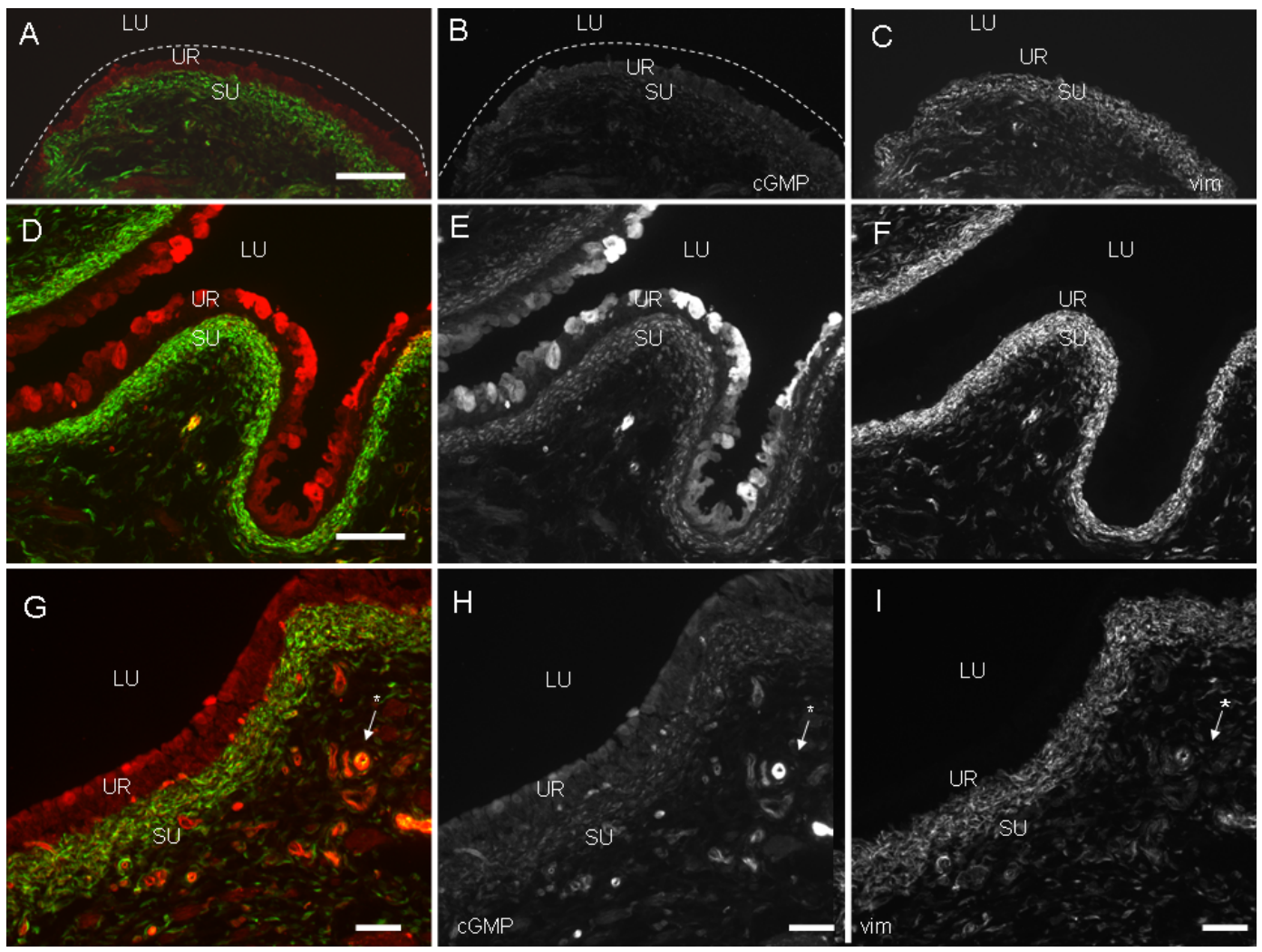

Figure 1. The distribution of $C G M P$ and vimentin without PDE inhibition, after IBMX inhibition and after PDE2 inhibition, in the urothelium of the lateral wall of the guinea pig bladder. In $A$, the guinea pig bladder without any PDE inhibition with the individual CGMP and the vimentin stainings are shown in panels $B$ and $C$, respectively. In $D$, the guinea pig bladder after the incubation with IBMX with the individual CGMP and the vimentin stainings are shown in panels $E$, and $F$, respectively. In $G$, the guinea pig bladder after incubation with the PDE2 selective inhibitor Bay 60-7550 inhibition with the individual CGMP and the vimentin stainings are shown in panels $H$ and I, respectively. In all panels, the bladder lumen (LU), the urothelium (UR) and the suburothelial layer (SU) are marked. In G-I, a blood vessel is visible in the suburothelial layer (marked with asterisk). Calibration bars 100 m 


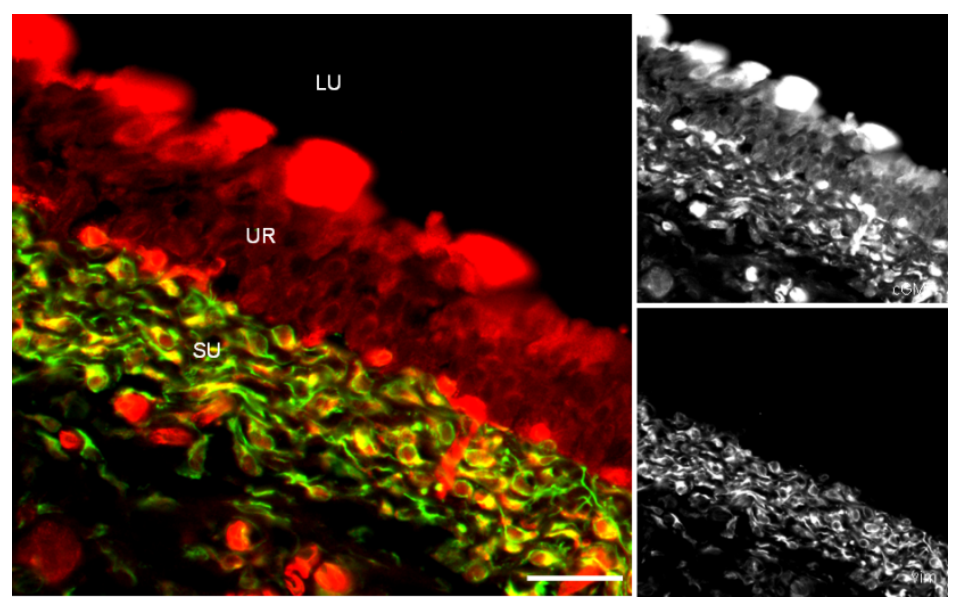

Figure 2. The distribution of CGMP and vimentin after PDE2 inhibition in the urothelium of the lateral wall of the guinea pig bladder at a higher magnification. The coloured panel shows a high-power image of the urothelium of the lateral wall of a guinea pig bladder stained with the antibody for CGMP (red) and vimentin (green). The bladder lumen (LU), the urothelium (UR) and the suburothelial layer (SU) are marked. The different layers of the urothelium can be noted. The outer layer stains positive for CGMP. The black and white panels show the individual images of CGMP and vimentin, respectively. Calibration bar $25 \mu \mathrm{m}$.

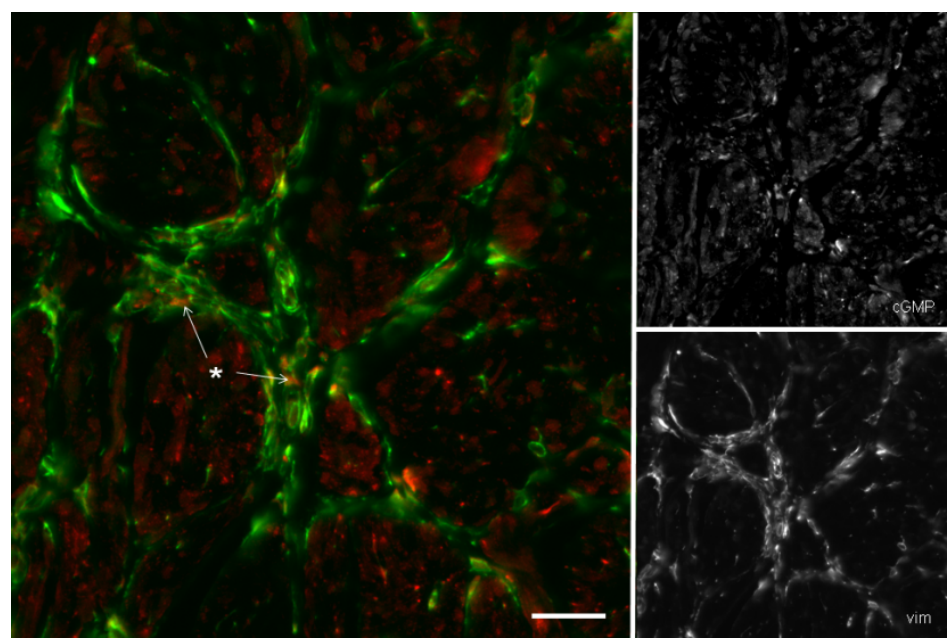

Figure 3. The distribution of CGMP and vimentin after PDE2 inhibition, in the inner muscle of the lateral wall of the guinea pig bladder. The coloured panel shows a low-power image of the inner muscle of the lateral wall of a guinea pig bladder stained with the antibody for CGMP (red) and vimentin (green). Nerves in the inner muscle stain positive (red) for cGMP. Furthermore, vimentin-positive cells are shown between the different muscle bundles which are also CGMP-positive (marked with asterisk). The black and white panels show the individual images of cGMP, vimentin and Hoechst, respectively. Calibration bar $50 \mu m$ 


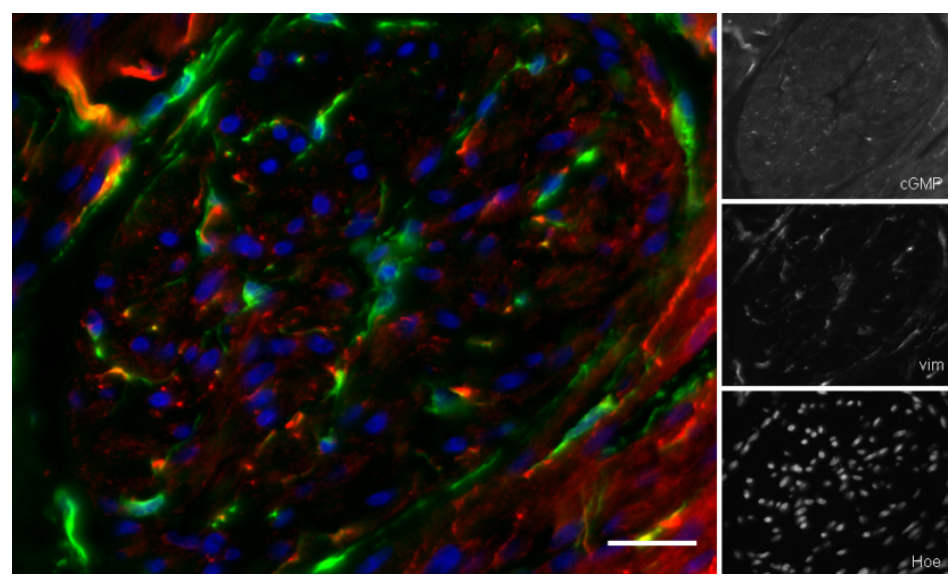

Figure 4. The distribution of CGMP and vimentin after PDE2 inhibition in the outer muscle of the lateral wall of the guinea pig bladder. The coloured panel shows a high-power image of the outer muscle of the lateral wall of the guinea pig bladder stained with the antibody for CGMP (red), vimentin (green) and Hoechst (blue). It can be noted that nerves of the outer muscle stains positive for cGMP, too. Furthermore, vimentin-positive cells are shown in the muscle and between the different muscle bundles. The black and white panels show the individual images of CGMP, vimentin and Hoechst, respectively. Calibration bar 25 $\mu \mathrm{m}$.

Figure 5 shows the distribution of CGMP and CGRP, in the nerves of the urothelium and outer muscle of the lateral wall of the guinea pig bladder after PDE2 inhibition. CGRP is a marker for afferent nerves ${ }^{27}$. In both the urothelium and outer muscle, CGRP-positive nerves can be found. In Figure 5A, a nerve in the urothelium is shown, staining for both, CGRP and cGMP. Figure 5B, shows a nerve of the urothelium which is CGRP-positive but does not stain for CGMP. In Figure 5C, a cGMP and CGRP-positive nerve, which is located in the outer muscle is shown and 5D shows an example of a CGRP-positive nerve of the outer muscle which is cGMP-negative. However, most CGRP-positive nerves are also cGMP-positive and only a small subpopulation of them is CGMP-negative.

This same phenomenon is also seen in nerves labelled with the efferent maker SV2, which is shown in Figure 6. In this figure, nerves of the urothelium and the outer muscle which stain positive for SV2 are shown. SV2 is a marker for efferent nerves ${ }^{28}$. In the urothelium, most SV2 nerves stain positive for CGMP, which shows that PDE2 is present in those nerves. As mentioned before, a small subpopulation of all SV2-positive nerves in the urothelium is cGMP-negative. The same pattern can be noted in the outer muscle layer. Almost all SV2-positive nerves are cGMP-positive. However, some cGMP-negative nerves that are SV2-positive are also present (Figure 6D). 


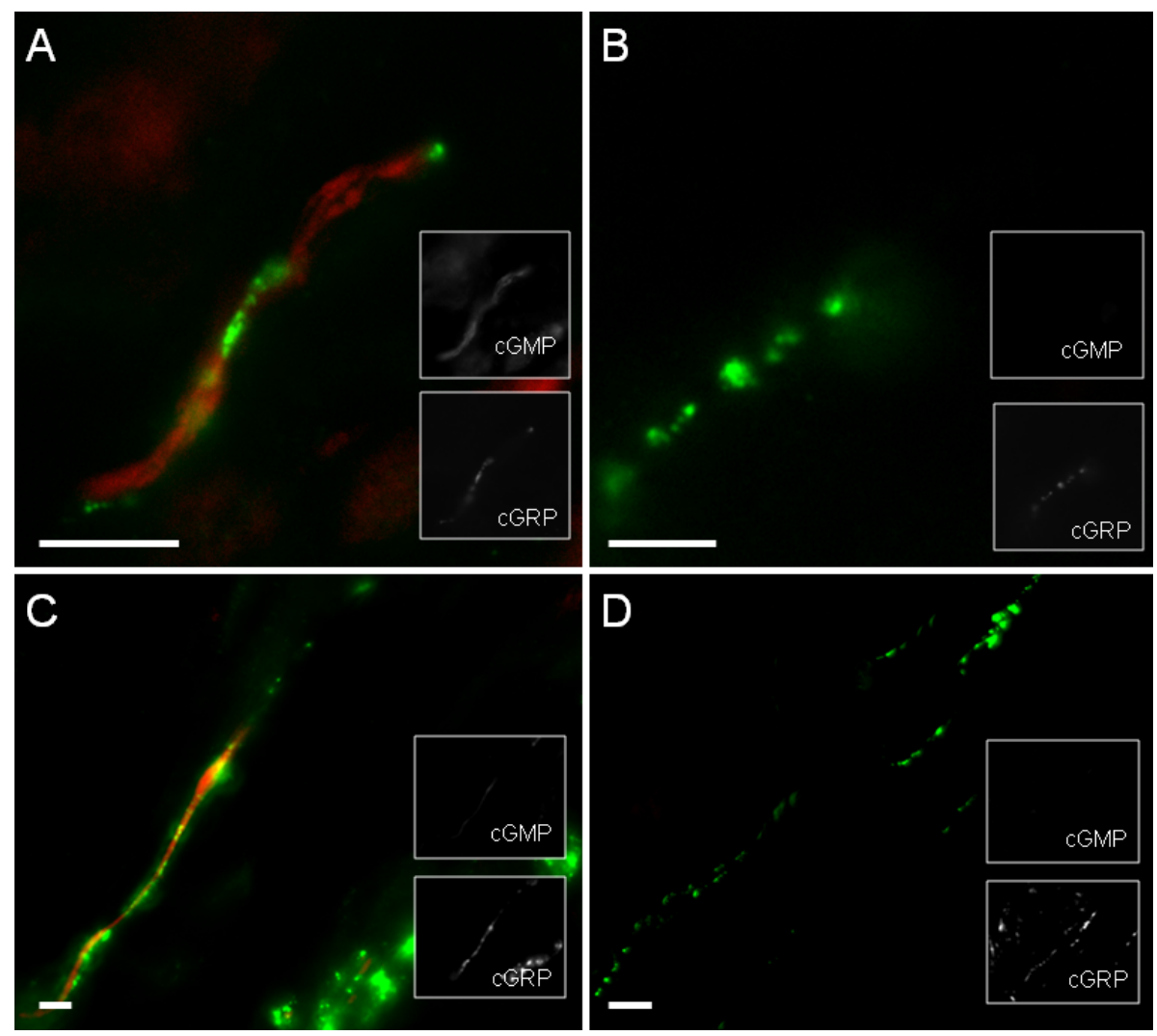

Figure 5. The distribution of CGMP and CGRP after PDE2 inhibition in the nerves of the urothelium and the outer muscle of the lateral wall of the guinea pig bladder. All panels show a high-power image of nerves of the lateral wall of a guinea pig bladder stained with the antibody for CGMP (red), CGRP (green) and Hoechst (blue). In a, a nerve of the urothelium is shown, staining for both, CGRP and CGMP. In B, a nerve of the urothelium which is CGRP-positive but does not stain for CGMP, is shown. In C, a CGMP-and CGRP-positive nerve is shown, which is located in the outer muscle. In D, a CGRP-positive nerve of the outer muscle which is CGMP-negative, is presented. However, a subpopulation of CGRP-positive nerves are CGMP-negative, most of them are CGMP-positive. The black and white panels show the individual images of CGMP and CGRP, respectively. Calibration bars $10 \mu \mathrm{m}$.

Figure 7 shows the distribution of cGMP and neurofilament in the nerves of the urothelium and the outer muscle. Neurofilament is another marker of afferent nerves ${ }^{29}$. Only cGMP- and neurofilament-positive nerves could be found in the urothelium and the outer muscle.

In Figure 8, the same results observed with neurofilament are seen for the general neuronal marker PGP 9.5 $5^{30}$. This shows that all PGP 9.5-positive nerves are cGMP-positive. 


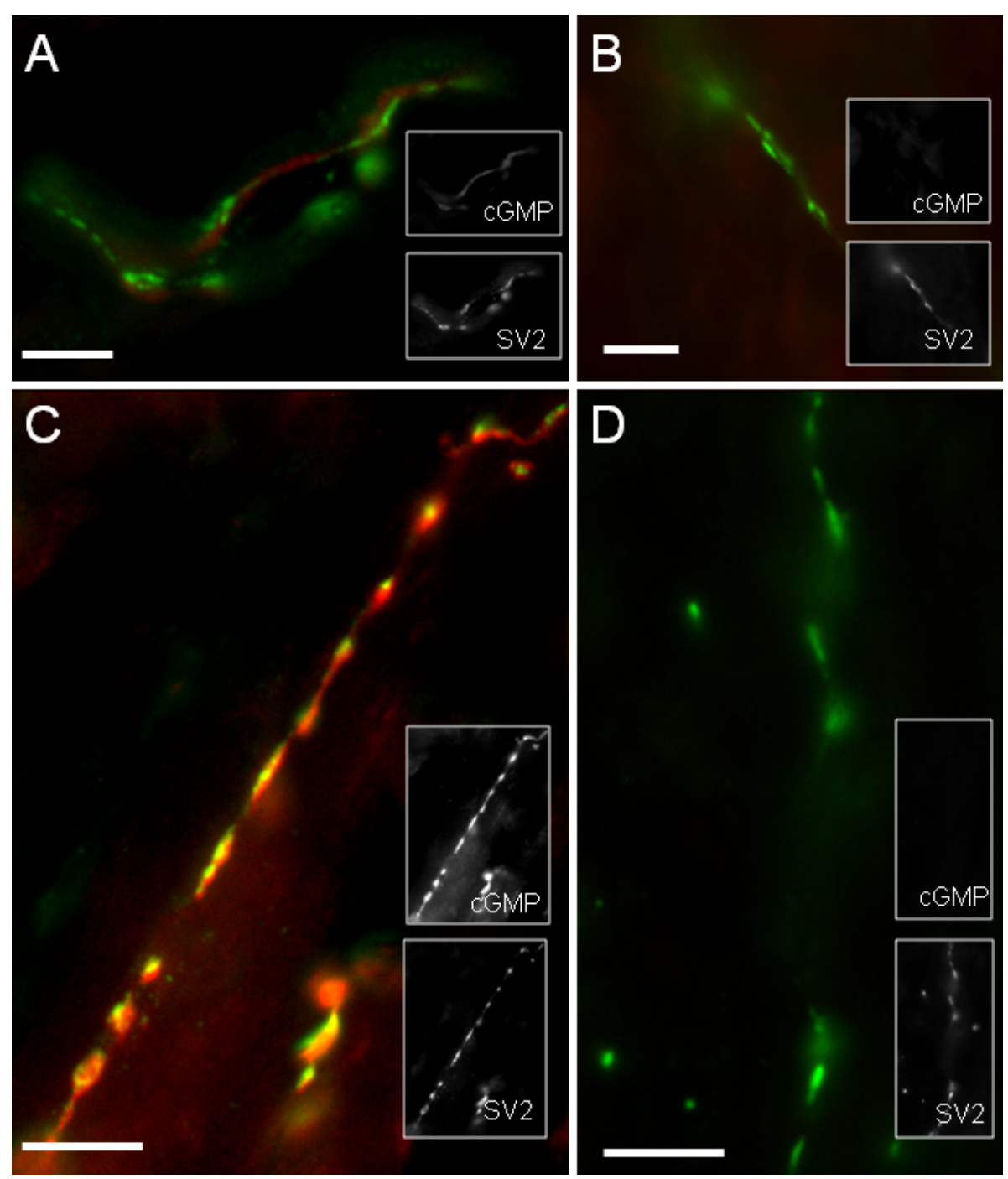

Figure 6. The distribution of CGMP and SV2 after PDE2 inhibition, in the nerves of the urothelium and the outer muscle of the lateral wall of the guinea pig bladder. All panels show a high-power image of nerves of the lateral wall of a guinea pig bladder stained with the antibody for CGMP (red), SV2 (green) and Hoechst (blue). In A, a nerve of the urothelium, staining for both, SV2 and CGMP, is shown. In B, a nerve of the urothelium which is SV2-positive but does not stain for CGMP, is presented. In C, CGMP- and SV2positive nerves, which are located in the outer muscle layer, are shown. In D, a SV2-positive nerve of the outer muscle which is CGMP-negative, is shown. However, a subpopulation of SV2-positive nerves is cGMPnegative, most of them are CGMP-positive. The black and white panels show the individual images of CGMP and SV2, respectively. Calibration bars $10 \mu \mathrm{m}$. 


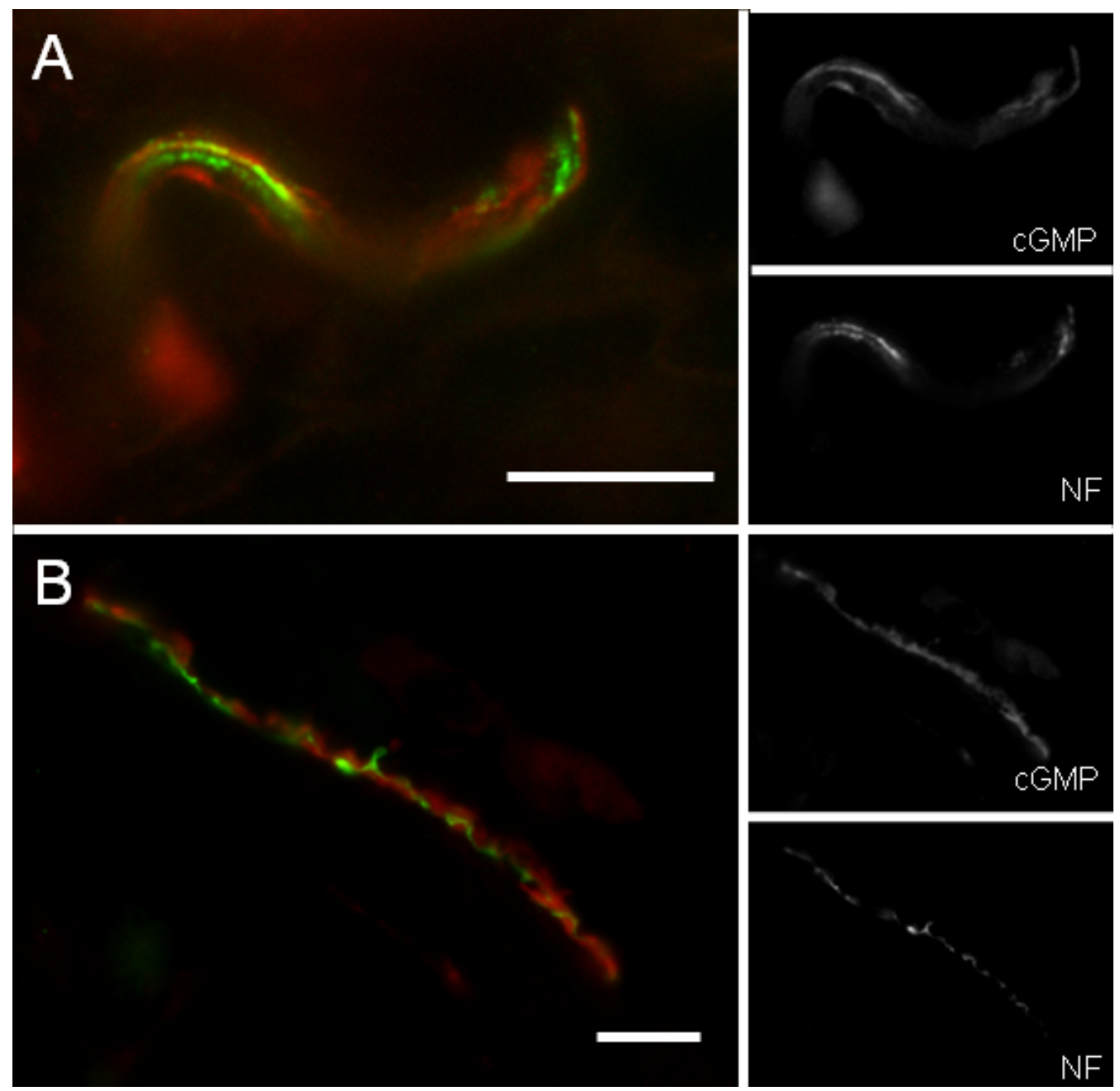

Figure 7. The distribution of CGMP and neurofilament (NF) after PDE2 inhibition in the nerves of the urothelium and the outer muscle of the lateral wall of the guinea pig bladder. Both $A$ and $B$ show a highpower image of nerves of the lateral wall of a guinea pig bladder stained with the antibody for CGMP (red), neurofilament (green) and Hoechst (blue). In A, a nerve of the urothelium staining for both neurofilament and CGMP, is shown. In B, a nerve of the outer muscle, also staining for CGMP and neurofilament, is depicted. No CGMP-negative nerves which were stained for neurofilament have been found. The black and white panels show the individual images of CGMP and neurofilament, respectively. Calibration bars $10 \mu m$. 


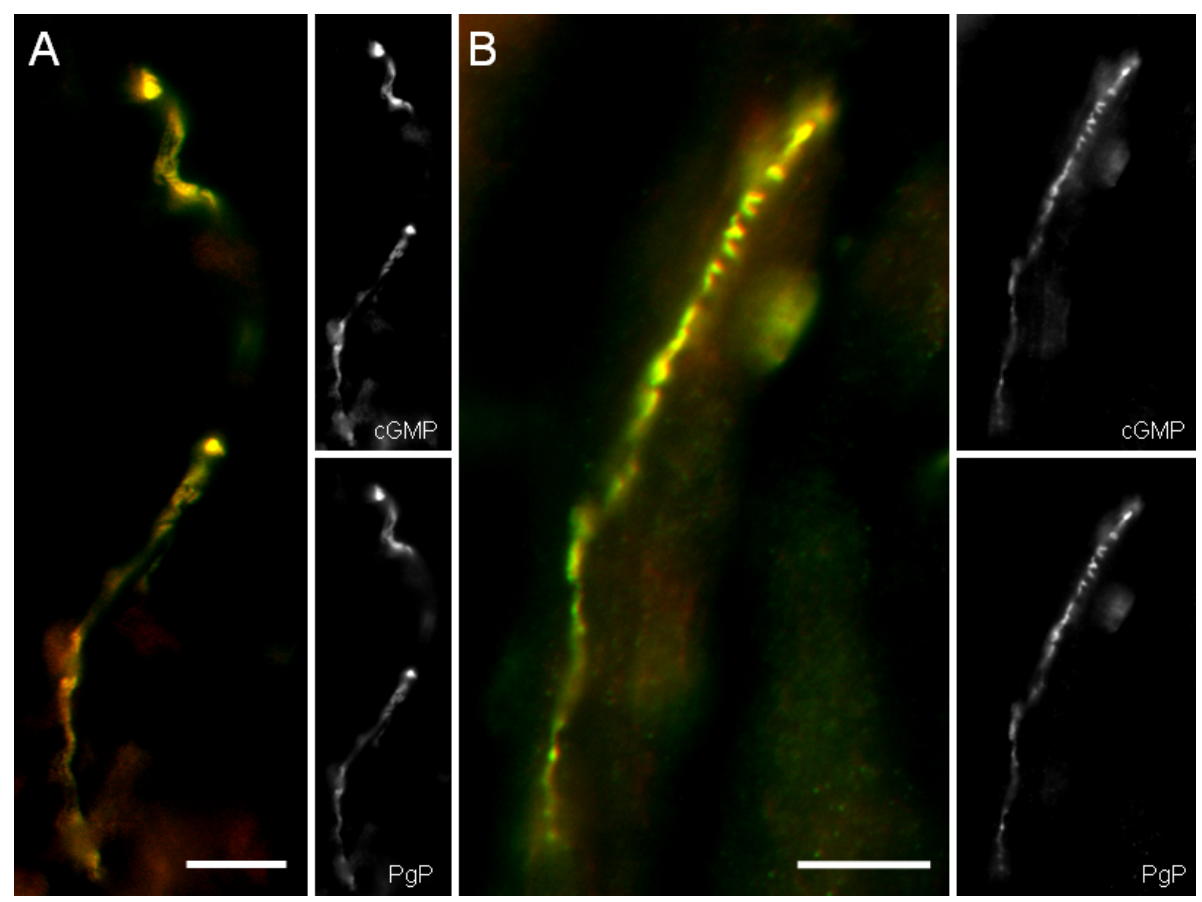

Figure 8. The distribution of CGMP and PgP after PDE2 inhibition, in the nerves of the urothelium and outer muscle of the lateral wall of the guinea pig bladder. Both panels $A$ and B show high-power images of nerves of the lateral wall of a guinea pig bladder stained with the antibody for CGMP (red), PgP (green) and Hoechst (blue). In A, a nerve of the urothelium staining for both, PgP and CGMP is shown. In B, a nerve of the outer muscle which also stained for CGMP and PgP, is depicted. No CGMP-negative nerves, which stained for PgP have been found. The black and white panels show the individual images of CGMP and PgP, respectively. Calibration bars $10 \mu \mathrm{m}$.

Expression of PDE2 in vascular endothelial cells has been shown in human cardiac and renal tissues, as well as in several human, bovine, and porcine synthetic/activated cultured arterial cells $^{31}$. Figure 9 shows a blood vessel of the outer muscle layer. The endothelium stains strongly positive for CGMP. This is in accordance with the findings from Figure 1.

In Figure 10, a cluster of interstitial cells in the outer muscle is displayed, staining positive for vimentin and cGMP. In this high-power image, it can be seen that some interstitial cells located in the outer muscle of the lateral wall of a guinea pig bladder are cGMP-positive, while others are not. An overview of the PDE2 distribution in the lateral wall of the guinea pig bladder is given in a cartoon which is displayed in Figure 11. 


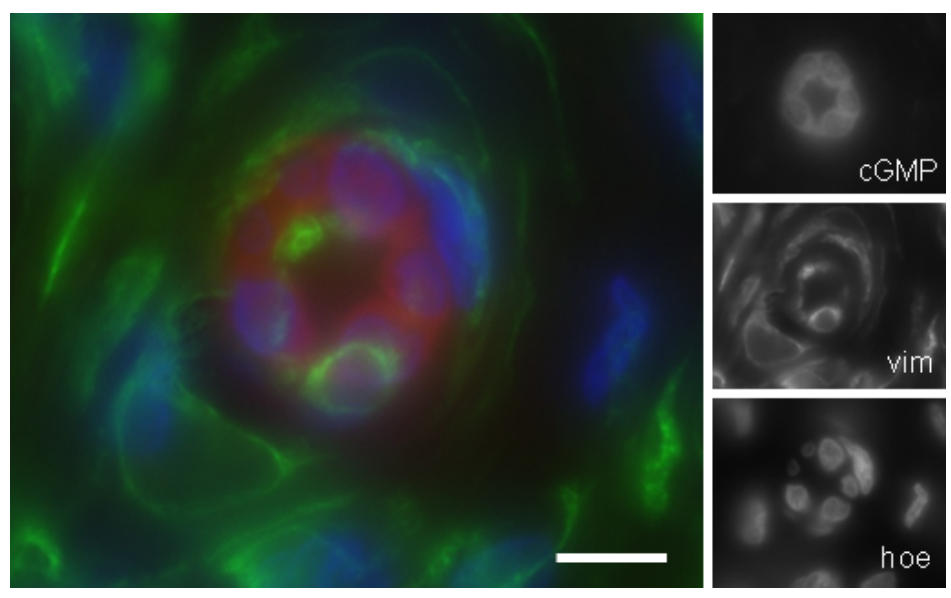

Figure 9. The distribution of CGMP and vimentin after PDE2 inhibition in the blood vessel of the lateral wall of the guinea pig bladder. The coloured panel shows a high-power image of a blood vessel, located in the outer muscle of the lateral wall of a guinea pig bladder stained with the antibody for cGMP (red), vimentin (green) and Hoechst. The epithelium of the blood vessel stains positive (red) for cGMP. The black and white panels show the individual images of CGMP and vimentin, respectively. Calibration bar $10 \mu m$.

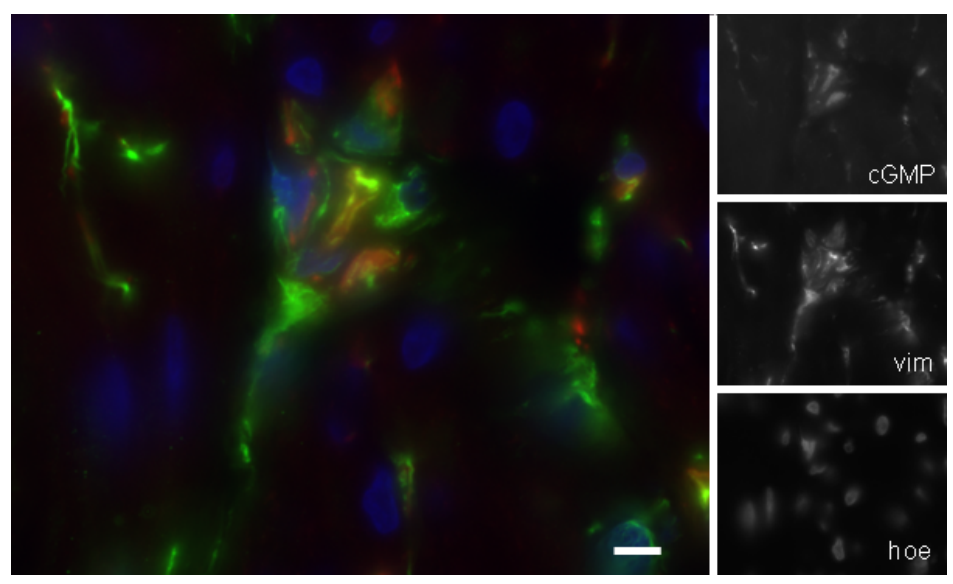

Figure 10. The distribution of CGMP and vimentin after PDE2 inhibition in the interstitial cells of the outer muscle of the lateral wall of the guinea pig bladder. The coloured panel shows a high-power image of some interstitial cells located in the outer muscle of the lateral wall of a guinea pig bladder stained with the antibody for CGMP (red), vimentin (green) and Hoechst. It can be noted that some of them are also cGMP-positive, while others are not. The black and white panels show the individual images of cGMP and vimentin, respectively. Calibration bar $10 \mu \mathrm{m}$ 


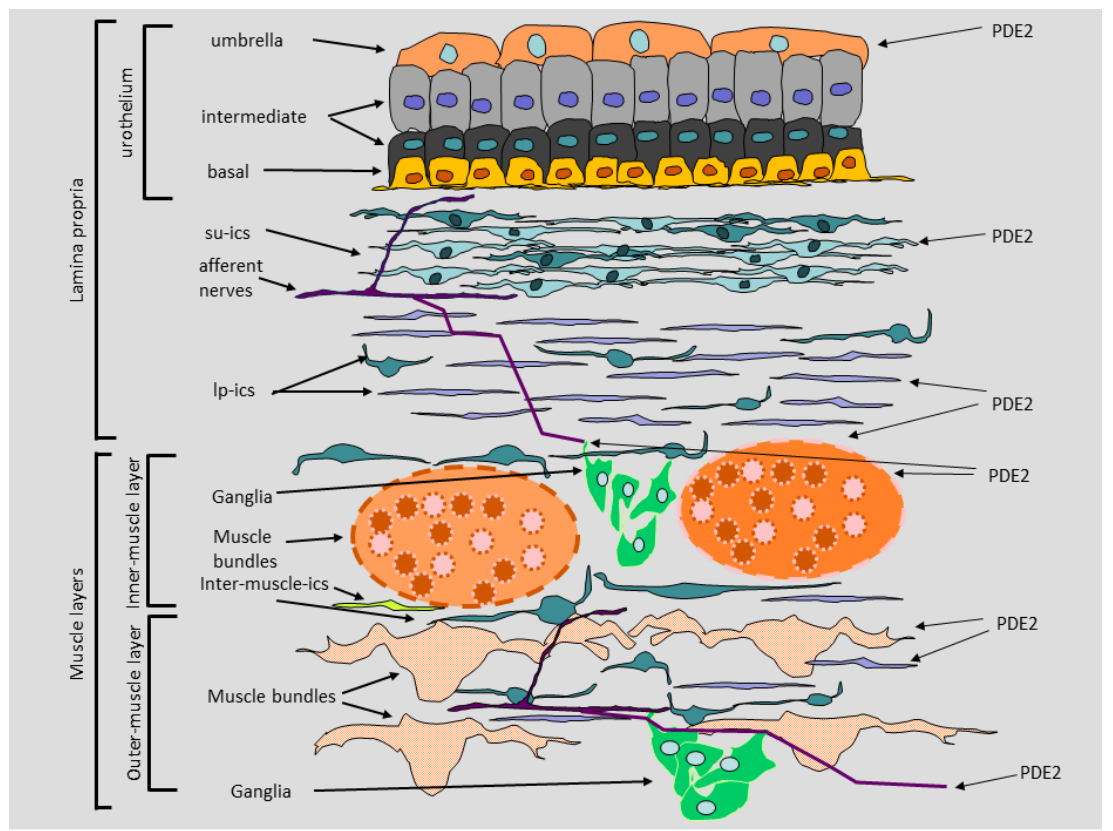

Figure 11. An overview of the PDE2 distribution in the lateral wall of the guinea pig bladder. PDE2 is present at several sites. In the urothelium, PDE2 is shown to be present in the umbrella cells and the basal layer of the urothelium. The suburothelial layer also contains PDE2. It is located in the interstitial cells and the endothelium of blood vessels. In the inner and outer muscle, PDE2 has been shown in the muscle bundles and between them. Furthermore, several nerve types contain PDE2.

\section{Discussion}

In the present study, we have shown the site of action of the PDE2 enzyme in the guinea pig urinary bladder. Since reliable PDE2 antibodies are lacking, we used the technique of cGMPimmunofluorescence detection after incubation of the bladder tissue under conditions of stimulated cGMP synthesis using an NO donor.

In the urothelium, PDE2 activity was detected in the umbrella cells. The intermediate and basal urothelial cells show a significant lower PDE2 activity. The different layers and different expression patron of PDE2 activity in the urothelium suggest different functions of the layers of the urothelium. This difference in function in the different urothelial layers is also described in an earlier study, where a sensory function of the umbrella cells has been suggested ${ }^{32}$. In the lamina propria, PDE2 activity was found in the interstitial cells of the suburothelium forming a network, which was distributed throughout the muscle layers. 
Bladder outlet obstruction causes changes in the proliferation of the networks of NO-responsive interstitial cells of the guinea pig bladder ${ }^{1}$. The major changes were to the urothelium (umbrella cells and intermediate urothelial cells), the network of cGMP-positive interstitial cells in the lamina propria and the muscle layers ${ }^{1}$. Some possible evidence for a role of interstitial NOresponsive cGMP-positive interstitial cells has come from experiments on the isolated mouse bladder. The only cells that respond to NO in the mouse bladder are the interstitial cells on the outer muscle bundles. When the bladder is exposed to muscarinic agonists to induce phasic activity, exogenous NO abolishes this activity. Since the only cells responding to NO are interstitial cells, this implies that they play a central role in the generation of phasic activity ${ }^{33}$. Although these data are purely descriptive and morphological, we could hypothesise that the presence of PDE2 activity on this interstitial cell network in the bladder, as shown in this study, might suggest a role for PDE2 in the signal transduction of the NO-responsive cGMP-positive interstitial cell network.

In addition, a second hypothesis can be put forward since PDE2 activity was also present in nerve fibres. It is known that the pathophysiological mechanisms underlying overactive bladder syndrome $(\mathrm{OAB})$, at least in partly, involve alterations in bladder afferent fibre activity. The bladder is innervated by two types of afferent nerves: the myelinated A-delta and unmyelinated C-fibres ${ }^{34}$. In normal conditions, mechanosensitive A-delta fibres are activated by distension and urothelium stretching resulting from a progressive increase in urine volume. These fibres then convey sensations of bladder fullness, during the bladder filling phase, to spinal and supraspinal centres coordinating the micturition reflex. In contrast, the normally silent, C-fibres are thought to assume a prominent role under pathophysiological conditions, where they become hyperexcitable and therefore are responsible for inducing detrusor hyperactivity ${ }^{35}$. In our study, nerves which were stained for CGRP, SV2, neurofilament and the general neuronal marker PGP 9.5 also showed PDE 2 activity. This can suggest that PDE2 could play a role in the signal transduction through the nervous system.

Both neurofilament and CGRP-positive nerve fibres are considered afferent fibres and co-stain with cGMP after PDE2 inhibition. As also shown in our study, afferent fibres had already been identified in the suburothelium as well as in the detrusor muscle ${ }^{36,37}$. Moreover, the concept of urothelial and suburothelial cells releasing chemical mediators which could affect neural activity and ultimately the threshold for bladder afferent nerve activation has been proven before ${ }^{36}$. From this, it could be speculated that modulation of PDE2 activity could modulate the sensory signal processing. 
On the other hand, our data also showed the efferent nerve marker SV2 co-staining with PDE2 activity, pointing to a possible effect on the motor signal transmission. Therefore, it seems likely that modulation of PDE2 could modulate the nervous signal transduction of the urinary bladder. Similar mechanisms are found in other organs. PDE inhibitors can modulate the nerve-induced off-response in the smooth muscle oesophagus, which supports the hypothesis that the peripheral NO-cGMP signalling system controls peristalsis in the smooth muscle oesophagus, and by extension, possibly in the bladder muscle ${ }^{34}$.

The results of our experiments are in accordance with both of the mentioned important hypothesis about the role of PDE2 in the signalling cascade of the urinary bladder. PDE2 activity is found in both the nervous system as well as the NO-responsive cGMP-positive interstitial cells. This indicates that PDE2 action cannot be limited to either the urothelium or suburothelium or to the nerves of urothelium and muscle layers. It seems that it is active in both of these systems. However, our study has some limitations as our data depend on the selectivity of the inhibitor and the co-relation of the cGMP assay with PDE activity, and we have not fully excluded the possibility of a more indirect process that could modulate cGMP metabolism when the PDE2 inhibitor is used. Furthermore, our data are purely morphological and therefore, every functional conclusion or hypothesis is speculative and needs further physiological experiments that can elucidate the exact effect of PDE2 inhibition on bladder function.

\section{Conclusion}

PDE2 presence has been found in the umbrella cells of the urothelium, the suburothelial interstitial cells and nerves which are present in the urothelium, suburothelium and both muscle layers. Therefore, PDE2 is suggested to play a role in the signal transduction throughout the whole bladder wall. Further functional experiments need to elucidate the specific signalling cascades and the possible role of PDE2 in bladder physiology. 


\section{References}

1. de Jongh R, van Koeveringe GA, van Kerrebroeck PE, Markerink-van Ittersum M, de Vente J, Gillespie JI. Alterations to network of NO/cGMP-responsive interstitial cells induced by outlet obstruction in guinea-pig bladder. Cell Tissue Res. 2007 Oct;330(1):147-60.

2. Gillespie JI, Drake MJ. The actions of sodium nitroprusside and the phosphodiesterase inhibitor dipyridamole on phasic activity in the isolated guinea-pig bladder. BJU Int. 2004 Apr;93(6):851-8.

3. Gillespie JI, Markerink-van Ittersum M, de Vente J. cGMP-generating cells in the bladder wall: identification of distinct networks of interstitial cells. BJU Int. 2004 Nov;94(7):1114-24.

4. Gillespie JI, Markerink-van Ittersum M, de Vente J. Expression of neuronal nitric oxide synthase (nNOS) and nitric-oxide-induced changes in cGMP in the urothelial layer of the guinea pig bladder. Cell Tissue Res. 2005 Sep;321(3):341-51.

5. Gillespie JI, Markerink-van Ittersum M, De Vente J. Endogenous nitric oxide/cGMP signalling in the guinea pig bladder: evidence for distinct populations of sub-urothelial interstitial cells. Cell Tissue Res. 2006 Aug;325(2):325-32.

6. Smet PJ, Jonavicius J, Marshall VR, de Vente J. Distribution of nitric oxide synthase-immunoreactive nerves and identification of the cellular targets of nitric oxide in guinea-pig and human urinary bladder by cGMP immunohistochemistry. Neuroscience. 1996 Mar;71(2):337-48.

7. Beavo JA. Cyclic nucleotide phosphodiesterases: functional implications of multiple isoforms. Physiol Rev. 1995 Oct;75(4):725-48.

8. de Vente J, Markerink-van Ittersum M, Vles JS. The role of phosphodiesterase isoforms 2, 5, and 9 in the regulation of NO-dependent and NO-independent cGMP production in the rat cervical spinal cord. J Chem Neuroanat. 2006 Jun;31(4):275-303.

9. Archer SL, Michelakis ED. Phosphodiesterase type 5 inhibitors for pulmonary arterial hypertension. N Engl J Med. 2009 Nov 5;361(19):1864-71.

10. Rosenzweig EB. Tadalafil for the treatment of pulmonary arterial hypertension. Expert Opin Pharmacother. 2010 Jan;11(1):127-32.

11. Feldman AM, McNamara DM. Reevaluating the role of phosphodiesterase inhibitors in the treatment of cardiovascular disease. Clinical cardiology. 2002 Jun;25(6):256-62.

12. Halene TB, Siegel SJ. PDE inhibitors in psychiatry--future options for dementia, depression and schizophrenia? Drug discovery today. 2007 Oct;12(19-20):870-8.

13. Morales AM, Mirone V, Dean J, Costa P. Vardenafil for the treatment of erectile dysfunction: an overview of the clinical evidence. Clinical interventions in aging. 2009;4:463-72.

14. Rowlands TE, Donnelly R. Medical therapy for intermittent claudication. European journal of vascular and endovascular surgery : the official journal of the European Society for Vascular Surgery. 2007 Sep;34(3):31421.

15. Rahnama'i MS, Uckert S, Hohnen R, van Koeveringe GA. The role of phosphodiesterases in bladder pathophysiology. Nat Rev Urol. 2013 Jul;10(7):414-24.

16. Uckert S, Kuczyk MA, Oelke M. Phosphodiesterase inhibitors in clinical urology. Expert review of clinical pharmacology. 2013 May;6(3):323-32.

17. Oelke M, Bachmann A, Descazeaud A, Emberton M, Gravas S, Michel MC, et al. EAU guidelines on the treatment and follow-up of non-neurogenic male lower urinary tract symptoms including benign prostatic obstruction. Eur Urol. 2013 Jul;64(1):118-40.

18. Fock EM, Lavrova EA, Bachteeva VT, Chernigovskaya EV, Parnova RG. Nitric oxide inhibits arginine-vasotocininduced increase of water osmotic permeability in frog urinary bladder. Pflugers Archiv : European journal of physiology. 2004 May;448(2):197-203.

19. Zhai K, Chang Y, Wei B, Liu Q, Leblais V, Fischmeister R, et al. Phosphodiesterase types 3 and 4 regulate the phasic contraction of neonatal rat bladder smooth myocytes via distinct mechanisms. Cellular signalling. 2014 May;26(5):1001-10. 
20. Truss MC, Uckert S, Stief CG, Forssmann WG, Jonas U. Cyclic nucleotide phosphodiesterase (PDE) isoenzymes in the human detrusor smooth muscle. II. Effect of various PDE inhibitors on smooth muscle tone and cyclic nucleotide levels in vitro. Urol Res. 1996;24(3):129-34.

21. Uckert S, Kuthe A, Jonas $U$, Stief CG. Characterization and functional relevance of cyclic nucleotide phosphodiesterase isoenzymes of the human prostate. J Urol. 2001 Dec;166(6):2484-90.

22. Podzuweit T, Nennstiel P, Muller A. Isozyme selective inhibition of cGMP-stimulated cyclic nucleotide phosphodiesterases by erythro-9-(2-hydroxy-3-nonyl) adenine. Cellular signalling. 1995 Sep;7(7):733-8.

23. Boess FG, Hendrix $M$, van der Staay FJ, Erb C, Schreiber R, van Staveren W, et al. Inhibition of phosphodiesterase 2 increases neuronal cGMP, synaptic plasticity and memory performance. Neuropharmacology. 2004 Dec;47(7):1081-92.

24. de Vente J, Markerink-van Ittersum M, Axer H, Steinbusch HW. Nitric-oxide-induced cGMP synthesis in cholinergic neurons in the rat brain. Exp Brain Res. 2001 Feb;136(4):480-91.

25. Rahnama'i MS, van Koeveringe GA, Hohnen R, Ona S, van Kerrebroeck PE, de Wachter SG. Distribution of phosphodiesterase type 5 (PDE5) in the lateral wall of the guinea pig urinary bladder. BJU Int. 2013 Jul;112(2):246-57.

26. van Staveren WC, Steinbusch HW, Markerink-van Ittersum M, Behrends S, de Vente J. Species differences in the localization of cGMP-producing and NO-responsive elements in the mouse and rat hippocampus using cGMP immunocytochemistry. Eur J Neurosci. 2004 Apr;19(8):2155-68.

27. Himms-Hagen J, Cui J, Lynn Sigurdson S. Sympathetic and sensory nerves in control of growth of brown adipose tissue: Effects of denervation and of capsaicin. Neurochemistry international. 1990;17(2):271-9.

28. Kong JH, Adelman JP, Fuchs PA. Expression of the SK2 calcium-activated potassium channel is required for cholinergic function in mouse cochlear hair cells. J Physiol. 2008 Nov 15;586(Pt 22):5471-85.

29. Kuniyoshi K, Ohtori S, Ochiai N, Murata R, Matsudo T, Yamada T, et al. Characteristics of sensory DRG neurons innervating the wrist joint in rats. European journal of pain. $2007 \mathrm{Apr} ; 11$ (3):323-8.

30. Ramos-Vara JA, Miller MA. Immunohistochemical detection of protein gene product 9.5 (PGP 9.5) in canine epitheliotropic T-cell lymphoma (mycosis fungoides). Veterinary pathology. 2007 Jan;44(1):74-9.

31. Sadhu K, Hensley K, Florio VA, Wolda SL. Differential expression of the cyclic GMP-stimulated phosphodiesterase PDE2A in human venous and capillary endothelial cells. The journal of histochemistry and cytochemistry : official journal of the Histochemistry Society. 1999 Jul;47(7):895-906.

32. Rahnama'i MS, van Koeveringe GA, Essers PB, de Wachter SG, de Vente J, van Kerrebroeck PE, et al. Prostaglandin receptor EP1 and EP2 site in guinea pig bladder urothelium and lamina propria. J Urol. 2010 Mar;183(3):1241-7.

33. Lagou M, Drake MJ, Markerink VANIM, J DEV, Gillespie JI. Interstitial cells and phasic activity in the isolated mouse bladder. BJU Int. 2006 Sep;98(3):643-50.

34. Park H, Clark E, Conklin JL. Effects of phosphodiesterase inhibitors on oesophageal neuromuscular functions. Neurogastroenterol Motil. 2003 Dec;15(6):625-33.

35. de Groat WC, Yoshimura N. Afferent nerve regulation of bladder function in health and disease. Handbook of experimental pharmacology. 2009 (194):91-138.

36. Birder LA. Urinary bladder urothelium: molecular sensors of chemical/thermal/mechanical stimuli. Vascul Pharmacol. 2006 Oct;45(4):221-6.

37. Smet PJ, Moore KH, Jonavicius J. Distribution and colocalization of calcitonin gene-related peptide, tachykinins, and vasoactive intestinal peptide in normal and idiopathic unstable human urinary bladder. Lab Invest. $1997 \mathrm{Jul} ; 77(1): 37-49$. 



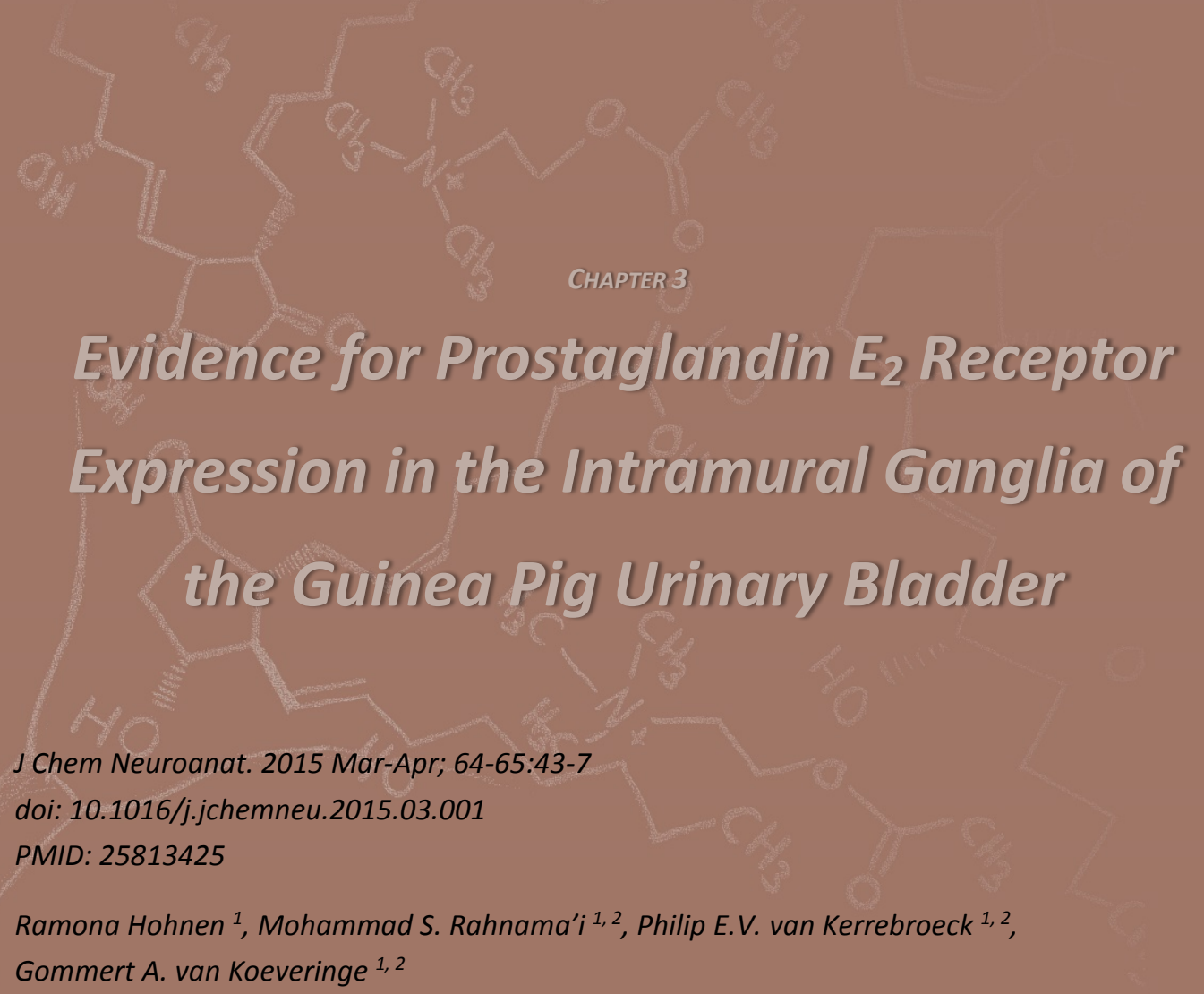

${ }^{1}$ European Graduate School of Neuroscience (EURON), Maastricht University P.O. Box 616, 6200 MD Maastricht, The Netherlands

${ }^{2}$ Maastricht University Medical Centre $\left(\mathrm{MUMC}^{+}\right)$, Urology department, P.O. Box 5800, 6202 AZ Maastricht, The Netherlands 


\section{Abstract}

Intramural ganglia are present in the bladder wall of several species including human, pig, and guinea pig. It has been suggested that there is a network of intramural ganglia in the bladder of these species that may be part of a motor-sensory system and receive afferent input. Prostaglandins (PGs) have been suggested to play a role in this afferent signalling mechanism. To investigate the distribution of the prostaglandin $E_{2}\left(P E_{2}\right)$ receptors EP1 and EP2 in and around intramural ganglia of the guinea pig, bladders of 6 guinea pigs were dissected, and processed for immunohistochemistry. Sections were examined for PGE receptor EP1- and EP2immuno-reactivity and co-stained for vimentin, a marker for interstitial cells (ICS) and cyclooxygenase 1 (COX-1), the enzyme responsible for PG synthesis.

Immunoreactivities for EP1 and EP2 were found in intramural ganglion cells. These cells were observed in between muscle bundles and on, or close to the serosal surface of the bladder. Furthermore, COX-1 was present in interstitial cells close to ganglion cells, indicating the possibility of a local synthesis of PGs near the ganglia. The co-staining of EP1 or EP2 with vimentin showed that processes of interstitial cells run through the ganglia, often encircling or ensheathing cells.

Therefore, it can be concluded that there is a close relationship between the intramural ganglia and the network of interstitial cells in the muscular layers of the bladder. EP1 and EP2 receptors are expressed on the ganglia and this arrangement suggests that intramural ganglia are involved in (pre)processing afferent information. 


\section{Introduction}

Complex neuronal pathways regulate the collection and storage of urine by the bladder and its periodic emptying ${ }^{1}$. The regulation of these pathways is not only of research interest but might also provide a basis for therapeutic intervention in patients with voiding dysfunction ${ }^{2-4}$. The presence of ganglia in the bladder wall has been described for a number of species, including the human, pig, and guinea pig $^{5-7}$. In the human bladder, the ganglia receive multiple synaptic contacts $^{5}$. Their role has been assumed to be the relay of activity in the parasympathetic nerves to the smooth muscle to initiate the micturition contraction ${ }^{8}$. Moreover, it has been suggested that the intramural ganglionic network influences and regulates the motor/sensory system within the bladder wall ${ }^{8}$.

Both the mucosa and muscle layers of the bladder are reported to be capable of synthesizing and releasing prostaglandins (PGs) in response to distension and inflammation ${ }^{9}$. Two enzymes are responsible for this PG production, i.e. cyclooxygenase 1 (COX-1) and COX-2; the former is generally described as a constitutive form ${ }^{10}$. In the guinea pig bladder, the prostaglandin $E_{2}$ $\left(P E_{2}\right)$ receptors EP1 and EP2 have been shown to be expressed in both urothelium ${ }^{11}$ and detrusor layer ${ }^{12,13}$.

Application of exogenous PGs can increase the bladder activity in different species, e.g. human ${ }^{14,15}$, rat ${ }^{16}$, guinea pig $^{17,18}$ and rabbit ${ }^{19}$ suggesting that they might play key roles in both the normal and pathological bladder. In fact, intravesical application of PGs has been explored as a model for the overactive bladder syndrome ${ }^{14,15,20}$.

In mice, PGE2 instillation into the bladder induced bladder overactivity. In EP1 knockout mice, this effect was diminished, suggesting that EP1 activation is mainly responsible for this phenomenon $^{21}$.

However, the exact mechanism of action of PGs is still unclear. PGs might act either directly or indirectly. Direct actions on the bladder might involve PGs being co-released at efferent nerve endings to directly affect the smooth muscle $\mathrm{e}^{10,18}$ or PGs might act presynaptically and indirectly effect the release of an excitatory transmitter ${ }^{8}$.

A major problem in establishing a role for PGs in the bladder is the lack of knowledge about the localisation of the prostaglandin receptors. Here we report details of the EP1 and EP2 receptor localisation in the intramural ganglia of the guinea pig bladder in combination with the localisation of COX-1 as a site of synthesis of PGs. 


\section{Materials and Methods}

Six male guinea pigs ( $n=6$, weight range; $270-300$ g) were killed by cervical dislocation. All procedures were done in agreement with Maastricht University animal ethical committee guidelines. The urinary bladder was removed and placed in Krebs' solution $(121.0 \mathrm{mM} \mathrm{NaCl}$, $1.87 \mathrm{mM} \mathrm{KCl}, 1.2 \mathrm{mM} \mathrm{CaCl}_{2}, 1.15 \mathrm{mM} \mathrm{MgSO}_{4}, 25 \mathrm{mM} \mathrm{NaHCO}_{3}, 1.17 \mathrm{mM} \mathrm{KH}_{2} \mathrm{PO}_{4}, 11.0 \mathrm{mM}$ glucose, $\mathrm{pH}$ 7.4) bubbled with $5 \% \mathrm{CO}_{2}$ and $95 \% \mathrm{O}_{2}$. The lateral wall of each bladder was dissected into sections (approximately $20 \mathrm{~mm}^{2}$ ) and maintained in Krebs' solution. Afterwards, bladder pieces were immersed in ice-cold fixative solution of $4 \%$ freshly prepared depolymerised paraformaldehyde in $0.1 \mathrm{M}$ phosphate buffer $(\mathrm{pH} 7,4)$ for 2 hours at $4^{\circ} \mathrm{C}$. The tissues were then put in $10 \%$ sucrose overnight and subsequently for about 8 hours in $20 \%$ and $30 \%$ sucrose respectively. Tissue pieces were then placed in Tissue-Tek ${ }^{\circledR}$ O.C.T. $\underline{\text { TM }}$ compound to $^{\circ}$ form a single block and snap frozen in isopentane which was cooled in liquid nitrogen. Cryostat sections $(10 \mu \mathrm{m})$ were cut, such that each section was perpendicular to the urothelial surface, and then thawed onto chrome alum-gelatin coated slides, followed by processing for immunohistochemistry.

Sections were dried for 20 minutes at room temperature followed by three washes with TRISbuffered saline (TBS; pH 7.6) and incubated for two nights with the primary antibodies at $4^{\circ} \mathrm{C}$. To visualise EP1 and EP2, we used rabbit antibodies raised against EP1 and EP2 (dilution 1:100, Cayman Chemicals). Sections were co-stained with antibodies against COX-1, which is responsible for prostaglandin synthesis (diluted 1:2000, Santa Cruz Biotech), and the interstitial cell marker vimentin (diluted 1:5000, Sigma-Aldrich). All primary antibodies were diluted in TBS containing $0.3 \%(\mathrm{v} / \mathrm{v})$ Triton $\mathrm{X}-100(\mathrm{TBS}-\mathrm{T})$. After incubation with the primary antibodies, sections were washed in TBS-T, TBS and TBS-T; each wash step lasted 20 minutes. Rabbit primary antibodies were visualised by using Alexa Fluor 488 donkey anti-rabbit IgG $(\mathrm{H}+\mathrm{L})$ conjugate (Molecular Probes), diluted 1:100 in TBS-T. Vimentin and COX-1 primary antibodies were visualised with Alexa Fluor 594 donkey anti-mouse IgG conjugate (Molecular Probes), diluted 1:100 and donkey anti-goat IgG conjugate (Molecular Probes), diluted 1:100, respectively. Sections were incubated with the secondary antibodies for 1 hour at room temperature in the dark. After being washed with TBS-T and TBS, sections were mounted with TBS-glycerol.

The specificity of the EP1 and EP2 antibodies has been explored in our previous paper by omission of the primary antibody, immunostaining after pre-incubation with the EP1- and EP2specific blocking peptide and Western blotting of both EP1 and EP2 on a guinea pig bladder material ${ }^{11}$. 
Confocal images were taken using a Bio-Rad MRC600 (Bio-Rad Laboratories Ltd, Hemel Hempstead, UK) equipped with an air-cooled Argon-Krypton mixed gas laser and mounted onto an Axiophote microscope (Zeiss), using oil-immersion objectives (40x, NA=3D1.3 or 63x, $N A=3 D 1.4)$. The laser-scanning microscope was used in the dual parameter set-up, according to the manufacturer's specifications, using dual wavelength excitation at 488 and $568 \mathrm{~nm}$. Emission spectra were separated by the standard sets of dichroic mirrors and barrier filters. Optical sections were recorded in the Kalman filtering mode using 5 scans for each picture. Z-Series were generated by collecting a stack consisting of optical sections using a step size of 0.18 or $0.36 \mu \mathrm{m}$ in the z-direction. The images were arranged using the Image J program.

\section{Results}

To investigate the distribution of the prostaglandin receptors EP1 and EP2 in and around clusters of intramural ganglion cells (ganglia) of the guinea pig, guinea pig urinary bladder sections were stained for the two PGE 2 -specific receptors EP1 and EP2 as well as the interstitial cell marker vimentin and the PGE 2 -producing enzyme COX-1. All the observations presented in our study were consistent in all 6 animals studied. Ganglia are known to be found in the lamina propria, throughout the muscle layers and on the outer (serosal) surface ${ }^{8}$.

In general, both EP1 and EP2 were expressed by intramural ganglia of the guinea pig urinary bladder. Most ganglia were located in the outer muscle. An overview of ganglia staining positive for EP1 is presented in Figure 1. It can be noted that the nuclei are shown in all images as dark spots, meaning that EP1-immunoreactivity was not present in the nuclei and only in the cytoplasma of intramural ganglia. Furthermore, EP1 positive ganglia were surrounded by vimentin-positive interstitial cells (Figures $1 \mathrm{C}$ and $\mathrm{E}$ ). A double staining with the COX-1 enzyme showed the close vicinity of the possible production site of PGs that may target the EP1 receptor on this ganglion (Figures $1 \mathrm{~B}$ and $\mathrm{D}$ ).

Moreover, EP2 receptor immunoreactivity was found present within intramural ganglia. Similar to the EP1 receptor, immunoreactivity for the EP2 receptor seemed to be present only in the cytoplasm and cell membrane of ganglionic cells (Figure 2). Again, nuclei were clearly visible as dark spots (Figures $2 \mathrm{C}$ and $\mathrm{E}$ ). The vimentin-positive interstitial cells surround those intramural ganglia (Figures $2 \mathrm{C}$ and $\mathrm{D}$ ) and COX-1-positive cells were located in close proximity to EP2positive intramural ganglia (Figure 2E).

Thus, immunoreactivity for both EP1 and EP2 were found in the cytoplasm of intramural ganglia and closely surrounded by interstitial cells and PG-producing COX-1-positive cells. 

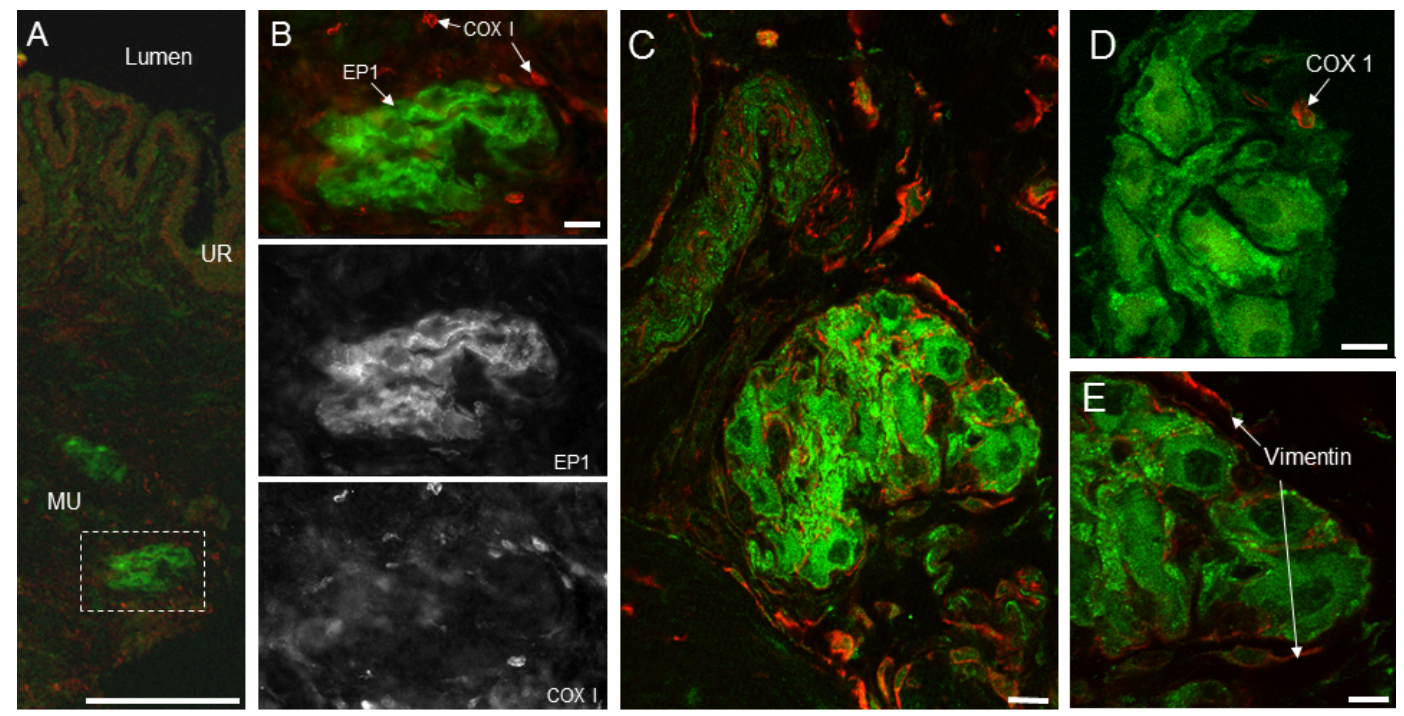

Figure 1. Immunostainings of EP1 (green) vimentin (red) and COX-1 (red) in the lateral wall of the guinea pig bladder. Panel A shows a cross-section of the bladder wall, containing urothelium (UR), suburothelium and muscle layer (MU) at low magnification (10x). A large intramural ganglion on the edge of the outer muscle layer is present in the boxed-in area. The boxed-in area is shown in panel B at a 40x magnification. An intramural ganglion stained for EP1 (green) and vimentin (red) is depicted in panel C. Panel D shows a ganglion in a different guinea pig bladder stained for EP1 (green) and COX-1 (red). In panel E, a magnification of an EP1-positive (green) ganglion cell in a third guinea pig bladder surrounded by vimentin fibres (red) is shown. Calibration bars: $200 \mu \mathrm{m}$ in panel $A$ and $10 \mu \mathrm{m}$ in panels B-E.

\section{Discussion}

Peripheral ganglia are found within the walls of many visceral organs where they make interconnections with adjacent ganglia forming local neural networks ${ }^{22}$. The function of these local networks has been found to depend on the organ.

For example in the gut, the ganglia play a role in the generation and coordination of peristaltic activity and secretion ${ }^{23}$, whereas in the choroid of the eye, they influence blood flow and contraction in the smooth muscle ${ }^{24-26}$. Such peripheral neural networks also receive input from collaterals of extrinsic primary sensory fibres. A similar arrangement has been reported within the cardiac ganglia ${ }^{27,28}$ and the ganglia in the oesophageal sphincter ${ }^{29}$. This arrangement of integrating sensory information and output to muscle by the neural network has been demonstrated to generate local reflexes within the tissues. 
The bladder has a similar micro-anatomical arrangement as the above named examples of organs in which ganglia have a role in the regulation of their physiological activity.
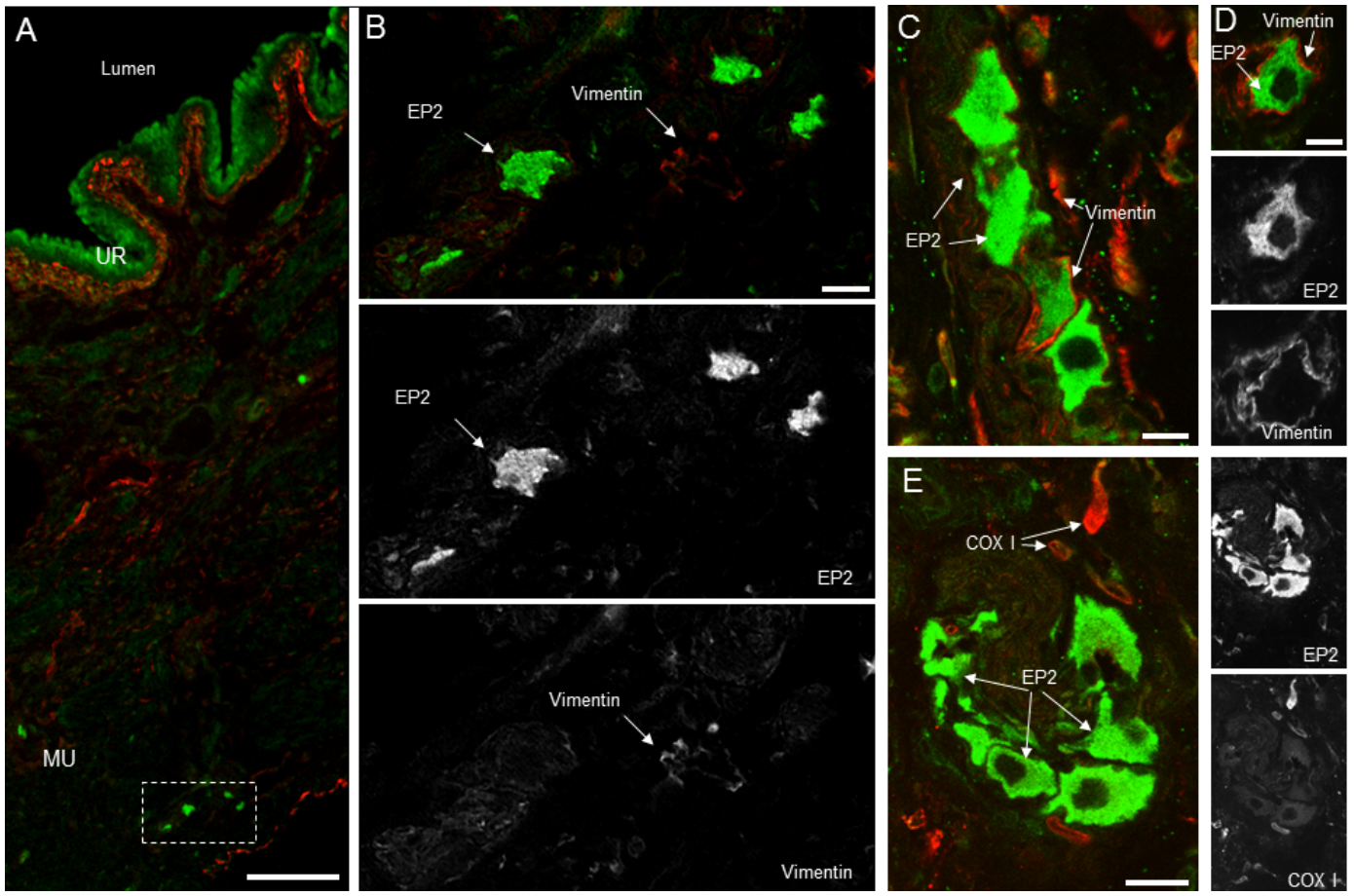

Figure 2. Immunostainings of EP2 (green), vimentin (red) and COX-1 (red) in the lateral wall of the guinea pig bladder. In panel $A$, a cross-section of the bladder wall containing urothelium (UR), suburothelium and muscle layer (MU) at low magnification (10x) is shown. Intramural ganglion cells are noted in the boxed-in area. A 20x magnification of the boxed-in area is shown in panel A with EP2 in green and vimentin in red. In panels $C$ and $D$, two intramural ganglia of two different guinea pig bladders are depicted. EP2 is marked with green and vimentin with red. A large EP2-positive intramural ganglion surrounded by a few COX-1-positive interstitial cells is shown in panel E. Calibration bars: $200 \mu \mathrm{m}$ in panel A and $10 \mu \mathrm{m}$ in panels $B-E$.

It can be hypothesised that the ganglia in the bladder wall have a role in the regulation of the physiological function of the urinary bladder, which is the storage and the periodic voiding of urine.

In humans, voiding must take place at a socially appropriate moment. In animals, the voluntary voiding is important in territorial marking. The regulation of this bladder function and the sensory awareness of the bladder filling along with the ability to postpone voiding to a more 
socially appropriate time, as well as the contraction of the bladder wall during voiding, need a complex regulatory mechanism.

Our observations described in this paper, reveal the complexities in the structure of the intramural ganglia of the lateral wall of the urinary bladder. Combining available data from previous studies $8,10,18,30,31$ and data described in this paper, we can conclude that fibres with processes originating near the urothelium (vimentin-positive interstitial cells as shown in Figures $1 C$ and $E$ and $2 A-D)$, send collateral axons to the intramural ganglia (sensory input). Furthermore, it has been suggested that the intramural ganglia are interconnected ${ }^{8}$ and that they might be influenced by messenger molecules, such as prostaglandins (signalling molecules modulating the ganglia). Outputs from the ganglia are most likely to target the detrusor (motor output).

Two different regulatory systems are present within the bladder wall. Firstly, the cholinergic neuronal system and secondly, the complex network of suburothelial and intramural interstitial cells, which can pick up sensory signals carried by messenger molecules such as adenosine triphosphate (ATP), cyclic guanosine monophosphate (cGMP), and prostaglandins. These two systems appear to be interconnected through ganglia, which receive information from both systems. In this way, sensory information is processed and regulated within the bladder wall. Motor activity such as the autonomic micro contractions ${ }^{10}$ can very well be regulated and modified by this system. This local regulation of sensory/motor activity by ganglia, could function without information being received or sent by the central nervous system. In other words, this mechanism appears to function at an unconscious level and only relay the information to the central nervous system when necessary, for example at a certain bladder filling or simply when we want to.

Data from previous studies support the assumption that ganglia form the interconnection between a molecular sensory system arranged by interstitial cells to a cholinergic neuronal system $^{8,32}$. As the inhibition of phasic activity in the isolated bladder is most pronounced when the bladder is rapidly emptied, the physiological stimulus for these fibres might not be a stretch of the bladder wall but the deformation resulting from emptying ${ }^{8}$. It is not known how this information is transformed to the nerves. However, we do know that the urothelium can produce and release various substances, e.g. ATP, nitric oxide (NO) $)^{33-36}$ and prostaglandins ${ }^{18}$. These substances have been shown to influence the afferent nerves ${ }^{33-36}$. Any of these agents, released during rapid emptying, could activate the interstitial cells and through ganglia and sensory fibres result in inhibition. In this way, chemical stimulation of afferents by substances released from the urothelium can influence local motor activity with or without information 
being processed to the central nervous system, depending on the complex processing of the ganglia within the bladder wall.

Although our study is a morphological study and all functional conclusions are hypothetical and need to be examined in further research, clinical implication of these findings can be important in the treatment of functional bladder disorders, such as the overactive bladder syndrome $(\mathrm{OAB})$. PGE2 instillation into the bladder induced overactivity in mice, which was (partly) due to EP1 activation ${ }^{21}$. From this, one could conclude that EP1 might play a role in the development of $\mathrm{OAB}$ and that this involvement could be via activation of ganglia. 


\section{References}

1. de Groat WC. Integrative control of the lower urinary tract: preclinical perspective. Br J Pharmacol. 2006 Feb;147 Suppl 2:S25-40.

2. Liu HT, Chancellor MB, Kuo HC. Urinary nerve growth factor level could be a biomarker in the differential diagnosis of mixed urinary incontinence in women. BJU Int. 2008 Nov;102(10):1440-4.

3. Liu HT, Kuo HC. Urinary nerve growth factor levels are elevated in patients with overactive bladder and do not significantly increase with bladder distention. Neurourol Urodyn. 2009;28(1):78-81.

4. Drake MJ. Emerging drugs for treatment of overactive bladder and detrusor overactivity. Expert Opin Emerg Drugs. 2008 Sep;13(3):431-46.

5. Gilpin CJ, Dixon JS, Gilpin SA, Gosling JA. The fine structure of autonomic neurons in the wall of the human urinary bladder. J Anat. 1983 Dec;137 ( Pt 4):705-13.

6. Dixon JS, Gilpin SA, Gilpin CJ, Gosling JA. Intramural ganglia of the human urinary bladder. Br J Urol. 1983 Apr;55(2):195-8.

7. Pirker ME, Montedonico S, Rolle U, Austvoll H, Puri P. Regional differences in nitrergic neuronal density in the developing porcine urinary bladder. Pediatr Surg Int. 2005 Mar;21(3):161-8.

8. Gillespie JI, Markerink-van Ittersum M, de Vente J. Sensory collaterals, intramural ganglia and motor nerves in the guinea-pig bladder: evidence for intramural neural circuits. Cell Tissue Res. 2006 Jul;325(1):33-45.

9. Saban R, Undem BJ, Keith IM, Saban MR, Tengowski MW, Graziano FM, et al. Differential release of prostaglandins and leukotrienes by sensitized guinea pig urinary bladder layers upon antigen challenge. J Urol. 1994 Aug;152(2 Pt 1):544-9.

10. de Jongh R, Grol S, van Koeveringe G, van Kerrebroeck P, de Vente J, Gillespie J. The localisation of cyclooxygenase immuno-reactivity (COX I-IR) to the urothelium and to interstitial cells in the bladder wall. Journal of cellular and molecular medicine. 2008 Aug 21.

11. Rahnama'i MS, van Koeveringe GA, Essers PB, de Wachter SG, de Vente J, van Kerrebroeck PE, et al. Prostaglandin receptor EP1 and EP2 site in guinea pig bladder urothelium and lamina propria. J Urol. 2010 Mar;183(3):1241-7.

12. Rahnama'i MS, Biallosterski BT, de Wachter SG, Van Kerrebroeck PE, van Koeveringe GA. The distribution of the prostaglandin E receptor type 2 (EP2) in the detrusor of the guinea pig. Prostaglandins Other Lipid Mediat. 2012 Dec;99(3-4):107-15.

13. Rahnama'i MS, de Wachter SG, van Koeveringe GA, van Kerrebroeck PE, de Vente J, Gillespie JI. The relationship between prostaglandin E receptor 1 and cyclooxygenase I expression in guinea pig bladder interstitial cells: proposition of a signal propagation system. J Urol. 2011 Jan;185(1):315-22.

14. Kim JC, Park EY, Hong SH, Seo SI, Park YH, Hwang TK. Changes of urinary nerve growth factor and prostaglandins in male patients with overactive bladder symptom. Int J Urol. 2005 Oct;12(10):875-80.

15. Kim JC, Park EY, Seo SI, Park YH, Hwang TK. Nerve growth factor and prostaglandins in the urine of female patients with overactive bladder. J Urol. 2006 May;175(5):1773-6; discussion 6.

16. Ishizuka O, Mattiasson A, Andersson KE. Prostaglandin E2-induced bladder hyperactivity in normal, conscious rats: involvement of tachykinins? J Urol. 1995 Jun;153(6):2034-8.

17. Rahnama'i MS, van Koeveringe GA, van Kerrebroeck PE, de Wachter SG. The effect of indomethacin on the muscarinic induced contractions in the isolated normal guinea pig urinary bladder. BMC urology. 2013;13:8.

18. de Jongh $\mathrm{R}$, van Koeveringe GA, van Kerrebroeck PE, Markerink-van Ittersum M, de Vente J, Gillespie JI. The effects of exogenous prostaglandins and the identification of constitutive cyclooxygenase I and II immunoreactivity in the normal guinea pig bladder. BJU Int. 2007 Aug;100(2):419-29.

19. Masick JM, Levin RM, Hass MA. The effect of partial outlet obstruction on prostaglandin generation in the rabbit urinary bladder. Prostaglandins Other Lipid Mediat. 2001 Oct;66(3):211-9.

20. Steers WD. Pathophysiology of overactive bladder and urge urinary incontinence. Rev Urol. 2002;4 Suppl 4:S7-S18.

21. Schroder A, Newgreen D, Andersson KE. Detrusor responses to prostaglandin E2 and bladder outlet obstruction in wild-type and Ep1 receptor knockout mice. J Urol. 2004 Sep;172(3):1166-70. 
22. Leranth C, Ungvary G. Axon types of prevertebral ganglia and the peripheral autonomic reflex arc. J Auton Nerv Syst. 1980 Mar;1(3):265-81.

23. Furness JB, Robbins HL, Xiao J, Stebbing MJ, Nurgali K. Projections and chemistry of Dogiel type II neurons in the mouse colon. Cell Tissue Res. 2004 Jul;317(1):1-12.

24. Schrodl F, Schweigert M, Brehmer A, Neuhuber WL. Intrinsic neurons in the duck choroid are contacted by CGRP-immunoreactive nerve fibres: evidence for a local pre-central reflex arc in the eye. Exp Eye Res. 2001 Feb;72(2):137-46.

25. Schrodl F, Tines R, Brehmer A, Neuhuber WL. Intrinsic choroidal neurons in the duck eye receive sympathetic input: anatomical evidence for adrenergic modulation of nitrergic functions in the choroid. Cell Tissue Res. 2001 May;304(2):175-84.

26. Schrodl F, De Laet A, Tassignon MJ, Van Bogaert PP, Brehmer A, Neuhuber WL, et al. Intrinsic choroidal neurons in the human eye: projections, targets, and basic electrophysiological data. Invest Ophthalmol Vis Sci. 2003 Sep;44(9):3705-12.

27. Hardwick JC, Mawe GM, Parsons RL. Evidence for afferent fiber innervation of parasympathetic neurons of the guinea-pig cardiac ganglion. J Auton Nerv Syst. 1995 Jun 25;53(2-3):166-74.

28. Gibbins IL, Teo EH, Jobling P, Morris JL. Synaptic density, convergence, and dendritic complexity of prevertebral sympathetic neurons. J Comp Neurol. 2003 Jan 13;455(3):285-98.

29. Mazzia C, Clerc N. Ultrastructural relationships of spinal primary afferent fibres with neuronal and nonneuronal cells in the myenteric plexus of the cat oesophago-gastric junction. Neuroscience. 1997 Oct;80(3):925-37.

30. Gillespie JI, Harvey IJ, Drake MJ. Agonist- and nerve-induced phasic activity in the isolated whole bladder of the guinea pig: evidence for two types of bladder activity. Exp Physiol. 2003 May;88(3):343-57.

31. Gillespie JI, Markerink-van Ittersum M, de Vente J. Expression of neuronal nitric oxide synthase (nNOS) and nitric-oxide-induced changes in cGMP in the urothelial layer of the guinea pig bladder. Cell Tissue Res. 2005 Sep;321(3):341-51.

32. Drake MJ, Mills IW, Gillespie JI. Model of peripheral autonomous modules and a myovesical plexus in normal and overactive bladder function. Lancet. 2001 Aug 4;358(9279):401-3.

33. Birder LA, Apodaca G, De Groat WC, Kanai AJ. Adrenergic- and capsaicin-evoked nitric oxide release from urothelium and afferent nerves in urinary bladder. Am J Physiol. 1998 Aug;275(2 Pt 2):F226-9.

34. Birder LA. Involvement of the urinary bladder urothelium in signaling in the lower urinary tract. Proc West Pharmacol Soc. 2001;44:85-6.

35. Birder LA, Nealen ML, Kiss S, de Groat WC, Caterina MJ, Wang E, et al. Beta-adrenoceptor agonists stimulate endothelial nitric oxide synthase in rat urinary bladder urothelial cells. J Neurosci. 2002 Sep 15;22(18):806370.

36. Ferguson DR, Kennedy I, Burton TJ. ATP is released from rabbit urinary bladder epithelial cells by hydrostatic pressure changes--a possible sensory mechanism? J Physiol. 1997 Dec 1;505 ( Pt 2):503-11. 



\section{CHAPTER 4}

\section{Ex Vivo Modulation of Muscarinically}

\section{Induced Contractions by PGE2 and an EP1}

Receptor Antragonist in the Guinea Pig

\section{Urinary Bladder}

Ramona Hohnen ${ }^{1}$, Mohammad S. Rahnama'i ${ }^{1,2}$, Matthijs van Gink ${ }^{1,2}$, Celine Meriaux ${ }^{1}$, Gommert A. Van Koeveringe ${ }^{1,2}$

${ }^{1}$ European Graduate School of Neuroscience (EURON), Maastricht University P.O. Box 616, 6200 MD Maastricht, The Netherlands

${ }^{2}$ Maastricht University Medical Centre $\left(\mathrm{MUMC}^{+}\right)$, Urology department, P.O. Box 5800, 6202 AZ Maastricht, The Netherlands 


\section{Abstract}

Mechanical and physical stimuli can evoke release of several substances by the urothelium, for example, prostaglandin $\mathrm{E} 2\left(\mathrm{PGE}_{2}\right)$, nitric oxide, acetylcholine and adenosine triphosphate. It has been shown, that $\mathrm{PGE}_{2}$ and acetylcholine seem to act in a positive feedback on molecular level. Therefore, the aim of our study was to investigate the role of $\mathrm{PGE}_{2}$ and one of its receptors, EP1, on muscarinic induced contractions.

The urethra and bladder of 24 guinea pigs were dissected after sacrifice of the animal. The bladder was catheterised transurethrally and placed into a preheated organ bath filled with Krebs buffer. The bladders were repeatedly stimulated with arecaidine alone or in combination with a) acetylsalicylic acid, b) PGE 2 or c) the EP1 antagonist ONO-8713. Intravesical pressure was measured and amplitude and frequency of the arecaidine induced response were analysed.

Adding $\mathrm{PGE}_{2}$ before muscarinic stimulations induced an amplifying effect on muscarinically induced contractions and inhibition of the $\mathrm{PGE}_{2}$ producing enzymes prior to an arecaidine stimulation decreased the amplitude during the initial phase of the response. Inhibition of EP1 resulted in a decreased frequency during the second phase of the arecaidine response.

In summary, this study provides evidence that the cholinergic and prostanoid systems in the urinary bladder act in a positive feedback loop and that the EP1 receptor plays a subtle role in this process. 


\section{Introduction}

Therapeutic options for patients suffering from the overactive bladder syndrome (OAB) are limited and often unsatisfactory. Therefore, new targets have to be identified, which might offer new therapeutic modalities. One of these potential targets could be the prostanoid system.

Urine levels of Prostaglandin E2 ( $\left.\mathrm{PGE}_{2}\right)$ are increased in patients suffering from the overactive bladder syndrome ${ }^{1,2}$. PGE 2 exerts its effect by binding one of four E prostanoid (EP) receptors, EP1-4. Morphological studies have shown that the EP1 and EP2 receptors are expressed in the urinary bladder throughout different tissue layers ${ }^{3,4}$. Administration of PGE 2 directly into the human urinary bladder causes strong sensations of urgency ${ }^{5}$. In animals, intravesical administration of $\mathrm{PGE}_{2}$ has been shown to provoke detrusor overactivity. It has been hypothesised that this is caused by activation of sensory bladder afferent neurons ${ }^{6-9}$. In addition, inhibition of EP1 and EP2 reduced the effect of PGE 2 dose-dependently in isolated guinea pig bladders ${ }^{10}$. In vivo studies in mice have shown that intravesical administration of $\mathrm{PGE}_{2}$ itself or an EP1 agonist reduced significantly the inter-micturition interval ${ }^{11}$. Inhibition of the $\mathrm{PGE}_{2}$ producing cyclooxygenase (COX) family inhibited the micturition reflex in rats with bladder overactivity which was less distinctive in control rats ${ }^{12}$.

At a molecular level, $\mathrm{PGE}_{2}$ has been shown to induce the release of acetylcholine (ACh) ${ }^{13}$. On the other hand, stimulation with the muscarinic agonist arecaidine evoked $\mathrm{PGE}_{2}$ release ${ }^{13}$. Another study showed that administration of the non-selective COX inhibitor indomethacin to a whole bladder preparation reduced contractions evoked by the muscarinic agonist arecaidine ex vivo ${ }^{14}$. Hence, it can be hypothesised that $\mathrm{PGE}_{2}$ exerts its effect on bladder activity by modulation of muscarinically induced contractions.

Acetylcholine is the primary neurotransmitter in the excitation-contraction coupling of the human detrusor muscle. Antimuscarinic drugs used in OAB treatment, inhibit the ACh binding on muscarinic receptors within the urinary bladder. The receptor subtypes $M 2$ and $M 3$ are expressed on detrusor smooth muscle cells, basal urothelial cells and suburothelial interstitial cells ${ }^{15-17}$. The high prevalence of side effects of antimuscarinics might be circumvented, if drugs are selected to not target the muscarinic system itself, but systems which modulate muscarinic induced contractions, such as the progstaglandin system. We hypothesise, that the prostaglandin system modulates muscarinic induced contractions ex vivo, and that the EP1 receptor plays an important role herein. To investigate this, the effect of manipulations in the prostaglandin system on muscarinic induced contractions has been explored in this study. 


\section{Methods}

\section{Animals}

A total number of 24 male guinea pigs were sacrificed by a percussive blow to the head, followed by exsanguination. All procedures were carried out with the approval of guidelines of the animal ethics committee of Maastricht University and were in line with European Community guidelines.

\section{Pressure recordings}

The urinary bladder and proximal urethra were excised immediately after sacrificing the animal and placed in Krebs solution (mM: $\mathrm{NaCl} 121.1 ; \mathrm{KCl} 1.87 ; \mathrm{CaCl}_{2} 1.2 ; \mathrm{MgSO}_{4} 1.15 ; \mathrm{NaHCO}_{3} 25$; $\mathrm{KH}_{2} \mathrm{PO}_{4}$ 1.17; glucose 11.0), aerated with $5 \% \mathrm{CO}_{2}$ and $95 \% \mathrm{O}_{2}\left(\mathrm{pH} 7.4,37^{\circ} \mathrm{C}\right)$. The bladder was emptied manually and the urethra was catheterised with a catheter made from PE-50 tubing with a small cuff at the end and fixed with a fine ligature. The bladder was then transferred to a heated organ bath $\left(40 \mathrm{~mL}, 33-36^{\circ} \mathrm{C}\right)$ containing constantly aerated Krebs solution, and the catheter was connected through a fluid filled tube containing a three-way connector to a IBP pressure transducer with a pvb connector (Codan, Germany). The transducer output was amplified, digitised at $1000 \mathrm{~Hz}$ and recorded using a data capture system (MP150 with AcqKnowledge 4.2 software, BIOPAC systems Inc, California). The transducer was calibrated before each experiment. Recordings started 30 minutes after the animal was sacrificed. The pressure recordings started with an incubation period of 30 minutes. Subsequently, the bladder was filled to $1.5 \mathrm{ml}$ in 1 hour and allowed to rest for another 60 minutes, followed by two washings steps, each lasting 15 minutes. During the washing steps, the Krebs solution in the organ bath was completely renewed. The bladder was stimulated for 30 minutes with the muscarinic agonist arecaidine but-2-ynyl ester tosylate (300nM, Tocris, Avonmouth, UK). After two more washing steps, each lasting 15 minutes, this stimulation type was repeated in order to create a stable muscarinic response. From here on, protocols differed dependent on the experimental group. An overview of all protocols starting at the second arecaidine stimulation is given in figure 1. 

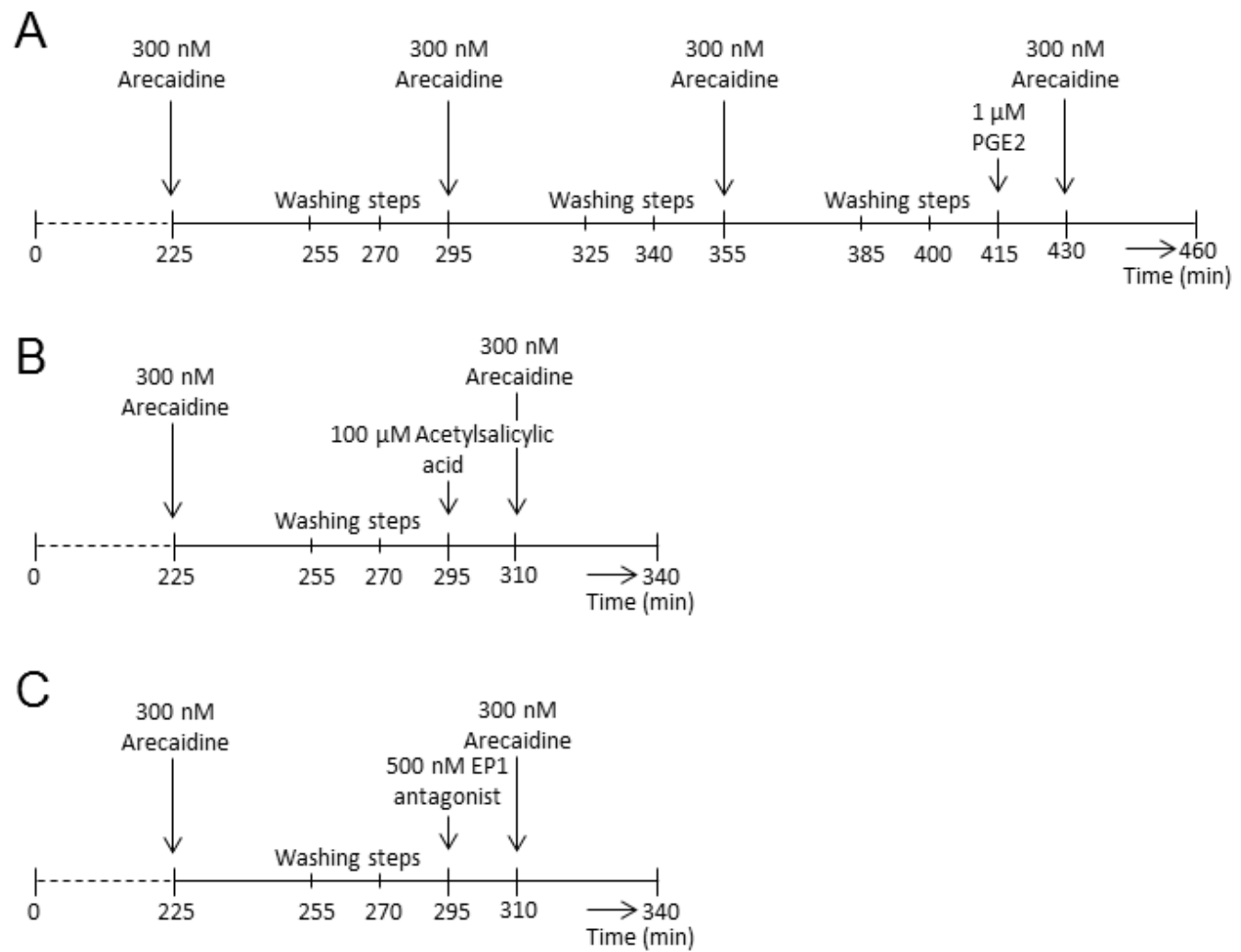

Figure 1. Overview of experimental groups and their protocols. Panel A shows the protocol used for bladders of the control group. After 3 stable and comparable arecaidine stimulations, each separated by two washing steps, PGE2 was added prior to a last arecaidine stimulation. In B, the protocol for the COXinhibition group is shown. After a stable arecaidine response, two washing steps were performed. Subsequently, PGE2 production was inhibitied by acetylsalicylic acid, followed by another arecaidine stimulation. The protocol for EP1 inhibition is show visualised in panel C. Again, a standardised, comparable arecaidine response was generated. After two washing steps, bladders were incubated with an EP1 antagonist prior to a last arecaidine response. $T=0$ on the time axis refers to the start of recording (approximately 30 minutes after sacrifice of the guinea pig).

\section{Experimental groups}

In this study, three experimental groups were designed. To verify that subsequent arecaidine stimulations were comparable to each other, a control group $(n=8)$ was introduced. Bladders of the control group underwent, after the initial arecaidine response mentioned above, three consecutive stimulations with $300 \mathrm{nM}$, each followed by two washing steps. After three comparable, consecutive arecaidine stimulations, bladders were washed again by two washing 
steps and incubated for 15 minutes with $1 \mu \mathrm{M}$ PGE 2 (Sigma Aldrich, Missouri, USA), followed by a last stimulation with $300 \mathrm{nM}$ arecaidine.

In a second experimental group $(n=8)$, the effect of inhibition of PGE2 production by the COXinhibitor acetylsalicylic acid was investigated. After a first comparable arecaidine response, bladders were washed during two washing steps and incubated for 15 minutes with $100 \mu \mathrm{M}$ acetylsalicylic acid. To investigate if $\mathrm{PGE}_{2}$ exerts its effect on muscarinic induced contractions by the EP1 receptor, a third experimental group was designed $(n=8)$. In this group, bladders were incubated with $500 \mathrm{nM}$ of the EP1 antagonist after the first comparable arecaidine stimulation and subsequent washing steps. After 15 minutes of incubation, bladders were stimulated again with the muscarinic agonist arecaidine.

\section{Drugs}

Concentrated drug solutions were added directly to the organ bath to achieve the required final dilution. All drugs were added to the solution bathing the serosal surface. $1 \mu \mathrm{M}$ of $\mathrm{PGE}_{2}$ (Sigma Aldrich, Missouri, USA) was used to stimulate the bladders with exogenous $\mathrm{PGE}_{2}$. The PGE 2 producing enzymes were inhibited by the general COX-inhibitor acetylsalicylic acid, used in a concentration of $100 \mu \mathrm{M}$ (Sigma Aldrich, Missouri, USA). Acetylsalicylic acid was used as it blocks both PGE2 producing enzymes, COX-1 and COX-2. Furthermore, effects on other regulators are not known. The EP1 antagonist ONO-8713 (ONO pharmaceutical, Osaka, Japan) was used in a concentration of $500 \mathrm{nM}$. As muscarinic agonist, $300 \mathrm{nM}$ of arecaidine but-2-ynyl ester tosylate (Tocris, Avonmouth, UK) was used. For all drugs, optimal concetrations were determinded by dose-response curves.

\section{Data processing and statistical analysis}

All data were processed in a maximised objective way, using MATLAB scripts to detect peaks

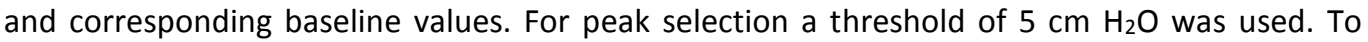
determine the moment of transition between the two phases, a strong low pass filter was deployed. This resulted in a simplified curve, starting with an ascending slope, which continues into a descending slope, shown in figure 2. This part reflects the irregular rise in pressure during the first phase of an arecaidine response and is followed by an irregular sinus curve, reflecting the second phase. The first minimum of this curve was determined as the moment of transition towards the second phase of an arecaidine induced response (figure 2). 
To analyse the effect of the drugs used to modify muscarinic induced contractions, the first comparable muscarinic response was used as reference and compared with subsequent responses after drug incubation. The effect was analysed using the Kruskal-Wallis test and Wilcoxon matched pairs test.

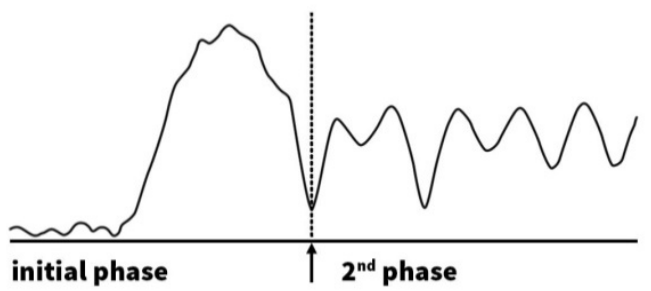

Figure 2: Separation of initial and second phases of arecaidine induced responses. The point of transition between the two phases was determined by deployment of a strong low pass filter. The simplified curve, resulting from the filtering process is shown in this figure. Afterwards, the first minimum after the strong rise was chosen as the point of transition from the initial phase towards the second phase.

\section{Results}

To ensure that consecutive arecaidine stimulations were comparable to each other, a control group was included. In this control group, bladders were subjected to four consecutive arecaidine stimulations. The first stimulation was used to standardise all bladders and therefore not taken into consideration during the analysis.

In general, the arecaidine response was divided into two phases. The initial phase was characterised by an irregular rise in pressure, low/mediate amplitude and high frequency contractions, and lasted for approximately 2-5 minutes. Afterwards, contraction trains with regular intervals developed. These phasic contractions were characterised by a higher amplitude and a lower frequency compared to the contractions of the initial phase (figure 3A). Due to distinct characteristic differences between these two phases, all responses were analysed for frequency and amplitude of both the first and the second phases. In addition, the length of the initial phase has been registered. In the control group, no significant differences were measured in between the consecutive arecaidine stimulations $\left(2^{\text {nd }}, 3^{\text {rd }}\right.$ and $4^{\text {th }}$ stimulations) for all parameters mentioned above (figures 3B-F). 
A

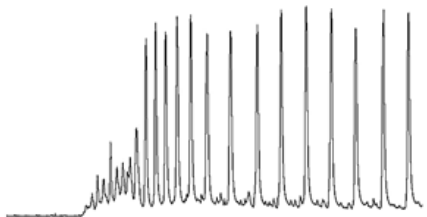

Initial phase $12^{\text {nd }}$ phase

$\mathrm{B}$

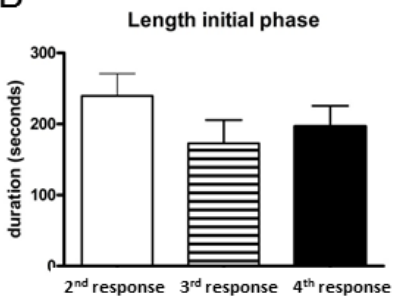

C

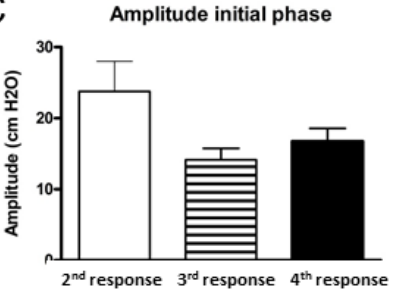

D

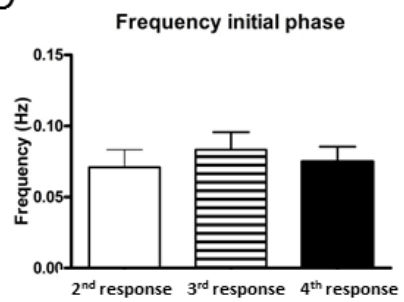

$E$

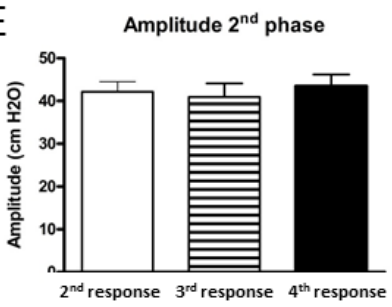

$\mathrm{F}$

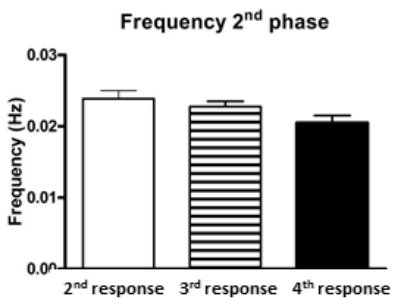

Figure 3. Characteristics and verification of muscarinic responses. In panel $A$, a typical example of an arecaidine response is shown. It could be divided into two phases. The initial phase was characterised by an irregular rise in pressure, low/mediate amplitude and high frequency contractions, and lasted for approximately 2-5 minutes. Afterwards, regular contractions developed. These phasic contractions were characterised by a higher amplitude and lower frequency compared to the contractions of the initial phase. Panel C-F show three consecutive arecaidine stimulations $\left(2^{\text {nd }}-4^{\text {th }}\right.$ stimulation $)$. All stimulations were separated from each other by two washing steps. In none of the analysed parameters significant changes could be detected between the consecutive stimulations. For each analysed parameter, a different graph is shown.

Subjectively, two different patterns in the arecaidine response were recognised after $\mathrm{PGE}_{2}$ stimulation. Some bladders showed an initial tonic increase in pressure followed by the low frequency phasic contractions, whereas others started with high frequency phasic contractions followed by similar low frequency contractions. Figures 4 B-E show typical examples of these two patterns. The two patterns were distributed more or less equally among the tested bladders. However, these differences in muscarinic responses were not detectable by the automated analysis. None of the analysed parameters showed significant changes. A general overview of a tracing with both arecaidine responses (before and after $\mathrm{PGE}_{2}$ administration) is presented in figure $4 \mathrm{~A}$. 
A

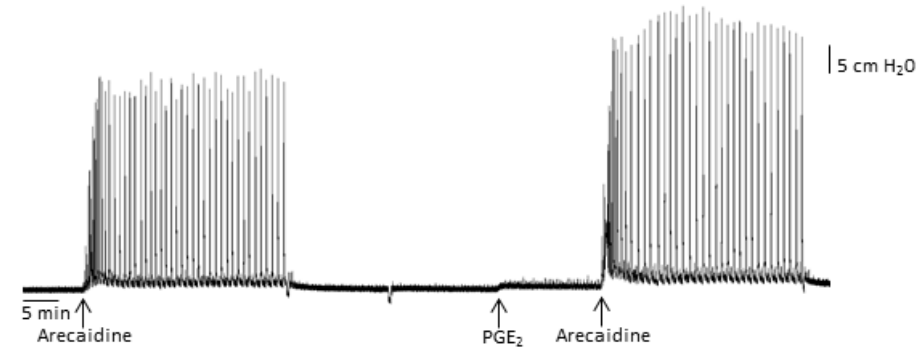

B

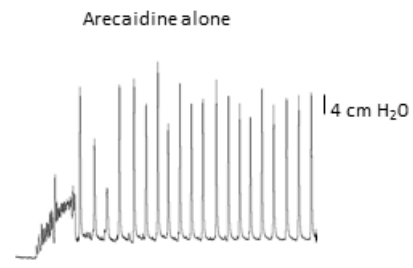

D PGE2 and arecaidine

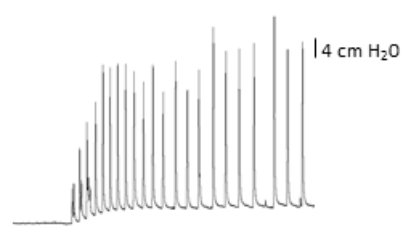

$\mathrm{F}$

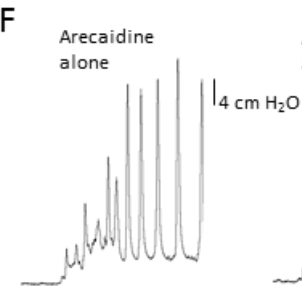

Acetylsalicylic acid and arecaidine

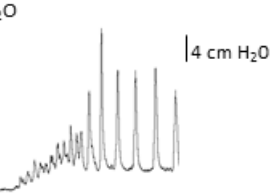

\section{C}

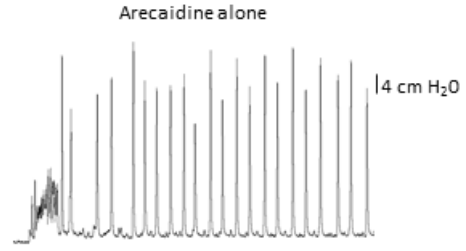

$E$

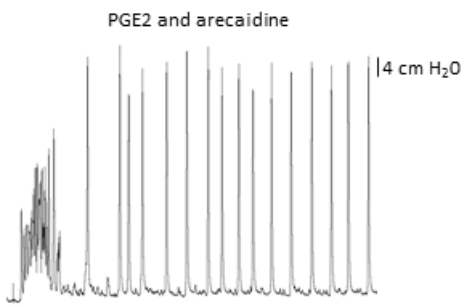

G

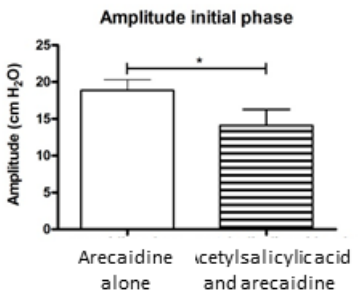

Figure 4. Effect of PGE2 and acetylsalicylic acid. Panels B-E show two different patterns observed during arecaidine stimulations after $P G E_{2}$ stimulation $(n=8)$. Panel $B$ and $C$ show arecaidine induced responses before PGE2 stimulation. Arecaidine induced responses of the same bladders after PGE2 stimulation are shown in panel $D$ and $E$, respectively. However, no significant differences could be detected using the automated analysis. In panel $A$, it seems that the bladder evolves faster into the second phase of the response, whereas in panel $B$, it seems that the initial phase of the response is reinforced. In panels $F$ and $G$, the effect of acetylsalicylic acid on the arecaidine induced response is shown $(n=8)$. Clearly the amplitude of the initial phase has been decreased. This effect is statistically significant $(p<0.01)$. 
Adding acetylsalicylic acid before stimulation with arecaidine resulted in a diminished rise in tonic pressure during the initial phase of the arecaidine response. In addition, the amplitude of the first phase of the muscarinic response decreased significantly after COX-inhibition. Figures $4 \mathrm{~F}$ shows a typical example of how the rise in pressure and amplitude during the initial phase of the arecaidine response changes due to the inhibition of COX-1 and COX-2 enzymes. The amplitude during the initial phase of an arecaidine induced response decreased significantly after inhibition of the COX enzymes $(p<0.01$, figure $4 \mathrm{H})$

In order to investigate whether the effect of PGE2 is exerted by binding to the EP1 receptor, bladders were incubated with an EP1 antagonist prior to the second comparable arecaidine stimulation. No significant changes were observed during the initial phase of the arecaidine induced response. However, during the second phase, the frequency of contractions decreased significantly $(p<0.01)$. No changes were detected regarding the amplitude during the second phase (figure 5).

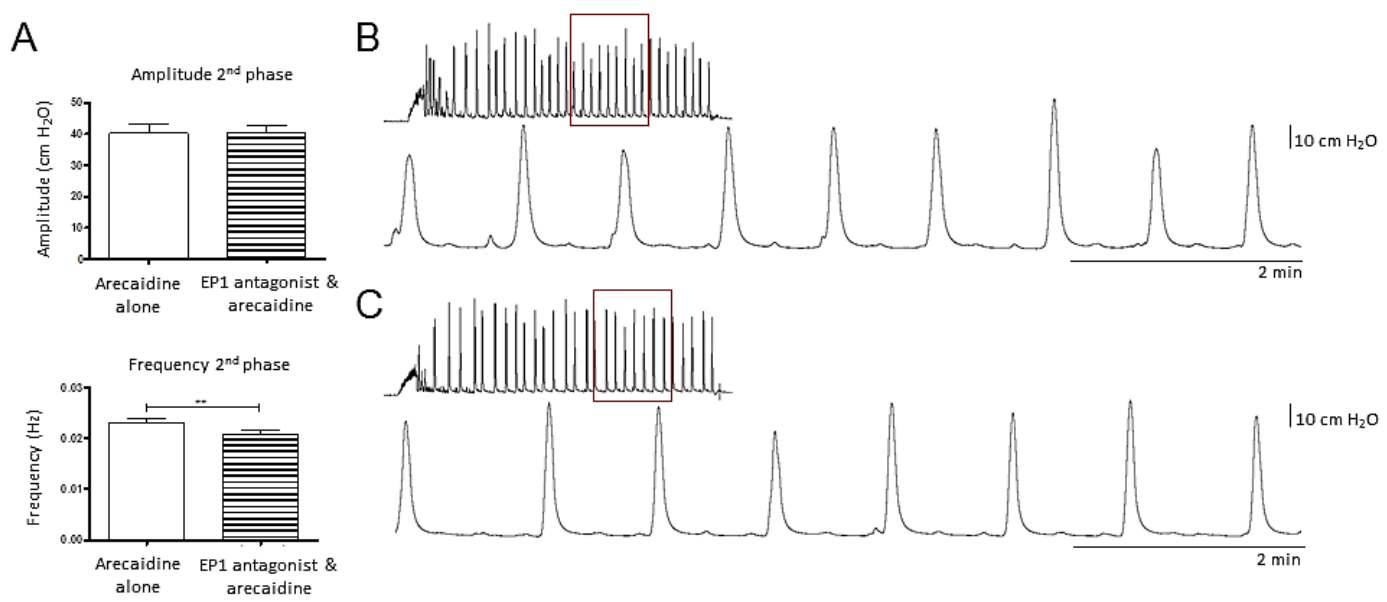

Figure 5. Effect of the EP1 antagonist ONO-8713 on muscarinic induced contractions. Panel A shows quantitative data of the second phase of arecaidine responses after EP1 inhibition ( $n=8)$. During this phase, frequency of contractions was reduced significantly $(p<0.01)$. No changes were detected in the amplitude of contractions during the second phase. Panels $B$ and $C$ show typical responses to arecaidine before (B) and after (C) EP1 inhibition.

\section{Discussion}

The aim of this study was to investigate whether muscarinically induced contractions can be modified by influencing the prostaglandin system. Adding $\mathrm{PGE}_{2}$ before muscarinic stimulations 
induced an amplifying effect on muscarinically induced contractions. During these amplified contractions two different response patterns were seen. Due to that, the bladders could be divided into two groups. Remarkably, most of these bladders still had increased baseline activity after stimulation with $\mathrm{PGE}_{2}$, comparable to those Rahnama'i et al described in their study ${ }^{14}$. Thus, PGE2 still has an effect on baseline spontaneous activity of those bladders, even if it is not clearly visible in muscarinic evoked responses. In 2012, Nile et al. already reported that PGE2 and $\mathrm{ACh}$ act in a positive feedback manner on a molecular level. This was shown in preparations of bladder strips containing urothelium and lamina propria ${ }^{13}$. Assuming that this positive feedback mechanism is also active in whole bladder preparations, e.g. in the present study, it can be hypothesised that endogenous $\mathrm{PGE}_{2}$, produced through this positive feedback has the same effect as exogenously administered PGE2. Thus, PGE2 seems to amplify muscarinically induced contractions. Responses could be divided into two distinct patterns of response after the amplification.

In addition, we showed that inhibition of the $\mathrm{PGE}_{2}$ producing enzymes prior to an arecaidine stimulation decreased the amplitude during the initial phase of the response. Again, this supports the theory of a positive feedback mechanism between PGE 2 and $\mathrm{ACh}$ on a whole bladder/functional level. In a normal situation, muscarinic stimulation seems to activate COX enzymes, which will lead to the production of more PGE2. PGE2 in turn will promote the release of more ACh, that results in an amplified contraction (figure 6). Because COX enzymes were inhibited during this part of the study, this feedback loop was interrupted, resulting in a diminished response.

Schroder et al. showed that the EP1 receptor plays a role when PGE2 exerts its effects on bladder activity ${ }^{8}$. Therefore, an EP1 antagonist was administered to isolated bladders and its effect on arecaidine induced responses was tested. Inhibition of EP1 resulted in a decreased frequency during the second phase of the arecaidine response but the amplitude did not change. However, this effect was not comparable to the effect which was seen after inhibition of the $\mathrm{PGE}_{2}$ producing COX enzymes by acetylsalicylic acid. This may reflect that other subtypes

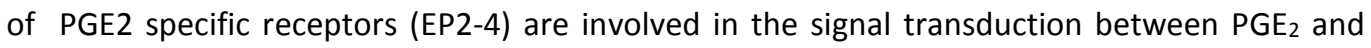
ACh. The exact mechanism has to be explored in future research in order to find a specific target which can be used to modulate muscarinic induced contractions and thereby avoid the high prevalence of side effects seen during current first line treatment regimens. 


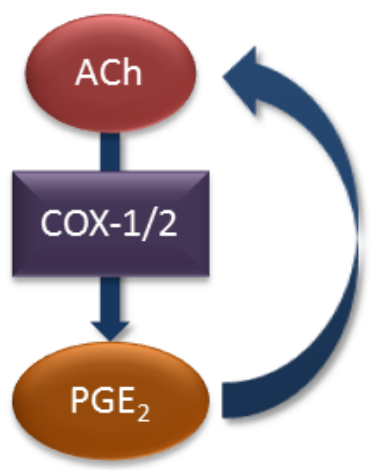

Figure 6. Positive feedback of ACh and PGE2 in the guinea pig urinary bladder. ACh activates the PGE 2 producing enzymes COX-1 and/or COX-2. This results in an increase of $P G E_{2}$ which in turn induces the secretion or release of more ACh. Via this pathway, a positive feedback takes place between the two signalling systems.

\section{Conclusions}

In summary, this study provides evidence that the cholinergic and prostanoid systems in the urinary bladder act in a positive feedback loop and that the EP1 receptor plays a subtle role in this process. In order to identify new treatment targets, the location of the different steps in the cascade and the targets for modulation of this process need to be determined in the near future. 


\section{References}

1. Kim JC, Park EY, Hong SH, Seo SI, Park YH, Hwang TK. Changes of urinary nerve growth factor and prostaglandins in male patients with overactive bladder symptom. Int J Urol. 2005 Oct;12(10):875-80.

2. Kim JC, Park EY, Seo SI, Park YH, Hwang TK. Nerve growth factor and prostaglandins in the urine of female patients with overactive bladder. J Urol. 2006 May;175(5):1773-6; discussion 6.

3. Rahnama'i MS, de Wachter SG, van Koeveringe GA, van Kerrebroeck PE, de Vente J, Gillespie JI. The relationship between prostaglandin $\mathrm{E}$ receptor 1 and cyclooxygenase I expression in guinea pig bladder interstitial cells: proposition of a signal propagation system. J Urol. 2011 Jan;185(1):315-22.

4. Rahnama'i MS, van Koeveringe GA, Essers PB, de Wachter SG, de Vente J, van Kerrebroeck PE, et al. Prostaglandin receptor EP1 and EP2 site in guinea pig bladder urothelium and lamina propria. J Urol. 2010 Mar;183(3):1241-7.

5. Schussler B. Comparison of the mode of action of prostaglandin E2 (PGE2) and sulprostone, a PGE2derivative, on the lower urinary tract in healthy women. A urodynamic study. Urol Res. 1990;18(5):349-52.

6. Ishizuka O, Mattiasson A, Andersson KE. Prostaglandin E2-induced bladder hyperactivity in normal, conscious rats: involvement of tachykinins? J Urol. 1995 Jun;153(6):2034-8.

7. Maggi CA, Giuliani S, Conte B, Furio M, Santicioli P, Meli P, et al. Prostanoids modulate reflex micturition by acting through capsaicin-sensitive afferents. Eur J Pharmacol. 1988 Jan 12;145(2):105-12.

8. Schroder A, Newgreen D, Andersson KE. Detrusor responses to prostaglandin E2 and bladder outlet obstruction in wild-type and Ep1 receptor knockout mice. J Urol. 2004 Sep;172(3):1166-70.

9. de Groat WC. Mechanisms underlying the recovery of lower urinary tract function following spinal cord injury. Paraplegia. 1995 Sep;33(9):493-505.

10. de Jongh R, van Koeveringe GA, van Kerrebroeck PE, Markerink-van Ittersum M, de Vente J, Gillespie JI. The effects of exogenous prostaglandins and the identification of constitutive cyclooxygenase I and II immunoreactivity in the normal guinea pig bladder. BJU Int. 2007 Aug;100(2):419-29.

11. Wang X, Momota Y, Yanase H, Narumiya S, Maruyama T, Kawatani M. Urothelium EP1 receptor facilitates the micturition reflex in mice. Biomed Res. 2008 Apr;29(2):105-11.

12. Angelico P, Guarneri L, Velasco C, Cova R, Leonardi A, Clarke DE, et al. Effect of cyclooxygenase inhibitors on the micturition reflex in rats: correlation with inhibition of cyclooxygenase isozymes. BJU Int. 2006 Apr;97(4):837-46.

13. Nile CJ, Gillespie Jl. Interactions between cholinergic and prostaglandin signaling elements in the urothelium: role for muscarinic type 2 receptors. Urology. 2012 Jan;79(1):240 e17-23.

14. Rahnama'i MS, van Koeveringe GA, van Kerrebroeck PE, de Wachter SG. The effect of indomethacin on the muscarinic induced contractions in the isolated normal guinea pig urinary bladder. BMC urology. 2013;13:8.

15. Chess-Williams R. Muscarinic receptors of the urinary bladder: detrusor, urothelial and prejunctional. Autonomic \& autacoid pharmacology. 2002 Jun;22(3):133-45.

16. Grol S, Essers PB, van Koeveringe GA, Martinez-Martinez P, de Vente J, Gillespie JI. M(3) muscarinic receptor expression on suburothelial interstitial cells. BJU Int. 2009 Aug;104(3):398-405.

17. Tyagi S, Tyagi P, Van-le S, Yoshimura N, Chancellor MB, de Miguel F. Qualitative and quantitative expression profile of muscarinic receptors in human urothelium and detrusor. J Urol. 2006 Oct;176(4 Pt 1):1673-8. 



\section{CHAPTER 5}

Distribution and Function of the EP3

\section{Receptor in the Guinea Pig Urinary}

Ramona Hohnen ${ }^{1}$, Celine Meriaux ${ }^{1}$, Frank Raven ${ }^{1}$, Gommert A. Van Koeveringe ${ }^{1,2}$

${ }^{1}$ European Graduate School of Neuroscience (EURON), Maastricht University

P.O. Box 616, 6200 MD Maastricht, The Netherlands

${ }^{2}$ Maastricht University Medical Centre $\left(\mathrm{MUMC}^{+}\right)$, Urology department,

P.O. Box 5800, 6202 AZ Maastricht, The Netherlands 


\section{Abstract}

The urothelium releases several substances like, prostaglandin $E_{2}$ ( $\left.P G E_{2}\right)$, nitric oxide, acetylcholine and adenosine triphosphate. The purinergic and cholinergic systems interact in a positive feedback. In this study, the role of the PGE 2 -specific receptor EP3 in this interaction is investigated as well as its distribution in the urinary bladder.

The bladder and proximal urethra of 21 male guinea pigs were dissected after sacrifice. For morphological investigation of EP3, five bladders were processed for immunohistochemistry. To investigate the functional role of EP3 in muscarinically induced contractions, 16 bladders were catheterised transurethrally and the effect of the EP3 receptor agonist ONO-AE-248 or antagonist ONO-AE-240 on arecaidine-induced responses was studied in an ex vivo organ bath setting.

EP3 was identified in the umbrella cells of the urothelium, in suburothelial interstitial cells and nerves of the suburothelial and muscle layer. Co- and close-localisation of EP3 with the cholinergic receptor M3 in the urothelium were detected. Activation of significantly decreased the frequency of contractions during the stable phase of the arecaidine-induced response. Inhibition of EP3 prior to muscarinic stimulations resulted in a decreased amplitude during the same period.

EP3 immune reactivity was detected in neuronal structures in the urothelial/ suburothelial and muscle layer as well as by suburothelial interstitial and urothelial cells. Activation of EP3 receptors in the urinary bladder decreased the frequency of muscarinically induced contractions. The EP3 receptor offers an interesting target to modulate muscarinically induced contractions. However, the underlying mechanism needs to be elucidated further. 


\section{Introduction}

The overactive bladder syndrome $(O A B)$ has been defined as a symptom complex of urinary urgency with or without incontinence, urinary frequency and nocturia. Antimuscarinic drugs serve as the first line treatment. However, due to an unsatisfactory effectivity and high prevalence of side effects, the patient compliance is poor. Acetylcholine (ACh) is the primary contractile neurotransmitter of the human detrusor muscle and antimuscarinics exert their effects on $\mathrm{OAB} /$ detrusor overactivity by inhibiting the binding of ACh on muscarinic receptors $\mathrm{M} 2$ and $\mathrm{M} 3$ on detrusor smooth muscle cells and other structures within the bladder wall. Because of high side effects and low compliance of antimuscarinics, there is a high need of more specific treatment strategies and new targets within the bladder wall. Those targets can influence bladder activity by themselves or modulate contractile regulators like ACh.

A potential candidate to modulate muscarinic contractions is the prostanoid system. Administration of indomethacin ex vivo to an intact bladder reduced muscarinically induced contractions $^{1}$. On a molecular level, Nile et al. showed that prostaglandin $E_{2}\left(P_{G} E_{2}\right)$ induces the release of $\mathrm{ACh}^{2}$. Stimulation with the muscarinic agonist arecaidine induces $\mathrm{PGE}_{2}$ release ${ }^{2}$. Therefore, $\mathrm{PGE}_{2}$ could be an interesting target to modulate muscarinically-induced contractions and thereby reduce possible side effects.

Prostaglandins play an important role in physiological processes in the bladder in both healthy and pathological conditions. In rodents, intravesical administration of $\mathrm{PGE}_{2}$ resulted in micturition and increased basal intravesical pressure as well as an increase in amplitude and frequency of non-voiding contractions ${ }^{3,4}$. Administration of $\mathrm{PGE}_{2}$ directly into the human urinary bladder caused strong sensations of urgency $^{5}$. Furthermore, it has been shown that urinary $P G E_{2}$ was significantly increased in male and female subjects suffering from $O A B^{6-8}$.

$P_{E_{2}}$ exerts its effect by binding to one of its four E prostanoid (EP) receptors, EP1 - 4. EP1 and EP2 expression has been in the urinary bladder wall throughout the different tissue layers ${ }^{9-11}$. A combined EP1/EP2 blocking agent reduced the effect of $\mathrm{PGE}_{2}$ dose-dependently in isolated guinea pig bladders ${ }^{12}$. Furthermore, intravesical administration of PGE 2 or an EP1 agonist had a significant effect on the inter-micturition interval ${ }^{13}$.

The EP3 receptor is expressed in dorsal root ganglion neurons ${ }^{14-17}$. EP3 receptor KO mice had a diminished response to $\mathrm{PGE}_{2}$ instillation as well as an enhanced bladder capacity at baseline ${ }^{18}$. In addition, stimulation of EP3 reduced the functional bladder capacity, while inhibition of the EP3 receptor increased bladder capacity in spontaneously hypertensive rats ${ }^{19}$. All studies 
investigated the effect of the EP3 receptor after central interference. However, presently it is unknown whether EP3 is present in the bladder itself and which effect stimulation or inhibition of EP3 would have on muscarinically induced contractions at bladder level.

In this study we investigated the structural presence of the PGE 2 -specific EP3 receptor in the urinary bladder of the guinea pig and whether it may modulate bladder activity by local effects in a functional study.

\section{Methods}

\section{Animals}

A total of 21 male guinea pigs were sacrificed by a percussive blow to the head, followed by exsanguination. All procedures were carried out with the approval of guidelines of the animal ethics committee of Maastricht University and were in line with European Community guidelines.

\section{Tissue processing}

Strips were cut from the lateral wall, and fixed using $4 \%$ freshly prepared depolymerised paraformaldehyde for 2 hours at $4^{\circ} \mathrm{C}$. Tissue was then fixed in three steps of two overnight and one daytime incubations at $4^{\circ} \mathrm{C}$ in $0.1 \mathrm{M}$ phosphate buffer with $10 \%, 20 \%$ and $30 \%$ sucrose. On day 3, tissues were placed in Tissue-Tek ${ }^{\circledR}$ O.C.T. ${ }^{\text {м }}$ compound to form a single block, snap frozen in isopentane which was cooled by liquid nitrogen. Cryostat sections (10 $\mu \mathrm{m})$ were cut such that each section was perpendicular to the urothelial surface. Sections were thawed on chrome alum-gelatin coated slides and processed for immunohistochemistry.

\section{Antibodies}

Four different primary antibodies were used to study EP3 location in the bladder wall. To detect EP3 polyclonal rabbit anti-EP3 (1:100, Santa Cruz biotechnologies, Inc) was used. Specificity of the antibody was tested by Western blot by the supplier. No specific blocking peptide was available for the EP3 antibody. To identify nerves in the tissue, sections were co-stained with polyclonal chicken anti-PGP 9.5 antibodies (1:3000, Abcam). Mouse anti-vimentin antibodies (1:1000, Biogenex) were used to detect interstitial cells. Polyclonal goat anti-M3 was used to detect the ACh receptor M3 (1:100, Santa Cruz biotechnologies, Inc). This antibody was tested 
and validated in prior publications ${ }^{20,21}$. All antibodies were diluted in Tris-buffered saline (TBS; $\mathrm{pH}$ range 7.4-7.6) containing $0.3 \%(\mathrm{v} / \mathrm{v})$ Triton X-100 (TBST-T).

\section{Immunohistochemistry}

The sections were prepared for immunohistochemistry by drying for 20 minutes at room temperature followed by three wash steps with TBS, each lasting 5 minutes. Slides were then incubated overnight with primary antibodies at $4^{\circ} \mathrm{C}$. After that, sections were washed in TBS-T, TBS, TBS-T; lasting 15 minutes each. Rabbit primary antibodies were visualised using Alexa Fluor 488 or Alexa Fluor 594 donkey anti-rabbit IgG $(\mathrm{H}+\mathrm{L})$ conjugate (Molecular Probes, Invitrogen Ltd, Paisly, UK), diluted 1:100 in TBS-T. Mouse primary antibodies were visualised with Alexa Fluor 594 donkey anti-mouse IgG conjugate (Molecular Probes, Invitrogen Ltd, Paisly, UK), diluted 1:100. The chicken primary antibody was visualised with Alexa Fluor 488 goat antichicken (Molecular Probes, Invitrogen Ltd, Paisly, UK), diluted 1:100. The goat primary antibody was visualized with Alexa Fluor 594 donkey anti-goat IgG conjugate (Molecular Probes, Invitrogen Ltd, Paisly, UK), also diluted 1:100. Sections were incubated with the secondary antibodies for 1 hour at room temperature in the dark. After washing with TBS-T and TBS, sections were mounted with TBS-glycerol. All stainings were duplicated and repeated on at least two separate days. Negative controls without primary antibody were used to confirm the results. A representative section of the bladder for all animals was studied.

\section{Microscopy}

Sections were analysed and photographed using an Olympus AX70 microscope using a 10x, 20x and 40x objectives. For the detection of Alexa 488 fluorescence, a narrow band-pass MNIBAfilter and for Alexa 594 a narrow excitation band U-M41007A filter was used (both from Chroma Technologies, Rockingham, VT, USA). The microscope was equipped with a cooled CCD Olympus Digital video camera F-view. Images were stored as 16-bits images and analysed using imageJ software.

\section{Pressure recordings}

The urinary bladder and proximal urethra were excised immediately after euthanasia of the animal and placed in Krebs' solution (mM: $\mathrm{NaCl} 121.1 ; \mathrm{KCl} 1.87 ; \mathrm{CaCl}_{2} 1.2 ; \mathrm{MgSO}_{4} 1.15 ; \mathrm{NaHCO}_{3}$

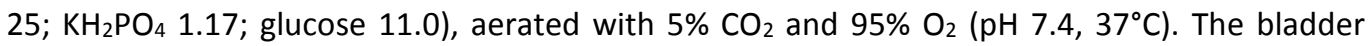
was emptied manually and the urethra was catheterised with a catheter made from PE-50 
tubing with a small cuff at the end and fixed with a fine ligature. After transferring the bladder to a heated organ bath $\left(40 \mathrm{~mL}, 33-36^{\circ} \mathrm{C}\right)$ containing constantly gassed Krebs' solution, the catheter was connected through a fluid filled tube containing a three-way connector to a pressure transducer (Codan, Germany). The transducer output was amplified, digitised at 1000 $\mathrm{Hz}$ and recorded using a data capture system (MP100 with AcqKnowledge 4.2 software, BIOPAC systems, Inc, California). The transducer was calibrated before each experiment. Recordings started 30 minutes after the animal was sacrificed. The pressure recordings started with a rest of 30 minutes. Subsequently, the bladder was filled to $1.5 \mathrm{ml}$ in 1 hour and allowed to rest for another hour, followed by two washings steps, each lasting 15 minutes. During the washing steps, the Krebs solution in the organ bath was completely refreshed by new one (also $37^{\circ} \mathrm{C}$ ). The bladder was stimulated with the muscarinic agonist arecaidine but-2-ynyl ester tosylate (300 nM, Tocris, Avonmouth, UK). After two more washing steps (each lasting 15 minutes), this stimulation was repeated to create a stable muscarinic response. Again two washing steps were performed before the bladder was stimulated with the EP3 agonist or the EP3 antagonist and incubated for 15 minutes, followed by a third muscarinic stimulation.

\section{Drugs}

Concentrated drug solutions were added directly to the bath to achieve the required final dilution. All drugs were added to the solution bathing the serosal surface. The EP3 agonist ONOAE-248 (ONO pharmaceutical, Osaka, Japan) was used in a concentration of $500 \mathrm{nM}$. The EP3 antagonist ONO-AE3-240 (ONO pharmaceutical, Osaka, Japan) was used in a concentration of 1 $\mathrm{nM}$. As muscarinic agonist, $300 \mathrm{nM}$ of arecaidine but-2-ynyl ester tosylate (Tocris, Avonmouth, UK) was used.

\section{Data processing and statistical analysis}

All data were processed in a maximised objective way, using Matlab ${ }^{\circledR}$ scripts to detect peaks and corresponding baseline values. For peak selection a threshold of $5 \mathrm{~cm} \mathrm{H}_{2} \mathrm{O}$ was used. To determine the moment of transition between the two phases, a strong low pass filter was deployed. This resulted in a simplified curve, starting with an ascending slope which continues into a descending slope, shown in Figure 1. This part reflects the irregular rise in pressure during the first phase of an arecaidine response and is followed by an irregular sinus curve, reflecting the second phase. The first minimum of this curve was determined as the moment of transition towards the second phase of an arecaidine-induced response (Figure 1). 


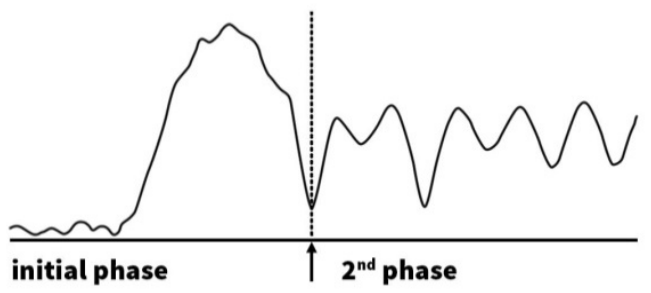

Figure 1. Discrimination between initial and second phases of arecaidine induced responses. The point of transition between the two phases was determined by deployment of a strong low pass filter. The simplified curve resulting from the filtering process is shown in this figure. Afterwards, the first minimal pressure measured after the strong rise was chosen as the point of transition from the initial phase towards the second phase.

To analyse the effect of the drugs used to modify muscarinically induced contractions, the first comparable muscarinic response was used as reference and compared with subsequent responses after drug incubation. The effect was analysed using the Kruskal-Wallis test and Wilcoxon matched pairs test.

\section{Results}

To identify the distribution of the PGE2-specific receptor EP3, an indirect immunohistochemical technique was used. Images were analysed for identification of the presence of EP3 as well as other markers. To visualise EP3, a polyclonal antibody was used. The specificity was tested by the supplier and negative controls were used in this study to confirm the results. Typical images are shown in Figures 2-4.

In Figure 2, an overview of the distribution of EP3 and vimentin in urothelium and suburothelium of the lateral wall of a guinea pig bladder is displayed. The umbrella cells of the urothelium stained strongly for EP3, whereas in the intermediate and basal layer, urothelial cells exhibited a less clear EP3 immune reactivity. Another observation was the strong EP3specific staining by thick nerve-like structures in the suburothelium. Thus, these thick EP3positive structures might represent suburothelial nerves. Most vimentin-positive suburothelial interstitial cells (SU-ICS) were also positive for EP3.

To investigate whether the strong EP3-positive, nerve-like structures were indeed suburothelial nerves, we co-stained sections for EP3 and PGP 9.5, a general nerve marker. Figure 3 illustrates an overview of this double staining. All PGP 9.5-positive nerves of the lateral wall of the guinea 
pig bladder stained positive for EP3 and were detected in the urothelial, suburothelial and muscle layers.

To investigate the interaction between the cholinergic and the prostaglandin signalling structures, sections were co-stained for EP3 together with the muscarinic receptor M3. An overview of the lateral wall of a guinea pig bladder, stained for EP3 and M3, is shown in Figure 4. Three different patterns of EP3 and M3 expression have been found in the urothelium. Firstly, umbrella cells of the urothelium stained positive for both EP3 and M3. However, not all umbrella cells showed this expression, resulting in a zebra-like pattern in transfer sections. Secondly, a clearly visible close-localisation of EP3 and M3 in the urothelium could be observed.
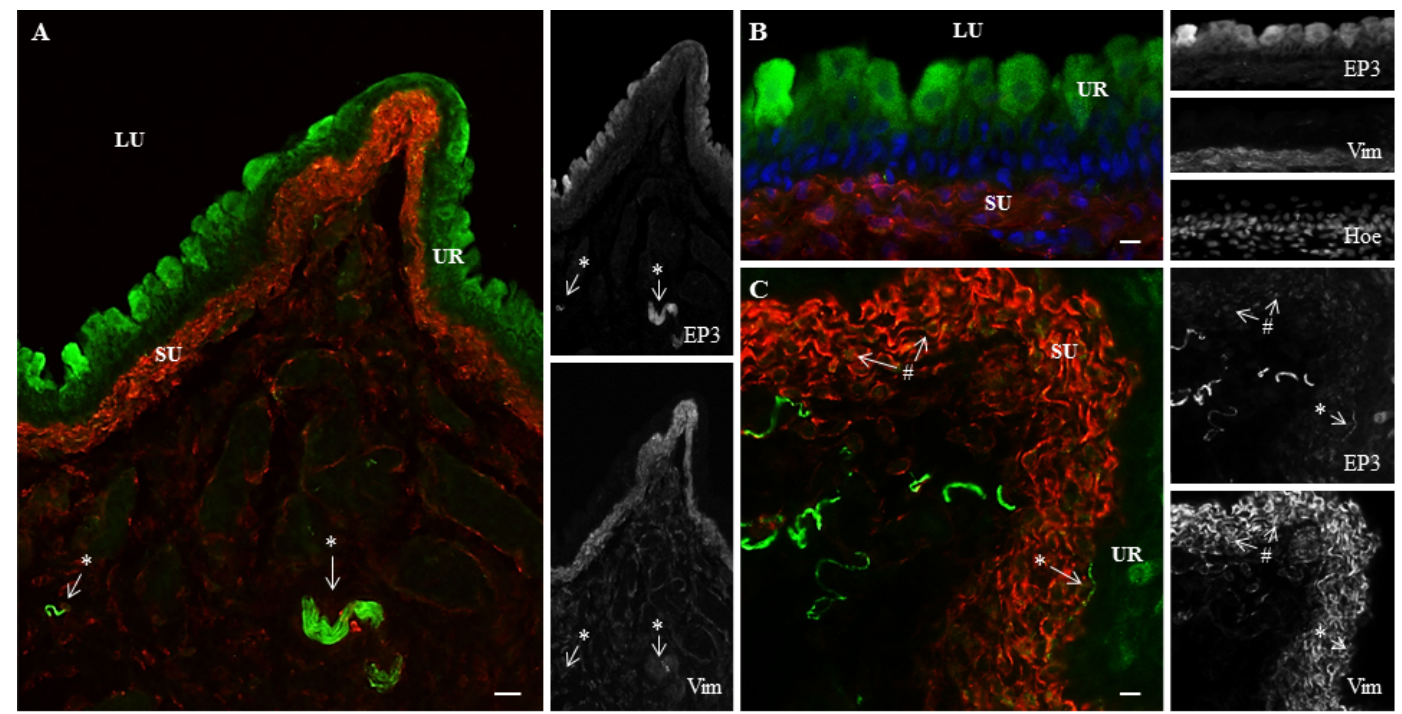

Figure 2. The distribution of EP3 and vimentin in the lateral wall of the guinea pig bladder. Panels show an image of the urothelium and suburothelium of the lateral wall of a guinea pig bladder stained with the antibody for EP3 (green) and vimentin (red). In panel A, a low power image of the urothelium and suburothelium is shown. The umbrella cells of the urothelium stain positive for EP3. Asterisk indicates EP3 specific staining of nerve-like structures in the suburothelium. Panel B shows a high power image of the urothelium of the lateral wall of a guinea pig bladder. The nuclei of the cells are visualised by a Hoechst nuclei staining (blue). Note strong EP3 staining in the umbrella cells of the urothelium and almost no staining in the basal layer. In panel $\mathrm{C}$ a high power image of the suburothelial layer is displayed. Hash sign indicates EP3 positive suburothelial interstitial cells, characterised by vimentin staining. EP3 specific staining of a nerve-like structure directly beneath the urothelium is indicated by an asterisk. The bladder lumen (LU), the urothelium (UR) and the suburothelial layer (SU) are marked. The black and white pictures show the individual EP3, vimentin (vim) and Hoechst (Hoe) stainings. Calibration bars: $25 \mu \mathrm{m}$ in panel A and $10 \mu \mathrm{m}$ in panels $B$ and $C$. 
The umbrella cells of the urothelium showed a strong staining for EP3 but not for M3. Immune reactivity of $M 3$ was found mostly in the basal layer of the urothelium but also in the suburothelial layer. Thirdly, close-localisation of EP3 and M3 in the umbrella cells of the urothelium can easily be seen. While strong staining can be detected in umbrella cells, other cell layers of the urothelium show less immune-reactivity. In this pattern, M3- and EP3-positive cells are in close proximity and present in all different layers of the urothelium.

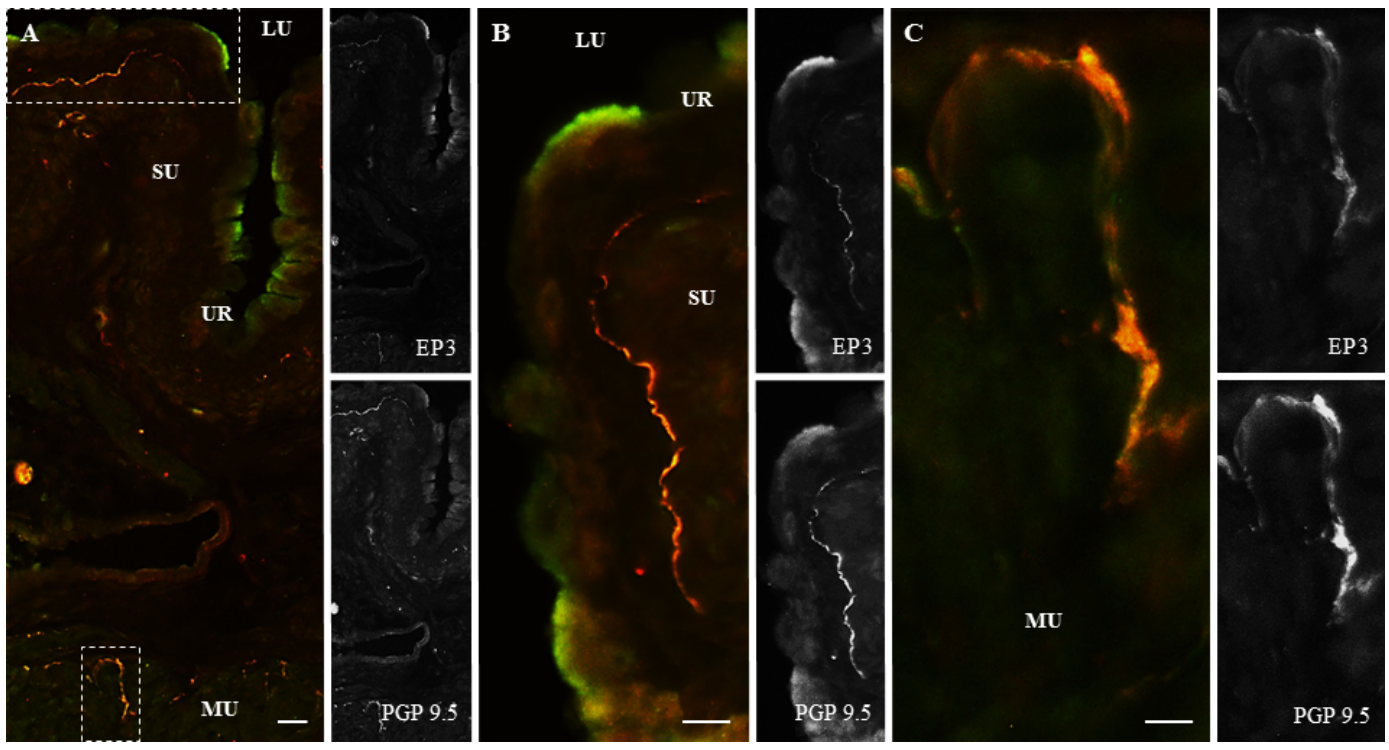

Figure 3. The distribution of EP3 and PGP 9.5 in the nerves of the lateral wall of the guinea pig bladder. Panels show an image of the lateral wall of a guinea pig bladder, stained with the antibody for EP3 (green) and PGP 9.5 (red), which is a general marker used to identify nerves. In panel A, a low power image of the urothelium, suburothelium and muscle is shown. Marked are nerves showing colocalisation of both EP3 and PGP 9.5 immunoreactivity, which are shown in more detail in panels $B$ and $C$. Panel $B$ demonstrates an enlarged image of a suburothelial nerve, positive for both EP3 and PGP 9.5. In panel C, an enlarged image of a nerve in the muscle layer, co-stained by PGP 9.5 and EP3 is displayed. The bladder lumen (LU), the urothelium (UR), the suburothelial layer (SU) and muscle layer (MU) are marked. The black and white insets show the individual EP3 and PGP 9.5 stainings. Calibration bars: $25 \mu \mathrm{m}$ in panel A and $10 \mu \mathrm{m}$ in panels B and $C$. 


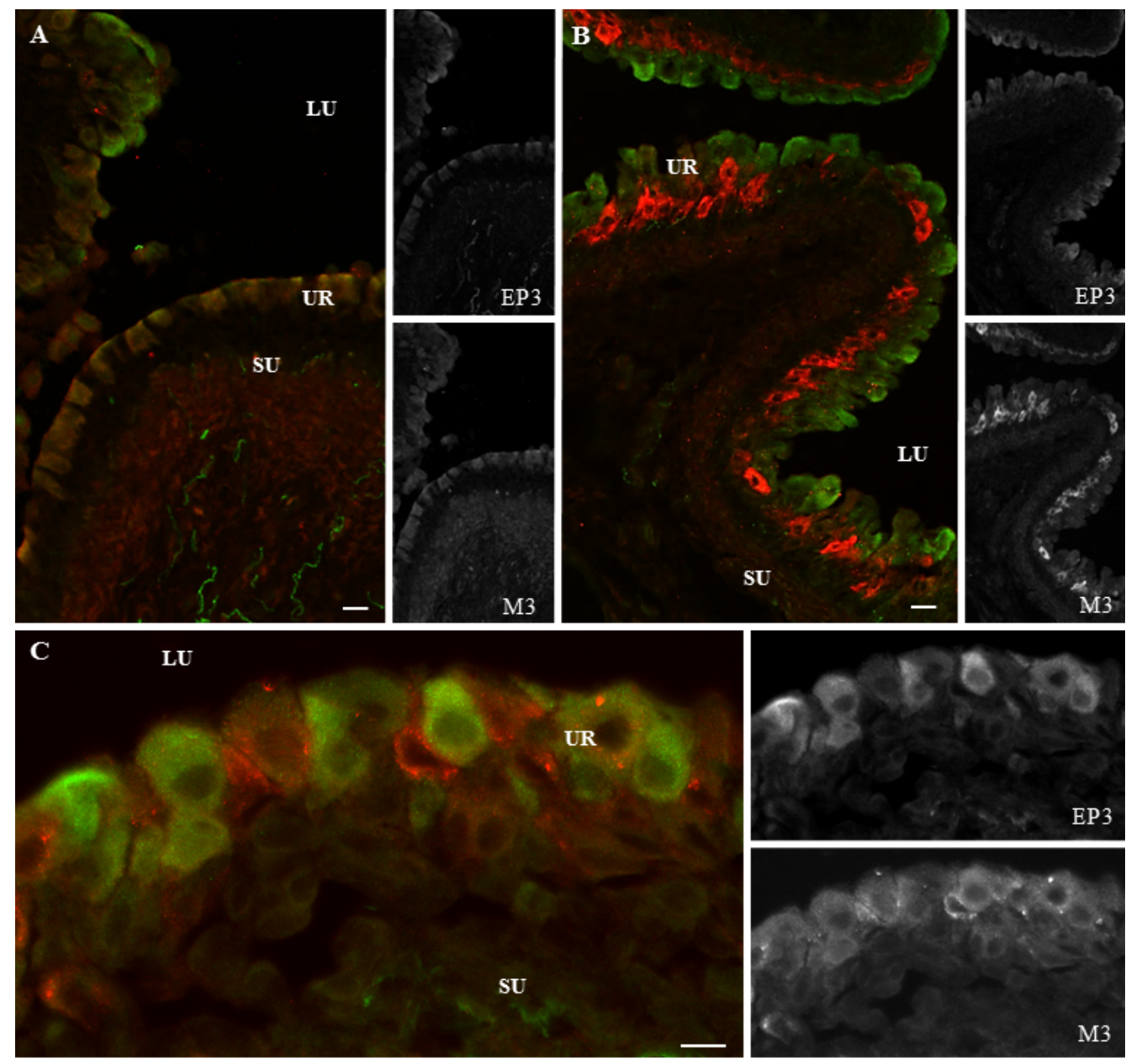

Figure 4. The distribution of EP3 and M3 in the lateral wall of the guinea pig bladder. Panels show an image of the urothelium and suburothelium of the lateral wall of a guinea pig bladder stained with the antibody for EP3 (green) and M3 (red). Three different patterns of EP3 and M3 are shown in the different panels. In panel A, a low power image of the urothelium and suburothelium can be seen. The umbrella cells of the urothelium stain positive for both EP3 and M3. Furthermore, it can be noted that the suburothelial layer stains positive for M3 while nerves in the suburothelium express EP3. Panel B shows a low power image of the urothelium and suburothelium. Clearly visible is the close-localisation of EP3 and M3 in the urothelium. Note strong staining in the umbrella cells of the urothelium for EP3 but not for M3. Expression of $\mathrm{M} 3$ was found in suburothelial layer but mostly in the basal layer of the urothelium. In panel $\mathrm{C}$, a high power image of the urothelium is displayed. Close-localisation of EP3 and M3 in the umbrella cells of the urothelium can easily be seen. The bladder lumen (LU), the urothelium (UR), and the suburothelial layer (SU) are marked. The black and white insets show the individual EP3 and M3 staining. Calibration bars: 25 $\mu \mathrm{m}$ in panels $A$ and $B, 10 \mu \mathrm{m}$ in panel $C$. 
A

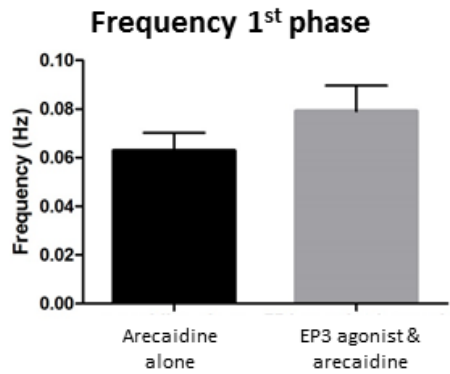

C

Frequency $2^{\text {nd }}$ phase

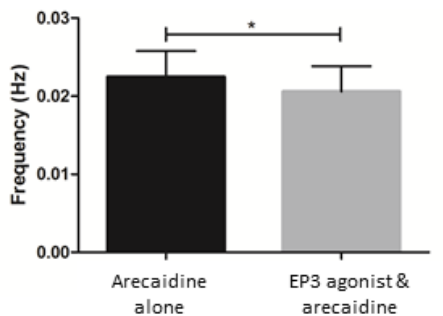

E

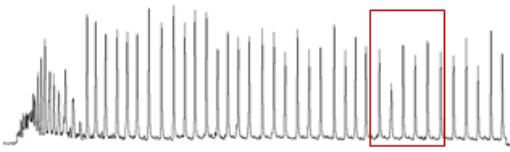

B

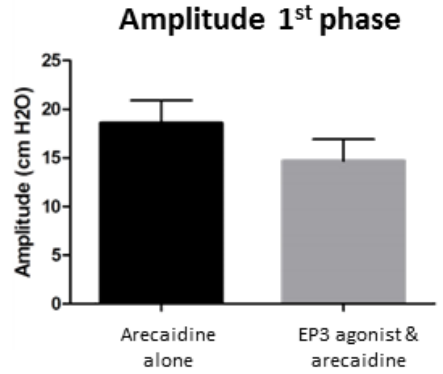

D

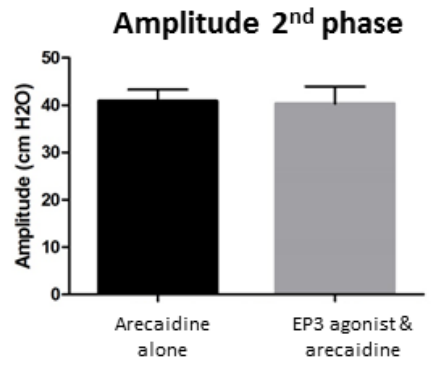

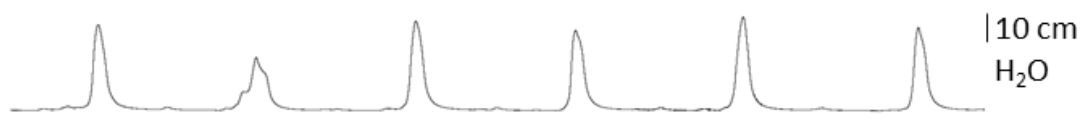

$1 \mathrm{~min}$

$\mathbf{F}$
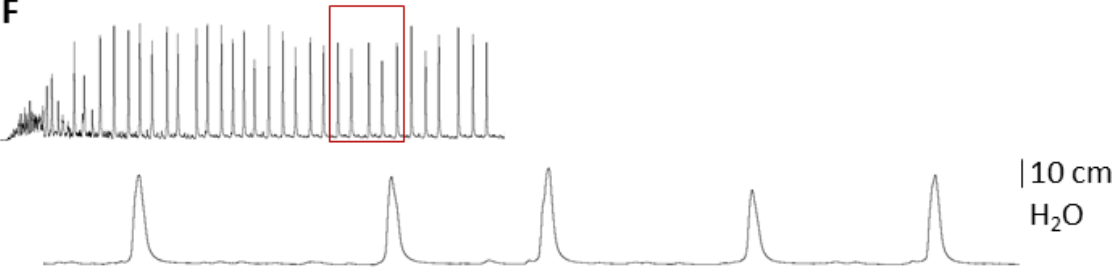

$1 \mathrm{~min}$

Figure 5. The effect of EP3 activation on muscarinically induced contractions. Panels A-D show quantified data of frequency and amplitude during both the first and the second phases of an arecaidine induced response before and after EP3 activation. Significant changes were exclusively observed at the frequency during the second phase. In this condition, a decrease was recorded, as shown in panel C. In panels $E$ and $F$, representative responses are shown before (E) and after (F) EP3 activation. 
To investigate the functional role of EP3 in the guinea pig urinary bladder, we performed ex vivo cystometry on the bladder by focusing on the modulatory effect of muscarinically induced contractions. Therefore, stimulations with the muscarinic agonist arecaidine were given alone or in combination with the EP3 agonist or antagonist.

In general, arecaidine responses could be divided into two phases. The initial phase was characterised by an irregular rise in pressure, low/mediate amplitude and high frequency contractions, and lasted for approximately two minutes. Afterwards, regular contractions developed. These phasic contractions were characterised by a higher amplitude and lower frequency compared to the contractions of the initial phase.

A

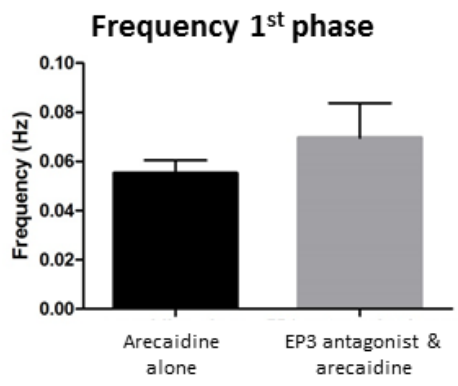

C

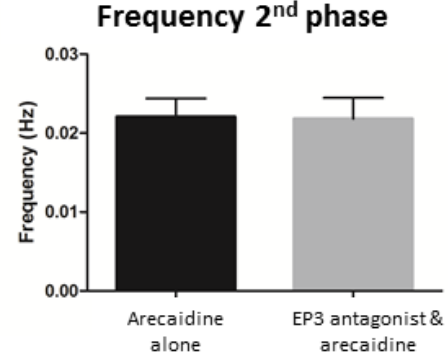

B

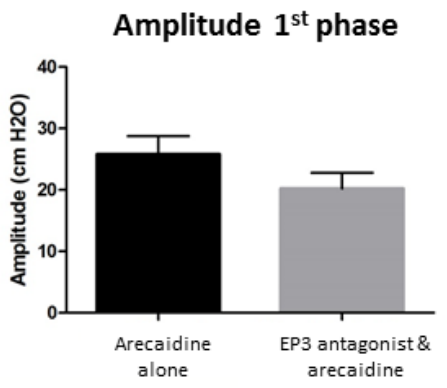

D

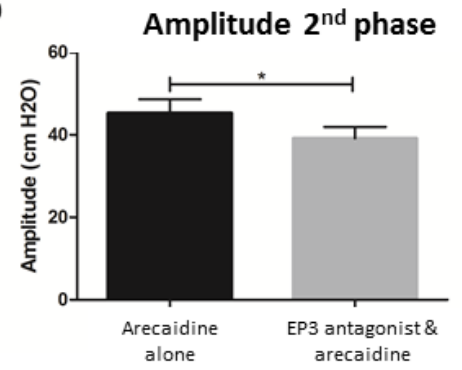

Figure 6. The effect of EP3 inhibition on muscarinically induced contractions. Panels A-D show quantified data of frequency and amplitude during both the first and the second phases of an arecaidine induced response before and after inhibition of EP3. Significant changes were exclusively observed at the frequency during the second phase. In this condition, a decrease was recorded, as shown in panel $\mathrm{C}$.

In order to ensure that the repeated arecaidine stimulations were comparable to each other, eight bladders were stimulated repeatedly with arecaidine alone and results were analysed with respect to amplitude and frequency for both, initial and the second phases. All first stimulations were significantly different from later ones. However, from the second stimulation on, no significant differences were found (data not shown). Therefore, the second and third arecaidine 
stimulations were used to compare and investigate the effect of EP3 stimulation and inhibition on muscarinically induced contractions. One bladder did not develop the typical first and second phases and was therefore excluded from the analysis. Again, frequency and amplitude were analysed for the initial and second phases of the muscarinic responses. When the EP3 agonist was applied prior to a muscarinic stimulation, no significant changes were detected during the initial phase. During the second phase, although the amplitude did not change, the frequency was significantly reduced (Figure 5). However, after analysis one response was identified as an outlier and was therefore removed from the data set. Therefore, six bladders remained to be analysed after exclusion of two bladders. When EP3 was inhibited prior to the muscarinic stimulation, no changes were observed during the initial phase. With EP3 antagonist, the amplitude of the second phase of the muscarinic response was significantly reduced whereas the frequency did not change after EP3 inhibition (Figure 6).

\section{Discussion}

In this study we showed that EP3 immune reactivity was present in the urinary bladder of the guinea pig, more specifically, in neuronal structures within the urothelium, suburothelium and muscle layer. Furthermore, suburothelial interstitial and urothelial cells had been shown to be immune reactive for the EP3 antibody. The specificity of the EP3 antibody had been shown by the supplier (Santa Cruz Biotechnologies, Inc). Our findings are in accordance with data of Su et al., who showed presence of EP3 mRNA in the rat urinary bladder ${ }^{16}$. In their study, whole bladder homogenates were used. Thus, no knowledge was gained on the location of EP3. Our study provided additional data on the location of EP3 in the guinea pig bladder. Immune reactivity for EP3 was found predominantly in the urothelial and suburothelial layers. Within the muscle layer, the EP3 receptor immune reactivity was merely present in neuronal structures. Knowing that EP3 immune reactivity had been shown in the bladder itself, it was of interest to investigate the functionality of this receptor. In the urothelium, M3-and EP3-positive cells were in close proximity to each other. This finding increased the probability of an interaction between cholinergic and prostanoid signalling on a structural level. PGE 2 and $A C h$ were shown to act together through a positive feedback mechanism at a bladder level, reinforcing each other's effects ${ }^{2}$ and inhibition of the $\mathrm{PGE}_{2}$ producing enzyme cyclooxygenase reduced muscarinically induced contractions ex vivo in guinea pig urinary bladders ${ }^{1}$. Therefore, the role of EP3 in this local positive feedback loop of $\mathrm{PGE}_{2}$ and $A C h$ was investigated.

When EP3 was activated prior to muscarinic stimulations, the frequency of bladder contractions was reduced during the second phase of the arecaidine response. These results were in conflict 
with findings of earlier studies on EP3 and bladder activity. EP3 receptor KO mice showed an enhanced bladder capacity at baseline ${ }^{18}$. In spontaneously hypertensive rats, stimulation of EP3 reduced functional bladder capacity, while inhibition increased bladder capacity ${ }^{19}$. Thus, EP3 agonists seem to have a stimulating, bladder activity enhancing effect. However, in our study, muscarinically induced contractions showed a reduced frequency after EP3 stimulation, resulting in an inhibitory effect of EP3 on bladder activity. This study was conducted in an ex vivo setting. All available literature on EP3 and bladder activity was based on in vivo studies. It had been shown that EP3 had an effect on the central nervous system, thereby regulating bladder activity ${ }^{22}$. This supports the assumption that the stimulating effect of EP3 in in vivo studies is based on its central effects. Importantly, it should be taken into account that, in this study, the effect was measured on muscarinic agonist induced contractions and not on baseline bladder activity.

When EP3 was inhibited prior to muscarinic stimulation, the amplitude decreased during the second phase of the contractile response. Generally, we would have expected the opposite effect of EP3 activation. EP3 activation had an inhibitory effect on frequency; EP3 inhibition decreases the amplitude of muscarinically induced contractions. Hence, both inhibition and activation had inhibitory effects on muscarinic contractile responses. The EP3 antagonist used in this study binds at higher concentrations not only to EP3, but also on EP4 receptors. In an additional study, we found that the effect on muscarinically induced contractions was even larger at concentrations at which EP4 was blocked additionally (unpublished data). Therefore, we assumed that EP4 was partly blocked at lower concentrations as well and that the effect of the EP3 inhibitor on muscarinically induced contractions shown in our study was, at least partly, due to inhibition of the EP4 receptor.

\section{Conclusion}

EP3 immune reactivity was found to be present in neuronal structures in the urothelial, suburothelial and muscle layers, as well as in urothelial and suburothelial interstitial cells. Activation of EP3 receptors in the urinary bladder decreased the frequency of muscarinically induced contractions. However, when centrally administered, stimulation of the EP3 receptor has been shown to have stimulating effects on bladder function. Therefore, the EP3 receptor could be an interesting target to modulate muscarinically induced contractions. However, future research should focus on elucidating the underlying mechanism by which this modulation works, as this is currently not yet fully understood. 


\section{References}

1. Rahnama'i MS, van Koeveringe GA, van Kerrebroeck PE, de Wachter SG. The effect of indomethacin on the muscarinic induced contractions in the isolated normal guinea pig urinary bladder. BMC urology. 2013;13:8.

2. Nile CJ, Gillespie JI. Interactions between cholinergic and prostaglandin signaling elements in the urothelium: role for muscarinic type 2 receptors. Urology. 2012 Jan;79(1):240 e17-23.

3. Ishizuka O, Mattiasson A, Andersson KE. Prostaglandin E2-induced bladder hyperactivity in normal, conscious rats: involvement of tachykinins? J Urol. 1995 Jun;153(6):2034-8.

4. Schroder A, Newgreen D, Andersson KE. Detrusor responses to prostaglandin E2 and bladder outlet obstruction in wild-type and Ep1 receptor knockout mice. J Urol. 2004 Sep;172(3):1166-70.

5. Schussler B. Comparison of the mode of action of prostaglandin E2 (PGE2) and sulprostone, a PGE2derivative, on the lower urinary tract in healthy women. A urodynamic study. Urol Res. 1990;18(5):349-52.

6. Kim JC, Park EY, Hong SH, Seo SI, Park YH, Hwang TK. Changes of urinary nerve growth factor and prostaglandins in male patients with overactive bladder symptom. Int J Urol. 2005 Oct;12(10):875-80.

7. Kim JC, Park EY, Seo SI, Park YH, Hwang TK. Nerve growth factor and prostaglandins in the urine of female patients with overactive bladder. J Urol. 2006 May;175(5):1773-6; discussion 6.

8. Yamauchi H, Akino H, Ito H, Aoki Y, Nomura T, Yokoyama O. Urinary prostaglandin E was increased in patients with suprapontine brain diseases, and associated with overactive bladder syndrome. Urology. 2010 Nov;76(5):1267 e13-9.

9. Rahnama'i MS, de Wachter SG, van Koeveringe GA, van Kerrebroeck PE, de Vente J, Gillespie Jl. The relationship between prostaglandin $\mathrm{E}$ receptor 1 and cyclooxygenase I expression in guinea pig bladder interstitial cells: proposition of a signal propagation system. J Urol. 2011 Jan;185(1):315-22.

10. Rahnama'i MS, Hohnen R, van Kerrebroeck PE, van Koeveringe GA. Evidence for prostaglandin E2 receptor expression in the intramural ganglia of the guinea pig urinary bladder. J Chem Neuroanat. 2015 Mar 23.

11. Rahnama'i MS, van Koeveringe GA, Essers PB, de Wachter SG, de Vente J, van Kerrebroeck PE, et al. Prostaglandin receptor EP1 and EP2 site in guinea pig bladder urothelium and lamina propria. J Urol. 2010 Mar;183(3):1241-7.

12. de Jongh R, van Koeveringe GA, van Kerrebroeck PE, Markerink-van Ittersum M, de Vente J, Gillespie JI. The effects of exogenous prostaglandins and the identification of constitutive cyclooxygenase I and II immunoreactivity in the normal guinea pig bladder. BJU Int. 2007 Aug;100(2):419-29.

13. Wang X, Momota Y, Yanase H, Narumiya S, Maruyama T, Kawatani M. Urothelium EP1 receptor facilitates the micturition reflex in mice. Biomed Res. 2008 Apr;29(2):105-11.

14. Kozaki Y, Kambe F, Hayashi Y, Ohmori S, Seo H, Kumazawa T, et al. Molecular cloning of prostaglandin EP3 receptors from canine sensory ganglia and their facilitatory action on bradykinin-induced mobilization of intracellular calcium. J Neurochem. 2007 Mar;100(6):1636-47.

15. Oida $H$, Namba $T$, Sugimoto $Y$, Ushikubi $F$, Ohishi $H$, Ichikawa A, et al. In situ hybridization studies of prostacyclin receptor mRNA expression in various mouse organs. Br J Pharmacol. 1995 Dec;116(7):2828-37.

16. Su X, Lashinger ES, Leon LA, Hoffman BE, Hieble JP, Gardner SD, et al. An excitatory role for peripheral EP3 receptors in bladder afferent function. American journal of physiology Renal physiology. 2008 Aug;295(2):F585-94.

17. Wang C, Li GW, Huang LY. Prostaglandin E2 potentiation of P2X3 receptor mediated currents in dorsal root ganglion neurons. Molecular pain. 2007;3:22.

18. McCafferty GP, Misajet BA, Laping NJ, Edwards RM, Thorneloe KS. Enhanced bladder capacity and reduced prostaglandin E2-mediated bladder hyperactivity in EP3 receptor knockout mice. Am J Physiol Renal Physiol. 2008 Aug;295(2):F507-14.

19. Jugus MJ, Jaworski JP, Patra PB, Jin J, Morrow DM, Laping NJ, et al. Dual modulation of urinary bladder activity and urine flow by prostanoid EP3 receptors in the conscious rat. $\mathrm{Br} J$ Pharmacol. 2009 Sep;158(1):372-81.

20. Grol S, Essers PB, van Koeveringe GA, Martinez-Martinez P, de Vente J, Gillespie JI. M(3) muscarinic receptor expression on suburothelial interstitial cells. BJU Int. 2009 Aug;104(3):398-405. 
21. Grol S, Nile CJ, Martinez-Martinez P, van Koeveringe G, de Wachter S, de Vente J, et al. M3 muscarinic receptor-like immunoreactivity in sham operated and obstructed guinea pig bladders. J Urol. 2011 May;185(5):1959-66.

22. Su X, Leon LA, Wu CW, Morrow DM, Jaworski JP, Hieble JP, et al. Modulation of bladder function by prostaglandin EP3 receptors in the central nervous system. Am J Physiol Renal Physiol. 2008 Oct;295(4):F98494. 


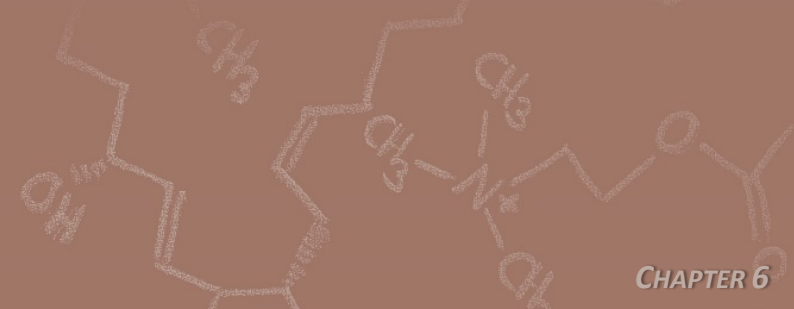

Regulatiory Pathways Involved in Detrusor

Underactivity-Potential Therapeutic

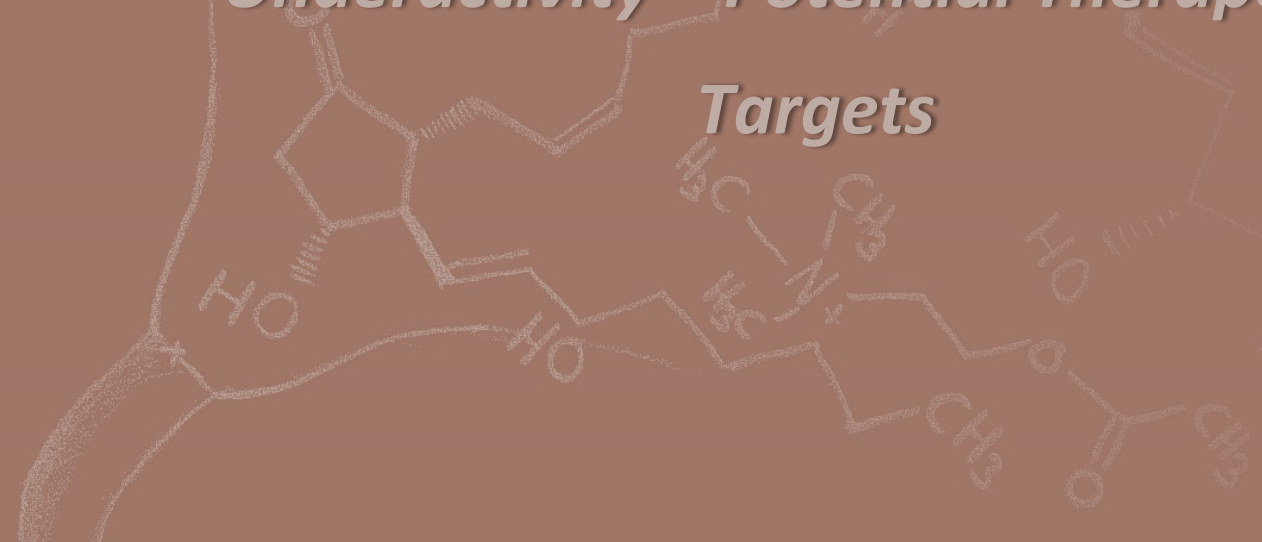




\section{Abstract}

Detrusor underactivity (DU) has been defined by the International Continence Society as a contraction of reduced strength and/or duration, resulting in prolonged bladder emptying and/or failure to achieve complete bladder emptying. Knowledge about the pathophysiological and molecular background of DU is limited. Aberrations in regulation of bladder contraction leading to DU can occur at several levels: 1 . urethral sensation, 2. sensation at bladder level, 3. within the central nervous system, 4. efferent processing/ bladder contractility. Potential targets for the treatment have been found at all different levels of lower urinary tract regulatory systems. Next to systems which are already known to play a role in bladder function, other possible treatment modalities have been identified, like stem cell therapy. In addition to the identification of new treatment targets, it is of utmost importance to identify the mechanisms leading to DU. Hormonal changes and processes accompanying oxidative stress are of great interest regarding this aspect. 


\section{Introduction}

The two major functions of the urinary bladder are storage of urine and emptying. Adequate bladder emptying requires a coordinated contraction of the bladder and relaxation of the urethra. Failure of this mechanism at any level in the 'brain - bladder' axis may result in complaints of a weak stream, recurrent urinary tract infections or post void residual. In general, these symptoms are considered as possible signs of an underactive bladder in humans. The International Continence Society (ICS) defined detrusor underactivity (DU) as a contraction of reduced strength and/or duration, resulting in prolonged bladder emptying and/or failure to achieve complete bladder emptying ${ }^{1}$. Compared to the overactive bladder, DU has received only little attention in recent years, mainly because of difficulties in evaluation. However, the topic is attracting research interest increasingly.

Detrusor underactivity is thought to be hidden behind other age related conditions, such as bladder outlet obstruction (BOO), more often than we think. Depending on the grade of obstruction and contractility characteristics of the bladder before BOO occurred, a compensatory state may remain for a variable period of time. Analogous to the human situation in bladder outlet obstruction, in animal models, prolonged outlet obstruction leads to bladder wall hypertrophy. An association has been shown with reduced blood flow to the smooth muscle cell layer, resulting in cyclic ischemia / reperfusion, and eventually muscle layer fibrosis and decreased vascularity ${ }^{2,3}$. In both, animals and humans these alterations in the chronic 'end stage' of BOO clinically present as either a thick fibrous, low capacity, poor contractile bladder or a high capacity, poor contractile bladder with a thin fibrous bladder wall ${ }^{4}$. This condition is often referred to as the decompensated state of the urinary bladder.

Bladder emptying issues are not only related to age. Incomplete emptying is also common in patients with bladder dysfunction caused by neurologic disease, for example in multiple sclerosis $(0-40 \%)^{5}$, Parkinson's disease $(53 \%)^{6}$, Multiple System Atrophy $(52-67 \%)^{7,8}$, and

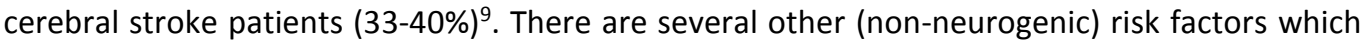
have been described ${ }^{10}$. Morphologically DU has been shown to be associated with increased collagen-to-muscle ratio, a decrease in neuronal innervation as well as a decrease in detrusor wall thickness. Despite all the risk factors described in the literature, only little is known about the pathophysiological and molecular background of $\mathrm{DU}^{11}$.

Multiple complex signalling systems play a role in the control of the urinary bladder. These systems are active in the end organ, in the spinal cord and the central nervous system. In this review, the potential treatment targets for DU in the various signalling systems will be 
described. More specifically the role of bladder and urethral sensation, afferent processing of signals, the interconnection between afferent and efferent signal processing, efferent signal processing, bladder contractility as well as the role of the urethra in bladder contraction will be discussed.

\section{Potential treatment targets involved in bladder sensory signalling}

Bladder sensation is an important process in voluntary control of micturition. If the brain would not get any information about the filling state of the urinary bladder, it would be impossible for the brain to estimate the appropriate time and place to void, or voiding will be initiated frequently to overcome and overfull bladder, or voiding will take place at an inappropriate time and place because the bladder is that full that it has to be emptied immediately. Delayed sensation could lead to DU, the detrusor contraction is not or too late initiated by stimuli from the central nervous system. Several structures are involved in bladder sensation; sensors and structures which are processing the sensory information towards the central nervous system (neuronal structures). A well-known example for sensors is stretch-sensitive receptors.

\section{Cholinergic System}

In the urinary bladder acetylcholine (ACh) has been shown to be released by the urothelium in response to chemical or mechanical stimulation in addition to the neuronal release as a neurotransmitter. Thus, both neuronal and non-neuronal ACh play a role in urinary bladder signalling, mostly in bladder sensation. Interestingly, intravesical administration of muscarinic or nicotinic receptor agonists or anticholinesterase inhibiting agents that increase the levels of endogenous ACh facilitates reflex bladder activity in rats and cats ${ }^{12}$. This finding indicates that there are probably potential new target mechanisms within the cholinergic system that are able to stimulate bladder activity. However, the exact mechanism still needs to be elucidated before specific targets can be identified.

\section{Purinergic System}

Adenosine triphosphate (ATP) plays an important role in bladder signalling and modulation of bladder signalling. It is co-released with ACh as neurotransmitter ${ }^{13}$, but can also be released by urothelial cells. Activation of ATP-specific receptors (P2X and P2Y receptors) will again increase the ATP release by the urothelium ${ }^{14}$. ATP-gated $P 2 Y$ receptors are expressed by suburothelial interstitial cells ${ }^{15}$, enabling them to respond to ATP released from the urothelium. Those cells 
probably act as a stretch-receptor organ together with afferent nerves, the urothelium and smooth muscle ${ }^{16}$. Therefore ATP seems to play an important role in bladder sensation. ATP is co-released with a yet unidentified smooth-muscle relaxant factor in response to cholinergic stimulation $^{12,17,18}$. ATP-specific receptors (P2X2 and P2X3) are expressed by afferent nerves and intravesical administration of ATP induces detrusor overactivity by activating these nerves ${ }^{19}$. Hence, increased activity of P2X2/P2X3 positive afferent nerves results in increased bladder activity. In this situation, receptor activation is clearly coupled to increased bladder activity and therefore this mechanism could be interesting on short/medium term to identify new targets to treat DU. For future research, it would be important to identify the exact mechanism by which the purinergic system can influence bladder sensation. Based on this investigation, a tool may be designed to target DU using the purinergic system.

\section{Vanilloids}

Bladder tissue expresses different classes of ion channels. Due to their ability to control ion inand efflux, depolarisation of the cell membrane is controlled. A well-known and -investigated class of ion channels expressed in the urinary bladder are transient receptor potential vanilloid (TRPV) channels. One member of the TRPV family is TRPV4, which is highly expressed in urothelial cells ${ }^{20}$. Smooth muscle cells of the urinary bladder express TRPV4 at lower levels ${ }^{20}$. A TRPV4 agonist increased the strength of contractions ${ }^{21}$. Next to increasing the strength of contractions, it has been hypothesised that TRPV4 agonists may increase the sensory input from the bladder to the spinal cord, thereby stimulating the voiding effect ${ }^{22}$. The effect of TRPV4 channel agonists in animal models of DU should be investigated in future studies to identify whether these substances are suitable as treatment targets for DU.

Another member of this family, the TRPV1 channel is expressed in nerve fibres within the detrusor muscle, submucosa and mucosa ${ }^{23,24}$. Activation of TRPV1 by capsaicin or other vanilloids results in membrane depolarisation and massive release of sensory neuropeptides, leading to desensitisation and cell death. Capsaicin excites C-fibres, leading to a period of prolonged desensitisation ${ }^{25}$. Furthermore, C-fibre afferents were functionally important in the pathogenesis of volume-dependent reflex contractions ${ }^{26-28}$. Taken together, strong activation of TRPV1 by capsaicin increases C-fibre activity, leading to a decrease in bladder sensation on the long term due to desensitisation. A crucial effect of this desensitisation is a decrease in bladder sensation. TRPV1 knockout mice showed an increased bladder capacity, comparable to DU 29 . Therefore, it would be interesting to determine whether a decreased amount of TRPV1 can be observed in patients with DU. 


\section{Macrophage migration inhibitory factor}

Macrophage migration inhibitory factor (MIF) is a pro-inflammatory cytokine and key mediator in bladder inflammation ${ }^{30}$. It is expressed by the urothelial cells ${ }^{30}$ and released via several inflammatory stimuli ${ }^{31}$. MIF knockout animals appear to be protected against an increase in collagen to muscle ratio and detrusor collagen after obstruction as well as a decrease in detrusor nucleated muscle counts, which was observed in wild type mice after obstruction ${ }^{32}$. Therefore, it seems likely that MIF plays a role in detrusor fibrosis and muscle cell loss after bladder outlet obstruction in vivo and is therefore an interesting target for further research on DU.

\section{Cannabinoids}

Cannabinoid receptors are G protein-coupled receptors, which are activated by cannabinoids. Both known subtypes of cannabinoid receptors, the cannabinoid receptor type 1 (CB1) and 2 (CB2), are expressed by the bladder in different species ${ }^{33,34}$, as well as in the central nervous system. In isolated bladders, stimulation of cannabinoid receptors inhibits contraction of bladder tissue ${ }^{33,34}$. However, theoretically, both receptors of cannabinoids should have contraction promoting effects, based on intracellular signalling cascades they work through. This discrepancy could be evoked by interference with other signalling systems. The theoretical effect on contraction only takes into account activation of the specific receptor and its signalling cascade and the effect on contraction. However, it could very well be that there is a cross talk in between different signalling systems, which is able to modify the response. There is still dispute which of the two cannabinoid receptors is responsible for the inhibitory effect. In CB1 knockout mice, the neuronal component of the contraction has been found to be different, indicating that a lack of CB1 receptors in the bladder is associated with a reduced release of contractionmediating transmitters ${ }^{35}$. Several studies have shown that activation of CB1 leads to an inhibited contractile response and sometimes even to reduced release of acetylcholine and reduced afferent nerve firing ${ }^{36-39}$. A CB1 receptor-specific antagonist was able to reverse the effect of CB1 activation on afferent nerve firing as shown by Walczak et al. ${ }^{39}$. Therefore, possibilities of CB1 antagonism need to be explored to a greater extent. More research is needed to investigate new treatment options for DU by influencing cannabinoid receptors. 


\section{Potential treatment targets involved in urethral sensory signalling}

It has been shown in animal and human studies that bladder control might at least partly be modulated by urethral signalling ${ }^{40}$. One example which shows clearly how important the urethra is in modulation of bladder contraction is the guarding reflex ${ }^{41}$. During contraction of the urethra, signals are sent via the pudendal nerve and spinal interneurons towards the bladder and motor neurons within the bladder wall are inhibited. In modulation of bladder activity by the urethra, different systems are involved. Regarding bladder contractility and the inducement of contractions, neuronal pathways will be discussed as well as hormones, transient receptor potential channels and muscarinic receptors.

\section{Pudendal nerve stimulation}

The pudendal nerve is the main nerve of the perineum and is responsible for the motor supply to external urethral sphincter as well as sending sensory information from the external genitalia towards the central nervous system. It has been shown in cats that electrical stimulation of pudendal nerve afferents results in both, inhibition and activation of the urinary bladder, depending on the urethral location of the stimulation and stimulation frequency ${ }^{42}$. By stimulation of the cranial urethral sensory nerve and the dorsal penile nerve, reflex bladder contractions can be evoked through a supraspinal and a spinal pathway, respectively ${ }^{43}$. Several studies showed that activity in pudendal afferents can lead to reflex bladder contractions and is able to initiate voiding ${ }^{43-45}$. Interestingly, this effect in response to pudendal nerve stimulation has been seen in humans as well. It has been shown that bladder contractions can be evoked by electrical stimulation of the proximal or distal urethra in patients with spinal cord injury ${ }^{46}$. As reflex bladder activity was recorded in individuals with complete or incomplete spinal cord injury, it has been suggested that these reflexes are mediated by spinal mechanisms ${ }^{46}$. The reflex responsible for this effect has been described by Barrington (Barrington's second reflex). Information of urethral flow is sent to the hind brain via pudendal nerves. Afterwards, efferent information is sent to the bladder by pelvic nerves, leading to bladder contraction. Electrical stimulation or neuromodulation of pudendal nerve afferents is a promising tool to treat DU and more research should be done on the underlying mechanism and how this tool can be adapted in patients. 


\section{Hormones}

Obvious natural age-related changes are alterations of several hormone levels, for example sexual hormones. These are involved in the regulatory control of bladder function. Both, estrogen and progesterone receptors are expressed within the bladder neck and the proximal urethra ${ }^{47-49}$ and hormonal decline during aging can lead to incontinence and urgency ${ }^{50,51}$. It has been shown that women receiving estrogen had a lower post void residual compared to those who do not receive additional estrogen ${ }^{52}$. This could be explained by various mechanisms, in which control estrogen is involved. Next to decreased levels of contractile muscle proteins ${ }^{53}$, lower levels of estrogen could lead to loss of caveolae ${ }^{54}$. Caveolae are small vesicles, involved in several signaling systems, such as calcium signalling. Thereby, a loss of caveolae could lead to a decrease in intracellular calcium entry ${ }^{54,55}$. In addition, decreased estrogen levels induce atrophy of the urogenital mucosa and involution of the vascular plexus ${ }^{56-59}$. Moreover, a lack of estrogen could contribute to DU by promoting axonal and muscle degeneration ${ }^{60}$. Disturbances regarding the extracellular matrix could involve estrogen as well, as higher collagenase activity was correlated with low concentrations of estrogen ${ }^{61}$. Thus, decreased levels of estrogen could possibly be associated with the development of DU. Testosterone replacement therapy improved bladder function by increasing bladder capacity and compliance and decreasing detrusor pressure at maximal flow in patients with symptomatic late-onset hypogonadism ${ }^{62}$. However, since testosterone deprivation plays an important role in bladder structure by increasing fibrosis and cell apoptosis in rats ${ }^{63}$, this could contribute to an association with DU as well. High density of collagen fibres, as they are present in decompensated bladders, were associated with rapidly decreasing testosterone levels ${ }^{63}$. Taken together, both estrogen and testosterone play a role in structure and function of the bladder wall.

\section{Transient receptor potential (TRP) channels}

One member of the transient receptor potential channel family is the transient receptor potential cation channel, member A1 (TRPA1). This receptor is generally known to be expressed by capsaicin-sensitive primary sensory neurons ${ }^{64}$ and activation leads amongst other effects to the local release of neurotransmitters in the periphery ${ }^{65}$. In the lower urinary tract, TRPA1 has been detected at different locations ${ }^{66}$. It has been shown to be present on capsaicin-sensitive primary sensory neurons in the rat bladder and on urothelial cells ${ }^{67}$. Furthermore, TRPA1 has been found on TRPV1-positive C-fibre bladder afferents ${ }^{67}$. In the human urethra, TRPA1 ion channels are expressed by sensory nerves, which also express TRPV1 and calcitonin gene related peptide $(\mathrm{cGRP})^{66}$. Vimentin-positive interstitial cells within the muscle layer on the 
boundaries of urethral smooth muscle bundles express TRPA1 as well ${ }^{66}$. TRPA1 detects stimuli such as mechanical stress, changes in temperature, pungent compounds, as well as various irritants $^{68}$ and can be activated by several irritants such as $\mathrm{H}_{2} \mathrm{~S}^{67}$ menthol ${ }^{69}$ and formalin ${ }^{70}$. Activation of TRPA1 has been shown to relax pre-contracted human urethra preparations ${ }^{66}$ and a role in afferent signalling from the human outflow region was suggested for TRPA ${ }^{66}$. However, it seems as if TRPA1 ion channels expressed on nerves are mainly involved in this effect and urothelial TRPA1 signals play a minor or no role in smooth muscle regulation of the normal human isolated urethra ${ }^{71}$. From this data, it can be concluded that TRPA1 agonists are in interesting target to treat DU and more research is needed to investigate the specific mechanism behind its effect and be able to target urethral TRPA1 receptors specifically.

\section{Muscarinic receptors}

In the urinary bladder, ACh has been shown to be released by the urothelium in response to chemical or mechanical stimulation in addition to the neuronal release as a neurotransmitter. Thus, neuronal and non-neuronal Ach play a role in urinary bladder signalling. In addition to the bladder, the urethral smooth muscle receives a rich cholinergic innervation ${ }^{72,73}$ and it has been shown that the muscarinic receptors $M 1, M 2$ and $M 3$ are involved in the mediation of contraction evoked by carbachol stimulation in the circular muscle of the rabbit urethra ${ }^{74,75}$. However, a predominance of the $M 2$ receptor has been shown in rabbit and pig urethra ${ }^{74,76}$. It has been suggested that the involvement in modulation of contraction by $\mathrm{M} 2$ is more distinct in the circular than in the longitudinal muscles ${ }^{76}$. Only the proximal third of the circular urethral muscle showed contractions in response to carbachol ${ }^{76}$. Taking into account, that contraction of the urethra leads to relaxation of the urinary bladder by activation of the guarding reflex, relaxation of the urethra is necessary to evoke bladder contractions. Therefore, it should be further investigated whether an increased contraction of the urethra, probably via increased cholinergic activation, could be a mechanistic cause of DU.

\section{Potential treatment targets within the central nervous system}

To be able to void at an appropriate time and place, afferent/sensory signals from the bladder conveying the fill level etc., are received by higher brain regions and processed further. When an appropriate time and place to void is determined, signals are sent towards the bladder via efferent pathways. This interconnection of afferent and efferent signal processing is another point of action where intervention could lead to a new treatment modality for DU. In addition 
to possible psychogenic treatment possibilities which are outside the scope of this paper, the following targets can be identified.

\section{Gamma-aminobutyric acid}

Gamma-aminobutyric acid (GABA) is one of the two highly prevalent inhibitory amino acid neurotransmitters, responsible for micturition regulation ${ }^{77}$. Two general classes of GABA receptors are known, i.e. $G_{A B A}$ and $G A B A_{B}$ receptors. After intrathecal injection of either $G_{A B A_{A}}$ or $G_{A B A}$ agonists bladder capacity increased and voiding pressure decreased in rats ${ }^{77}$ and in a small clinical trial of three subjects, intrathecal administration of a $G_{A B A_{A}}$ receptor agonist increased the volume threshold for inducing the micturition reflex ${ }^{78}$. By inhibition of GABA, using receptor antagonists, inhibitory mechanisms could be switched off, which would probably lower the threshold of micturition, thereby opening up new points of action for potential treatment targets for DU.

\section{Glycine}

Glycine is, next to GABA, the second most abundant inhibitory amino acid neurotransmitter which is responsible for micturition regulation ${ }^{79}$. Extracellular glycine concentration is regulated by the two $\mathrm{Na}^{+} / \mathrm{Cl}^{-}$-dependent glycine transporters (GlyT1 and GlyT2) ${ }^{80}$. Inhibition of GlyT2 decreased the intercontraction interval and micturition threshold in cyclophosphamide-treated rats, which was fully restored by the receptor antagonist strychnine ${ }^{81}$. Furthermore, decreased levels of glycine have been detected in the spinal cord of rats with detrusor overactivity secondary to chronic spinal cord injury. This decrease as well as the detected bladder overactivity were restored by dietary glycine supplement administration ${ }^{82}$. Taken together, it would be useful to investigate the effect of glycine receptor antagonists like strychnine in animal models of DU. However, when developing potential treatment strategies involving glycine and its receptors, it should be taken into account that the ability to select the appropriate moment of micturition remains unaltered.

\section{Dopamine}

Dopaminergic pathways induce different effects on the micturition reflex, dependent on the receptor subtype which is involved. D1-like dopaminergic receptors (D1 and D5 subtypes) facilitate the micturition reflex, whereas D2-like receptors (D2, D3 or D4 subtypes) have an inhibitory effect on micturition ${ }^{83-90}$. In awake rats, inhibition of D1 receptors facilitated the 
micturition reflex ${ }^{86}$ and microinjection of dopamine into the pontine micturition centre reduced bladder capacity and facilitated the micturition reflex in cats ${ }^{91}$. However, activation of central D2 dopaminergic receptors facilitated the micturition reflex pathway in rats and monkeys ${ }^{85,87-90}$, probably due to interactions with/within the brainstem. In the striatum, dopamine levels are increased during the urine storage phase ${ }^{92}$. Thus, D1 receptor-specific antagonists could be an interesting tool to treat DU at the interconnection point of afferent and efferent signaltransduction. However, again possible consequences for the conscious control of micturition have to be taken into account when these treatment possibilities are considered.

\section{Potential treatment targets aiming at the detrusor contractile mechanism}

Bladder contraction can be regulated at different levels on the efferent side. Efferent neuronal pathways can be changed, the innervation of the bladder itself or local regulatory systems modulating bladder contractility could be altered. All of them should be taken into consideration when searching for new treatment targets for DU.

\section{Oxidative stress}

Oxidative stress and the generation of reactive oxygen species (ROS) as a consequence of ischemia and reperfusion in the urinary bladder may play an important role in the pathophysiology of DU. An overview of the underlying mechanism of this hypothesis is presented in Figure 1.

In healthy conditions, the bladder undergoes constantly episodes of bladder ischemia and repeated ischemia/reperfusion events during a micturition cycle ${ }^{93}$. During these events, ROS are produced as well. However, under physiological conditions, the bladder seems to be able to handle this by its own protective mechanisms to prevent ROS-induced damage ${ }^{93}$. If the damage gets to intense, these mechanisms fail and free oxygen radicals induce bladder dysfunction by attacking and damaging cell membranes, mostly those of nerves and synapses ${ }^{94}$. This leads to apoptosis and thus bladder denervation. Furthermore, severe ischemia/reperfusion events, which can lead to decreased contractility, lead to increased intracellular calcium $\left(\mathrm{Ca}^{2+}\right)$ levels and therefore activation of $\mathrm{Ca}^{2+}$ - specific hydrolytic enzymes such as phospholipase A2 and calpain $^{95}$. These enzymes damage cellular and subcellular bladder membrane structures, especially neuronal and synaptic membranes, leading to apoptosis and denervation of the detrusor muscle ${ }^{96}$. 


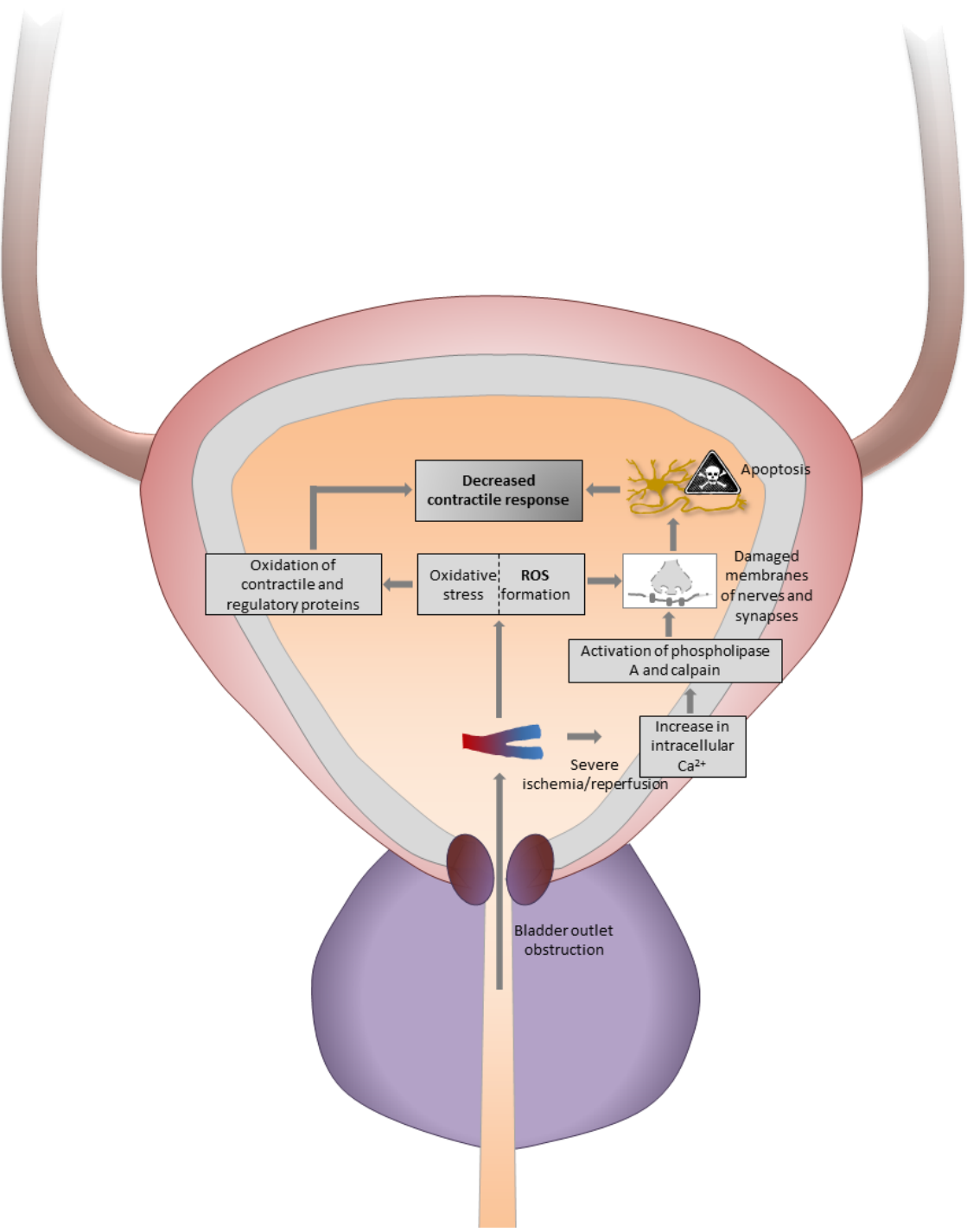

Figure 1. Underlying mechanism of a decreased contractile response induced by oxidative stress and ROS formation. Bladder outlet obstruction can lead to severe ischemia/reperfusion events inside the bladder wall. Subsequently, oxidative stress and ROS formation are induced as well as increased intracellular $\mathrm{Ca}^{2+}$, followed by activation of phospholipase $A$ and calpain, leading to damaged membranes of nerves and synapses. In addition to phospholipase $A$ and calpain, damage of neural membranes and synapses can be induced by ROS. These damages lead to apoptosis of neural cells, resulting in decreased contractility. Furthermore, contractile and regulatory proteins are altered by oxidation due to oxidative stress, leading also to a decreased contractile response. 
During ischemia/reperfusion events, as they occur also after acute urinary retention, great amounts of ROS are produced and bladder dysfunction is caused by these free radicals ${ }^{97}$. However, ischemia alone did not worsen bladder smooth muscle contraction induced by carbachol and $\mathrm{KCl}$, but subsequent reperfusion $\mathrm{did}^{98}$. Thus, it seems that reperfusion plays a more important role in the development of bladder dysfunction after ischemia/reperfusion insults, as free radicals are mainly produced during this phase ${ }^{99}$. It has been shown that ischemia caused bladder dysfunction and decreased contractile responses in vivo and in vitro $^{96,100-102}$. Free radical scavengers and antioxidants prevent bladder dysfunction due to ischemia/reperfusion events ${ }^{97,103,104}$. Apoptosis after ischemia/reperfusion in animals with acute urinary retention and subsequent bladder emptying was associated with decreased Manganese superoxide dismutase (MnSOD) expression and increased poly (ADP-ribose) polymerase (PARP) activity $^{105}$. MnSOD is a major mitochondrial antioxidant enzyme involved in the suppression of apoptosis, via regulation of the Bcl-2 family proteins such as B-cell lymphoma $2(\mathrm{Bcl}-2)$ and the $B C L 2$-associated $X$ protein $(B a x)^{106,107}$. As mentioned before, nerves have an increased sensitivity to apoptosis after ischemia/reperfusion, leading to bladder denervation.

Bladder denervation seems to be one of the key events leading to bladder dysfunction after ischemia/reperfusion events as the response to neurogenic stimulation was more sensitive to ischemia and reperfusion than myogenic contractile responses to carbachol, ATP and $\mathrm{KCl}$ in rat bladders $^{108}$. This is in accordance with the reduced ACh-esterase staining of nerves, and thus increasing denervation in detrusor muscle biopsies taken from patients with $\mathrm{BOO}^{109}$. It has been hypothesised that, if bladder ischemia/reperfusion becomes severe, progression of denervation and damage to detrusor muscle may cause DU and voiding symptoms ${ }^{110}$. In addition to denervation, ROS can cause oxidation of contractile and regulatory proteins in the urinary bladder and thereby induce contractile dysfunction ${ }^{111,112}$. Selective protein oxidation and elevated levels of desmin were measured after BOO, while $\alpha$-smooth muscle actin and $\beta$-actin did not change ${ }^{113}$. In an oxidated form, desmin may have a compromised ability to perform normal contractile or regulatory activities in the cell, which will lead to impaired bladder contractile function ${ }^{113}$. Thus, taken together, severe ischemia/reperfusion leads to increased generation of ROS, which results in detrusor dysfunction via two mechanisms, i.e. oxidation of contractile proteins and bladder denervation. In general, this could be prevented by inducing vasodilatation during obstruction, since administration of a vasodilator (an inducible form of nitric oxide synthase) prevented detrusor dysfunction after $\mathrm{BOO}^{114}$. Furthermore, administration of antioxidants and free radical scavengers could eliminate the increased amount of ROS presence and therefore overcome protein oxidation and bladder denervation. 


\section{Nitric oxide}

Nitric oxide (NO) is released by the urothelium as a response to stress ${ }^{115,116}$ and considered as an inhibitory neurotransmitter in various areas of afferent and efferent neuronal systems. Inhibition of the NO-producing enzyme NO synthase (NOS) increased bladder contraction frequency ${ }^{117}$ and Munoz et al. showed an increased NO release in underactive bladders in the rat $^{118}$. Since NO was increased in underactive bladders and inhibition of the NO-producing enzyme increased bladder contraction frequency, it is certainly an interesting target for future research on DU.

\section{Prostanoid system}

Prostaglandin E2 (PGE2) is released by the urothelium in response to stretch ${ }^{119}$. Under healthy conditions, PGs are produced by cyclooxygenase enzyme type 1 (COX-1) during bladder extension ${ }^{120}$. Cyclooxygenase enzyme type 2 (COX-2) acts mostly in pathological conditions ${ }^{121}$. $P_{G} E_{2}$ exerts its effects by binding to one of its four prostaglandin $E$ receptors (EP), classified as EP1-4. Recently, two studies investigated the effect and tolerability of a combined EP2 and EP3 receptor agonist ${ }^{122,123}$. In vitro studies showed that application of this agonist led to contraction of the bladder and relaxation of the urethra ${ }^{123}$. Furthermore, this agonist improved bladder function in a monkey model for DU by increasing the voided volume per micturition and the maximum flow rate ${ }^{123}$. In a first study conducted in humans, it has been shown that this EP2/EP3 agonist was generally well tolerated ${ }^{122}$. To summarize, stimulation of EP2 and EP3 is a promising tool to improve bladder function in individuals with DU. However, additional studies are needed to investigate if the effect detected in monkeys is also present in humans.

\section{Melastin}

Another subfamily of TRP receptors are the transient receptor potential melastin (TRPM) channels. Activation of the TRPM type 4 (TRPM4) channel, which is expressed in for example guinea pig detrusor muscle cells ${ }^{124}$, led to depolarisation of the membrane resulting in enhanced activity of voltage-dependent $\mathrm{Ca}^{2+}$ channels to favour $\mathrm{Ca}^{2+}$ entry, thereby modulating $\mathrm{Ca}^{2+}$ signalling ${ }^{125}$. In the guinea pig, an inhibition of the TRPM4 receptor decreased spontaneous phasic activity, and decreased pharmacologically induced and nerve-evoked contractions of detrusor strips ${ }^{124}$. It will be valuable to investigate the possible effects of specific agonists to this receptor, thereby probably increasing bladder contraction amplitudes. 


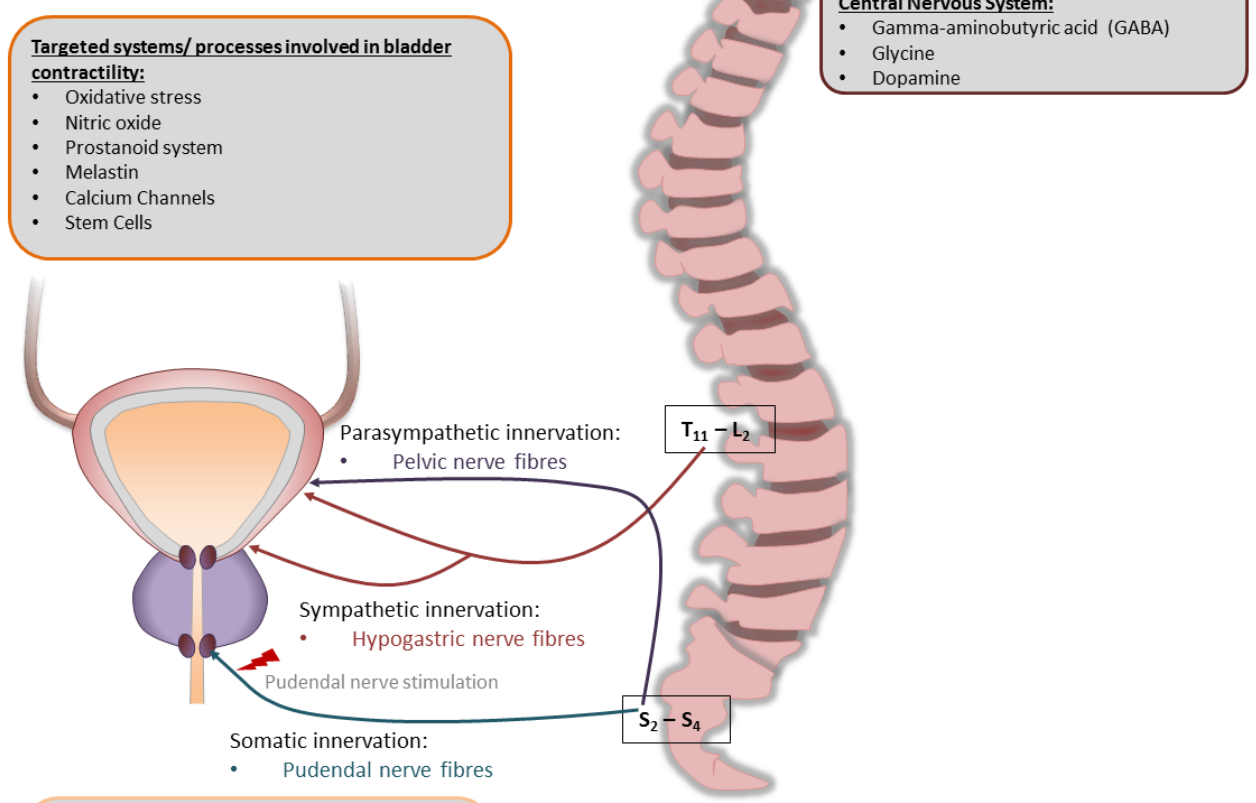

Targeted systems/ processes involved in bladder
sensory signalling:
- Cholinergic system
- Purinergic system
- Manilloids
- Cannabhage migration inhibitory factor (MIF)

Targeted systems/processes involved in urethral sensory signalling:

- Pudendal nerve stimulation

- Hormones

- Transient receptor potential (TRP) channels

Muscarinic receptors

Figure 2. Targeted systems involved in regulation of bladder contractions. Various systems are involved in the regulation of bladder contraction and interference can take place at several levels of lower urinary tract regulatory systems, both peripherally and centrally. Sensation can be influenced at bladder and urethral levels. Within the bladder wall, the cholinergic and purinergic systems, as well as vanilloids, cannabinoids and the macrophage migration inhibitory factor offer potential targets to alter sensation for the treatment of DU. Within the urethra, hormones, transient receptor potential channels and muscarinic receptors are of interest, as well as pudendal nerve stimulation. Processing of the sensory signals takes place in the central nervous system, involving GABA, glycine and dopamine as potential targets. Moreover, modulation of contractility at bladder level offers interesting treatment options for DU, involving oxidative stress, nitric oxide, the prostanoid system, melastin, calcium channels and stem cells. 


\section{Calcium channels}

$\mathrm{Ca}^{2+}$-activated $\mathrm{K}^{+}\left(\mathrm{K}_{\mathrm{ca}}\right)$ channels are present in the urinary bladder and are in general subdivided into three groups, i.e. large conductance $\mathrm{K}_{\mathrm{Ca}}$ (BK) channels, small-conductance (SK)- and intermediate conductance $\mathrm{K}_{\mathrm{Ca}}$ channels ${ }^{126}$. In the guinea pig urinary bladder, SK channels have been shown to be present and functional in the detrusor muscle ${ }^{127}$. The selective SK channel opener SKA-31 significantly decreased human detrusor smooth muscle excitability and contractility by selective potentiation of the SK channel activity ${ }^{128}$. Hence, selective blockage could probably increase bladder activity, thereby providing a possible treatment target for DU.

\section{Stem cells}

Stem cell therapy may offer a treatment option for DU as well. Tremp et al. used adult stem cells to evaluate the use of them for the treatment of bladder voiding dysfunctions. Bladder hypocontractility was induced using the obstruction model and autologous stem cells (adiposederived stem cells and muscle precursor cells) were injected directly into the damaged bladder tissue at multiple locations. The stem cell treatment after obstruction resulted in improved voiding pressures and a reduced connective tissue-to-muscle ratio compared to only obstructed animals. Furthermore, an increase in the expression of the contractile proteins was measured after stem cell therapy ${ }^{129}$.

Overall, stem cell therapy is a promising approach to be able to treat voiding dysfunction, and therefore also DU in future. This therapeutic option might be useful especially in case of irreversible fibrosis or muscle loss, provided the prerequisite that functional innervation will be present. However, the process of differentiation into smooth muscle cells with all its required growth promoting factors has to be investigated in more detail to optimise this technique and adapt it towards a specific clinical situation. Furthermore, ethical problems have to be solved by using dedifferentiated somatic cells for example.

\section{Conclusion}

Potential new therapeutic targets for the treatment of DU have been found at all different levels of lower urinary tract regulatory systems (Figure 2). Usually, targets which modulate bladder contractility directly would be in focus when new treatment targets have to be identified. However, this review showed that targets for new treatment modalities can be found at all different levels from bladder sensation to contractility. Next to systems which are already known to play a role in bladder function, other possible treatment modalities have been 
identified, like stem cell therapy. In addition to the identification of new treatment targets, it is of utmost importance to identify the mechanisms leading to DU. Hormonal changes and processes accompanying oxidative stress are of great interest regarding this aspect. However, to be more precise about predictions regarding the effectivity of those targets that were identified, appropriate animal models of DU are needed for testing. To test the clinical treatment effects, adequate and validated diagnostic tools are needed for diagnosis and follow up. 


\section{References}

1. Abrams P, Cardozo L, Fall M, Griffiths D, Rosier P, Ulmsten U, et al. The standardisation of terminology in lower urinary tract function: report from the standardisation sub-committee of the International Continence Society. Urology. 2003 Jan;61(1):37-49.

2. Gosling JA, Kung LS, Dixon JS, Horan P, Whitbeck C, Levin RM. Correlation between the structure and function of the rabbit urinary bladder following partial outlet obstruction. J Urol. 2000 Apr;163(4):1349-56.

3. Schroder A, Chichester P, Kogan BA, Longhurst PA, Lieb J, Das AK, et al. Effect of chronic bladder outlet obstruction on blood flow of the rabbit bladder. J Urol. 2001 Feb;165(2):640-6.

4. Levin RM, Haugaard N, O'Connor L, Buttyan R, Das A, Dixon JS, et al. Obstructive response of human bladder to $\mathrm{BPH}$ vs. rabbit bladder response to partial outlet obstruction: a direct comparison. Neurourol Urodyn. 2000;19(5):609-29.

5. de Seze M, Ruffion A, Denys P, Joseph PA, Perrouin-Verbe B, Genulf. The neurogenic bladder in multiple sclerosis: review of the literature and proposal of management guidelines. Multiple sclerosis. 2007 Aug;13(7):915-28.

6. Sakakibara R, Uchiyama T, Yamanishi T, Shirai K, Hattori T. Bladder and bowel dysfunction in Parkinson's disease. Journal of neural transmission. 2008;115(3):443-60.

7. Sakakibara R, Hattori T, Uchiyama T, Yamanishi T. Videourodynamic and sphincter motor unit potential analyses in Parkinson's disease and multiple system atrophy. J Neurol Neurosurg Psychiatry. 2001 Nov;71(5):600-6.

8. Bloch F, Pichon B, Bonnet AM, Pichon J, Vidailhet M, Roze E, et al. Urodynamic analysis in multiple system atrophy: characterisation of detrusor-sphincter dyssynergia. Journal of neurology. 2010 Dec;257(12):1986-91.

9. Tibaek S, Gard G, Klarskov P, Iversen HK, Dehlendorff C, Jensen R. Prevalence of lower urinary tract symptoms (LUTS) in stroke patients: a cross-sectional, clinical survey. Neurourol Urodyn. 2008;27(8):763-71.

10. van Koeveringe GA, Vahabi B, Andersson KE, Kirschner-Herrmans R, Oelke M. Detrusor underactivity: a plea for new approaches to a common bladder dysfunction. Neurourol Urodyn. 2011 Jun;30(5):723-8.

11. van Koeveringe GA, Rademakers KL, Birder LA, Korstanje C, Daneshgari F, Ruggieri MR, et al. Detrusor underactivity: Pathophysiological considerations, models and proposals for future research. ICI-RS 2013. Neurourol Urodyn. 2014 Jun;33(5):591-6.

12. Hawthorn MH, Chapple CR, Cock M, Chess-Williams R. Urothelium-derived inhibitory factor(s) influences on detrusor muscle contractility in vitro. Br J Pharmacol. 2000 Feb;129(3):416-9.

13. Fry CH, Meng E, Young JS. The physiological function of lower urinary tract smooth muscle. Auton Neurosci. 2010 Apr 19;154(1-2):3-13.

14. Birder LA. Urothelial signaling. Auton Neurosci. 2009 Feb 16;153(1-2):33-40.

15. Wu C, Sui GP, Fry CH. Purinergic regulation of guinea pig suburothelial myofibroblasts. J Physiol. 2004 Aug 15;559(Pt 1):231-43.

16. Wiseman OJ, Fowler CJ, Landon DN. The role of the human bladder lamina propria myofibroblast. BJU Int. 2003 Jan;91(1):89-93.

17. Beckel JM, Kanai A, Lee SJ, de Groat WC, Birder LA. Expression of functional nicotinic acetylcholine receptors in rat urinary bladder epithelial cells. Am J Physiol Renal Physiol. 2006 Jan;290(1):F103-10.

18. Yoshida M, Miyamae K, Iwashita H, Otani M, Inadome A. Management of detrusor dysfunction in the elderly: changes in acetylcholine and adenosine triphosphate release during aging. Urology. 2004 Mar;63(3 Suppl 1):17-23.

19. Rong W, Spyer KM, Burnstock G. Activation and sensitisation of low and high threshold afferent fibres mediated by P2X receptors in the mouse urinary bladder. J Physiol. 2002 Jun 1;541(Pt 2):591-600.

20. Everaerts W, Nilius B, Owsianik G. The vanilloid transient receptor potential channel TRPV4: from structure to disease. Prog Biophys Mol Biol. 2010 Sep;103(1):2-17.

21. Young JS, Johnston L, Soubrane C, McCloskey KD, McMurray G, Eccles R, et al. The passive and active contractile properties of the neurogenic, underactive bladder. BJU Int. 2013 Feb;111(2):355-61.

22. Everaerts W, De Ridder D. Unravelling the underactive bladder: a role for TRPV4? BJU Int. 2013 Feb;111(2):353-4. 
23. Avelino A, Cruz C, Nagy I, Cruz F. Vanilloid receptor 1 expression in the rat urinary tract. Neuroscience. 2002;109(4):787-98.

24. Birder LA, Kanai AJ, de Groat WC, Kiss S, Nealen ML, Burke NE, et al. Vanilloid receptor expression suggests a sensory role for urinary bladder epithelial cells. Proc Natl Acad Sci U S A. 2001 Nov 6;98(23):13396-401.

25. Jancso N, Jancso-Gabor A, Szolcsanyi J. The role of sensory nerve endings in neurogenic inflammation induced in human skin and in the eye and paw of the rat. British journal of pharmacology and chemotherapy. 1968 May;33(1):32-41.

26. Cheng CL, Liu JC, Chang SY, Ma CP, de Groat WC. Effect of capsaicin on the micturition reflex in normal and chronic spinal cord-injured cats. Am J Physiol. 1999 Sep;277(3 Pt 2):R786-94.

27. de Groat WC, Kawatani M, Hisamitsu T, Cheng CL, Ma CP, Thor K, et al. Mechanisms underlying the recovery of urinary bladder function following spinal cord injury. J Auton Nerv Syst. 1990 Jul;30 Suppl:S71-7.

28. Yoshimura N, de Groat WC. Plasticity of $\mathrm{Na}+$ channels in afferent neurones innervating rat urinary bladder following spinal cord injury. J Physiol. 1997 Sep 1;503 ( Pt 2):269-76.

29. Caterina MJ, Leffler A, Malmberg AB, Martin WJ, Trafton J, Petersen-Zeitz KR, et al. Impaired nociception and pain sensation in mice lacking the capsaicin receptor. Science. 2000 Apr 14;288(5464):306-13.

30. Meyer-Siegler KL, Iczkowski KA, Vera PL. Macrophage migration inhibitory factor is increased in the urine of patients with urinary tract infection: macrophage migration inhibitory factor-protein complexes in human urine. J Urol. 2006 Apr;175(4):1523-8.

31. Vera PL, Iczkowski KA, Leng L, Bucala R, Meyer-Siegler KL. Macrophage migration inhibitory factor is released as a complex with alpha1-inhibitor-3 in the intraluminal fluid during bladder inflammation in the rat. $J$ Urol. 2005 Jul;174(1):338-43.

32. Taylor JA, Zhu Q, Irwin B, Maghaydah Y, Tsimikas J, Pilbeam C, et al. Null mutation in macrophage migration inhibitory factor prevents muscle cell loss and fibrosis in partial bladder outlet obstruction. Am J Physiol Renal Physiol. 2006 Dec;291(6):F1343-53.

33. Bakali E, Elliott RA, Taylor AH, Willets J, Konje JC, Tincello DG. Distribution and function of the endocannabinoid system in the rat and human bladder. Int Urogynecol J. 2013 May;24(5):855-63.

34. Gratzke C, Streng T, Park A, Christ G, Stief CG, Hedlund P, et al. Distribution and function of cannabinoid receptors 1 and 2 in the rat, monkey and human bladder. $J$ Urol. 2009 Apr;181(4):1939-48.

35. Fullhase C, Campeau L, Sibaev A, Storr M, Hennenberg M, Gratzke C, et al. Bladder function in a cannabinoid receptor type 1 knockout mouse. BJU Int. 2014 Jan;113(1):144-51.

36. Hayn $\mathrm{MH}$, Ballesteros I, de Miguel F, Coyle $\mathrm{CH}$, Tyagi S, Yoshimura $\mathrm{N}$, et al. Functional and immunohistochemical characterization of $\mathrm{CB} 1$ and $\mathrm{CB} 2$ receptors in rat bladder. Urology. 2008 Nov;72(5):1174-8.

37. Pertwee RG, Fernando SR. Evidence for the presence of cannabinoid CB1 receptors in mouse urinary bladder. Br J Pharmacol. 1996 Aug;118(8):2053-8.

38. Tyagi V, Philips BJ, Su R, Smaldone MC, Erickson VL, Chancellor MB, et al. Differential expression of functional cannabinoid receptors in human bladder detrusor and urothelium. J Urol. 2009 Apr;181(4):1932-8.

39. Walczak JS, Price TJ, Cervero F. Cannabinoid CB1 receptors are expressed in the mouse urinary bladder and their activation modulates afferent bladder activity. Neuroscience. 2009 Mar 31;159(3):1154-63.

40. Birder LA, de Wachter S, Gillespie J, Wyndaele JJ. Urethral sensation: basic mechanisms and clinical expressions. Int J Urol. 2014 Apr;21 Suppl 1:13-6.

41. Park JM, Bloom DA, McGuire EJ. The guarding reflex revisited. Br J Urol. 1997 Dec;80(6):940-5.

42. Woock JP, Yoo PB, Grill WM. Intraurethral stimulation evokes bladder responses via 2 distinct reflex pathways. J Urol. 2009 Jul;182(1):366-73.

43. Yoo PB, Woock JP, Grill WM. Bladder activation by selective stimulation of pudendal nerve afferents in the cat. Experimental neurology. $2008 \mathrm{Jul} ; 212(1): 218-25$.

44. Boggs JW, Wenzel BJ, Gustafson KJ, Grill WM. Frequency-dependent selection of reflexes by pudendal afferents in the cat. J Physiol. 2006 Nov 15;577(Pt 1):115-26.

45. Tai C, Wang J, Wang X, de Groat WC, Roppolo JR. Bladder inhibition or voiding induced by pudendal nerve stimulation in chronic spinal cord injured cats. Neurourol Urodyn. 2007;26(4):570-7.

46. Yoo PB, Horvath EE, Amundsen CL, Webster GD, Grill WM. Multiple pudendal sensory pathways reflexly modulate bladder and urethral activity in patients with spinal cord injury. J Urol. 2011 Feb;185(2):737-43.

47. Batra SC, losif CS. Female urethra: a target for estrogen action. J Urol. 1983 Feb;129(2):418-20. 
48. Batra SC, losif CS. Progesterone receptors in the female lower urinary tract. J Urol. 1987 Nov;138(5):1301-4.

49. Seidlova-Wuttke D, Schultens A, Jarry H, Wuttke W. Urodynamic effects of estradiol (E2) in ovariectomized (ovx) rats. Endocrine. $2004 \mathrm{Feb} ; 23(1): 25-32$.

50. Smith PG, Bradshaw S. Innervation of the proximal urethra of ovariectomized and estrogen-treated female rats. Histology and histopathology. 2004 Oct;19(4):1109-16.

51. Zucchi EV, Jarmy-Di Bella Zl, Castro RA, Takano CC, Simoes MJ, Girao MJ, et al. Influence of estrogen replacement and aging on the expression of nerve growth factor in the urethra of female rats. Neurourol Urodyn. 2012 Jun;31(5):702-5.

52. Stern JA, Hsieh YC, Schaeffer AJ. Residual urine in an elderly female population: novel implications for oral estrogen replacement and impact on recurrent urinary tract infection. J Urol. 2004 Feb;171(2 Pt 1):768-70.

53. Sanchez-Ortiz RF, Wang Z, Menon C, DiSanto ME, Wein AJ, Chacko S. Estrogen modulates the expression of myosin heavy chain in detrusor smooth muscle. Am J Physiol Cell Physiol. 2001 Mar;280(3):C433-40.

54. Zhu Q, Resnick NM, Elbadawi A, Kuchel GA. Estrogen and postnatal maturation increase caveolar number and caveolin-1 protein in bladder smooth muscle cells. J Urol. 2004 Jan;171(1):467-71.

55. Lai HH, Boone TB, Yang G, Smith CP, Kiss S, Thompson TC, et al. Loss of caveolin-1 expression is associated with disruption of muscarinic cholinergic activities in the urinary bladder. Neurochemistry international. 2004 Dec;45(8):1185-93.

56. Endo RM, Girao MJ, Sartori MG, Simoes MJ, Baracat EC, Rodrigues de Lima G. Effect of estrogen-progestogen hormonal replacement therapy on periurethral and bladder vessels. International urogynecology journal and pelvic floor dysfunction. 2000;11(2):120-3.

57. Hashimoto T, Ishigooka M, Zermann DH, Sasagawa I, Nakada T. Effects of estrogen and progesterone on urinary bladder in female rabbit: evaluation by quantitative morphometric analysis. Urology. 1999 Mar;53(3):642-6.

58. Suguita M, Giraio MJ, Simoes MJ, Sartori MG, Baracat EC, Rodrigues de Lima GR. A morphologic and morphometric study of the vesical mucosa and urethra of castrated female rats following estrogen and/or progestogen replacement. Clinical and experimental obstetrics \& gynecology. 2000;27(3-4):176-8.

59. Zucchi EV, Sartori MG, Jarmy-Di Bella ZK, da Silva ID, Rodrigues de Lima G, Girao MJ. Expression of vascular endothelial growth factor in the lower urinary tract in rats after castration and estrogen administration. Menopause. 2006 May-Jun;13(3):500-5.

60. Zhu Q, Ritchie J, Marouf N, Dion SB, Resnick NM, Elbadawi A, et al. Role of ovarian hormones in the pathogenesis of impaired detrusor contractility: evidence in ovariectomized rodents. J Urol. 2001 Sep;166(3):1136-41.

61. Sato T, Ito A, Mori Y, Yamashita K, Hayakawa T, Nagase H. Hormonal regulation of collagenolysis in uterine cervical fibroblasts. Modulation of synthesis of procollagenase, prostromelysin and tissue inhibitor of metalloproteinases (TIMP) by progesterone and oestradiol-17 beta. Biochem J. 1991 May 1;275 (Pt 3):64550.

62. Karazindiyanoglu S, Cayan S. The effect of testosterone therapy on lower urinary tract symptoms/bladder and sexual functions in men with symptomatic late-onset hypogonadism. The aging male : the official journal of the International Society for the Study of the Aging Male. 2008 Sep;11(3):146-9.

63. Lorenzetti F, Pintarelli VL, Seraphim DC, Dambros M. Low testosterone levels induce apoptosis via active 3caspase dependent signaling in the bladder wall of male rats. Aging Male. 2012 Dec;15(4):216-9.

64. Story GM, Peier AM, Reeve AJ, Eid SR, Mosbacher J, Hricik TR, et al. ANKTM1, a TRP-like channel expressed in nociceptive neurons, is activated by cold temperatures. Cell. 2003 Mar 21;112(6):819-29.

65. Everaerts W, Gevaert T, Nilius B, De Ridder D. On the origin of bladder sensing: $\operatorname{Tr}(i)$ ps in urology. Neurourol Urodyn. 2008;27(4):264-73.

66. Gratzke C, Streng T, Waldkirch E, Sigl K, Stief C, Andersson KE, et al. Transient receptor potential A1 (TRPA1) activity in the human urethra--evidence for a functional role for TRPA1 in the outflow region. Eur Urol. 2009 Mar;55(3):696-704.

67. Streng T, Axelsson HE, Hedlund P, Andersson DA, Jordt SE, Bevan S, et al. Distribution and function of the hydrogen sulfide-sensitive TRPA1 ion channel in rat urinary bladder. Eur Urol. 2008 Feb;53(2):391-9.

68. Nilius B, Owsianik G, Voets T, Peters JA. Transient receptor potential cation channels in disease. Physiol Rev. 2007 Jan;87(1):165-217. 
69. Karashima Y, Damann N, Prenen J, Talavera K, Segal A, Voets T, et al. Bimodal action of menthol on the transient receptor potential channel TRPA1. J Neurosci. 2007 Sep 12;27(37):9874-84.

70. McNamara CR, Mandel-Brehm J, Bautista DM, Siemens J, Deranian KL, Zhao M, et al. TRPA1 mediates formalin-induced pain. Proc Natl Acad Sci U S A. 2007 Aug 14;104(33):13525-30.

71. Weinhold P, Gratzke C, Streng T, Stief C, Andersson KE, Hedlund P. TRPA1 receptor induced relaxation of the human urethra involves TRPV1 and cannabinoid receptor mediated signals, and cyclooxygenase activation. $J$ Urol. 2010 May;183(5):2070-6.

72. Andersson KE. New roles for muscarinic receptors in the pathophysiology of lower urinary tract symptoms. BJU Int. 2000 Oct;86 Suppl 2:36-42; discussion -3.

73. Mattiasson A, Andersson KE, Andersson PO, Larsson B, Sjogren C, Uvelius B. Nerve-mediated functions in the circular and longitudinal muscle layers of the proximal female rabbit urethra. J Urol. 1990 Jan;143(1):155-60.

74. Mutoh S, Latifpour J, Saito M, Weiss RM. Evidence for the presence of regional differences in the subtype specificity of muscarinic receptors in rabbit lower urinary tract. J Urol. 1997 Feb;157(2):717-21.

75. Nagahama K, Tsujii T, Morita T, Azuma H, Oshima H. Differences between proximal and distal portions of the male rabbit posterior urethra in the physiological role of muscarinic cholinergic receptors. Br J Pharmacol. 1998 Jul;124(6):1175-80.

76. Yamanishi T, Chapple CR, Yasuda K, Yoshida K, Chess-Williams R. The role of M2 muscarinic receptor subtypes mediating contraction of the circular and longitudinal smooth muscle of the pig proximal urethra. $J$ Urol. 2002 Jul;168(1):308-14.

77. Igawa Y, Mattiasson A, Andersson KE. Effects of GABA-receptor stimulation and blockade on micturition in normal rats and rats with bladder outflow obstruction. J Urol. 1993 Aug;150(2 Pt 1):537-42.

78. Bushman W, Steers WD, Meythaler JM. Voiding dysfunction in patients with spastic paraplegia: urodynamic evaluation and response to continuous intrathecal baclofen. Neurourol Urodyn. 1993;12(2):163-70.

79. Miyazato M, Sugaya K, Nishijima S, Ashitomi K, Hatano T, Ogawa Y. Inhibitory effect of intrathecal glycine on the micturition reflex in normal and spinal cord injury rats. Experimental neurology. 2003 Sep;183(1):232-40.

80. Zafra F, Aragon C, Olivares L, Danbolt NC, Gimenez C, Storm-Mathisen J. Glycine transporters are differentially expressed among CNS cells. J Neurosci. 1995 May;15(5 Pt 2):3952-69.

81. Yoshikawa S, Oguchi T, Funahashi Y, de Groat WC, Yoshimura N. Glycine transporter type 2 (GlyT2) inhibitor ameliorates bladder overactivity and nociceptive behavior in rats. Eur Urol. 2012 Oct;62(4):704-12.

82. Miyazato M, Sugaya K, Nishijima S, Ashitomi K, Morozumi M, Ogawa Y. Dietary glycine inhibits bladder activity in normal rats and rats with spinal cord injury. $J$ Urol. 2005 Jan;173(1):314-7.

83. Albanese A, Jenner P, Marsden CD, Stephenson JD. Bladder hyperreflexia induced in marmosets by 1-methyl4-phenyl-1,2,3,6-tetrahydropyridine. Neurosci Lett. 1988 Apr 22;87(1-2):46-50.

84. Hashimoto K, Oyama T, Sugiyama T, Park YC, Kurita T. Neuronal excitation in the ventral tegmental area modulates the micturition reflex mediated via the dopamine D1 and D2 receptors in rats. J Pharmacol Sci. 2003 Jun;92(2):143-8.

85. Kontani H, Inoue T, Sakai T. Dopamine receptor subtypes that induce hyperactive urinary bladder response in anesthetized rats. Jpn J Pharmacol. 1990 Dec;54(4):482-6.

86. Seki S, Igawa Y, Kaidoh K, Ishizuka O, Nishizawa O, Andersson KE. Role of dopamine D1 and D2 receptors in the micturition reflex in conscious rats. Neurourol Urodyn. 2001;20(1):105-13.

87. Yokoyama O, Yoshiyama M, Namiki M, de Groat WC. Glutamatergic and dopaminergic contributions to rat bladder hyperactivity after cerebral artery occlusion. Am J Physiol. 1999 Apr;276(4 Pt 2):R935-42.

88. Yoshimura N, Kuno S, Chancellor MB, De Groat WC, Seki S. Dopaminergic mechanisms underlying bladder hyperactivity in rats with a unilateral 6-hydroxydopamine (6-OHDA) lesion of the nigrostriatal pathway. $\mathrm{Br} J$ Pharmacol. 2003 Aug;139(8):1425-32.

89. Yoshimura N, Mizuta E, Kuno S, Sasa M, Yoshida O. The dopamine D1 receptor agonist SKF 38393 suppresses detrusor hyperreflexia in the monkey with parkinsonism induced by 1-methyl-4-phenyl-1,2,3,6tetrahydropyridine (MPTP). Neuropharmacology. 1993 Apr;32(4):315-21.

90. Yoshimura N, Mizuta E, Yoshida O, Kuno S. Therapeutic effects of dopamine D1/D2 receptor agonists on detrusor hyperreflexia in 1-methyl-4-phenyl-1,2,3,6-tetrahydropyridine-lesioned parkinsonian cynomolgus monkeys. J Pharmacol Exp Ther. 1998 Jul;286(1):228-33. 
91. de Groat W, Roppolo JR, Yoshimura N, Sugaya K. Neural control of the urinary bladder and colon. In: Taché Y, Wingate D, Burks T, editors. Innervation of the gut: Pathophysiological implications. Boca Raton, Florida: CRC Press; 1994. p. 167-90.

92. Yamamoto T, Sakakibara R, Hashimoto K, Nakazawa K, Uchiyama T, Liu Z, et al. Striatal dopamine level increases in the urinary storage phase in cats: an in vivo microdialysis study. Neuroscience. 2005;135(1):299303.

93. Greenland JE, Brading AF. Urinary bladder blood flow changes during the micturition cycle in a conscious pig model. J Urol. 1996 Nov;156(5):1858-61.

94. Shimizu S, Saito M, Kinoshita Y, Kazuyama E, Tamamura M, Satoh I, et al. Acute urinary retention and subsequent catheterization cause lipid peroxidation and oxidative DNA damage in the bladder: preventive effect of edaravone, a free-radical scavenger. BJU Int. 2009 Sep;104(5):713-7.

95. Zhao Y, Levin SS, Wein AJ, Levin RM. Correlation of ischemia/reperfusion or partial outlet obstructioninduced spectrin proteolysis by calpain with contractile dysfunction in rabbit bladder. Urology. 1997 Feb;49(2):293-300.

96. Levin RM, Levin SS, Zhao Y, Buttyan R. Cellular and molecular aspects of bladder hypertrophy. Eur Urol. 1997;32 Suppl 1:15-21.

97. Lin AT, Chen KK, Yang CH, Chang LS. Mannitol facilitates rabbit urinary bladder recovery from overdistension injury. Urology. 2000 Oct 1;56(4):702-7.

98. Yuan WS, Xu L, Liu MD, Wang YB, Li D. [The different contraction between rat gastric longitudinal and circular smooth muscle induced by extracellular nucleotides]. Zhongguo ying yong sheng li xue za zhi= Zhongguo yingyong shenglixue zazhi = Chinese journal of applied physiology. 2014 Jan;30(1):14-7.

99. Li C, Jackson RM. Reactive species mechanisms of cellular hypoxia-reoxygenation injury. Am J Physiol Cell Physiol. 2002 Feb;282(2):C227-41.

100. Bratslavsky G, Kogan B, Levin RM. Urethra is more sensitive to ischemia than bladder: evidence from an in vitro rat study. J Urol. 2001 Jun;165(6 Pt 1):2086-90.

101. Bratslavsky G, Whitbeck C, Horan P, Levin RM. Effects of in vivo ischemia on contractile responses of rabbit bladder to field stimulation, carbachol, ATP and KCl. Pharmacology. 1999 Oct;59(4):221-6.

102. Lin AT, Chen MT, Yang CH, Chang LS. Blood flow of the urinary bladder: effects of outlet obstruction and correlation with bioenergetic metabolism. Neurourol Urodyn. 1995;14(3):285-92.

103. Matsumoto S, Hanai T, Yoshioka N, Shimizu N, Sugiyama T, Uemura H, et al. Edaravone protects against ischemia/reperfusion-induced functional and biochemical changes in rat urinary bladder. Urology. 2005 Oct;66(4):892-6.

104. Pessina F, Marazova K, Ninfali P, Avanzi L, Manfredini S, Sgaragli G. In vitro neuroprotection by novel antioxidants in guinea-pig urinary bladder subjected to anoxia-glucopenia/reperfusion damage. Naunyn Schmiedebergs Arch Pharmacol. 2004 Dec;370(6):521-8.

105. Li WJ, Shin MK, Oh SJ. Time dependent bladder apoptosis induced by acute bladder outlet obstruction and subsequent emptying is associated with decreased MnSOD expression and Bcl-2/Bax ratio. J Korean Med Sci. 2010 Nov;25(11):1652-6.

106. Sharma DR, Sunkaria A, Bal A, Bhutia YD, Vijayaraghavan R, Flora SJ, et al. Neurobehavioral impairments, generation of oxidative stress and release of pro-apoptotic factors after chronic exposure to sulphur mustard in mouse brain. Toxicol Appl Pharmacol. 2009 Oct 15;240(2):208-18.

107. Xu Z, Lin S, Wu W, Tan H, Wang Z, Cheng C, et al. Ghrelin prevents doxorubicin-induced cardiotoxicity through TNF-alpha/NF-kappaB pathways and mitochondrial protective mechanisms. Toxicology. 2008 May 21;247(2-3):133-8.

108. Bratslavsky G, Kogan BA, Matsumoto S, Aslan AR, Levin RM. Reperfusion injury of the rat bladder is worse than ischemia. J Urol. 2003 Nov;170(5):2086-90.

109. Gosling JA, Gilpin SA, Dixon JS, Gilpin CJ. Decrease in the autonomic innervation of human detrusor muscle in outflow obstruction. J Urol. 1986 Aug;136(2):501-4.

110. Yamaguchi O, Nomiya M, Andersson KE. Functional consequences of chronic bladder ischemia. Neurourol Urodyn. 2013 Nov 30.

111. Andersson KE, Arner A. Urinary bladder contraction and relaxation: physiology and pathophysiology. Physiol Rev. 2004 Jul;84(3):935-86. 
112. Mannikarottu A, Lin AD, Whitebeck C, Leggett R, Kogan B, Levin R. Effect of partial bladder outlet obstruction on nitrotyrosine levels and their correlation with contractile function. Neurourol Urodyn. 2006;25(4):397-401.

113. Siflinger-Birnboim A, Levin RM, Hass MA. Partial outlet obstruction of the rabbit urinary bladder induces selective protein oxidation. Neurourol Urodyn. 2008;27(6):532-9.

114. Lemack GE, Zimmern PE, Vazquez D, Connell JD, Lin VK. Altered response to partial bladder outlet obstruction in mice lacking inducible nitric oxide synthase. J Urol. 2000 Jun;163(6):1981-7.

115. Birder LA. Urinary bladder urothelium: molecular sensors of chemical/thermal/mechanical stimuli. Vascul Pharmacol. 2006 Oct;45(4):221-6.

116. Birder LA, Nakamura Y, Kiss S, Nealen ML, Barrick S, Kanai AJ, et al. Altered urinary bladder function in mice lacking the vanilloid receptor TRPV1. Nat Neurosci. 2002 Sep;5(9):856-60.

117. Ozawa $\mathrm{H}$, Chancellor MB, Jung SY, Yokoyama T, Fraser MO, Yu Y, et al. Effect of intravesical nitric oxide therapy on cyclophosphamide-induced cystitis. J Urol. 1999 Dec;162(6):2211-6.

118. Munoz A, Smith CP, Boone TB, Somogyi GT. Overactive and underactive bladder dysfunction is reflected by alterations in urothelial ATP and NO release. Neurochem Int. 2011 Feb;58(3):295-300.

119. Birder LA. More than just a barrier: urothelium as a drug target for urinary bladder pain. Am J Physiol Renal Physiol. 2005 Sep;289(3):F489-95.

120. Poggesi L, Nicita G, Castellani S, Selli C, Galanti G, Turini D, et al. The role of prostaglandins in the maintenance of the tone of the rabbit urinary bladder. Invest Urol. 1980 May;17(6):454-8.

121. Frolich JC. A classification of NSAIDs according to the relative inhibition of cyclooxygenase isoenzymes. Trends Pharmacol Sci. 1997 Jan;18(1):30-4.

122. Chapple C, Bruce M, Ohno T, Kuwayama T, Deacon S. Safety, tolerability and pharmacokinetics of single and multiple ascending doses of the EP2/EP3 receptor agonist ONO-8055, a potential new therapy for Underactive Bladder, in healthy subjects AUA Annual meeting; New Orleans, LA, USA2015.

123. Matsuya H, Otsuki T, Kida J, Wakamatsu D, Okada H, Sekido N. ONO-8055, a novel and potent prostanoid EP2 and EP3 receptor dual agonist, improves voiding dysfunction in a monkey underactive bladder model AUA Annual Meeting; New Orleans, LA, USA2015.

124. Smith AC, Hristov KL, Cheng Q, Xin W, Parajuli SP, Earley S, et al. Novel role for the transient potential receptor melastatin 4 channel in guinea pig detrusor smooth muscle physiology. Am J Physiol Cell Physiol. 2013 Mar 1;304(5):C467-77.

125. Fliegert R, Glassmeier G, Schmid F, Cornils K, Genisyuerek S, Harneit A, et al. Modulation of Ca2+ entry and plasma membrane potential by human TRPM4b. FEBS J. 2007 Feb;274(3):704-13.

126. Petkov GV. Role of potassium ion channels in detrusor smooth muscle function and dysfunction. Nat Rev Urol. 2012 Jan;9(1):30-40.

127. Parajuli SP, Soder RP, Hristov KL, Petkov GV. Pharmacological activation of small conductance calciumactivated potassium channels with naphtho[1,2-d]thiazol-2-ylamine decreases guinea pig detrusor smooth muscle excitability and contractility. J Pharmacol Exp Ther. 2012 Jan;340(1):114-23.

128. Soder RP, Parajuli SP, Hristov KL, Rovner ES, Petkov GV. SK channel-selective opening by SKA-31 induces hyperpolarization and decreases contractility in human urinary bladder smooth muscle. Am J Physiol Regul Integr Comp Physiol. 2013 Jan 15;304(2):R155-63.

129. Tremp M, Salemi S, Largo R, Andersson KE, J AP, Aboushwareb T, et al. Adipose-derived stem cells (ADSCs) and muscle precursor cells (MPCs) for the treatment of bladder voiding dysfunction. World J Urol. $2013 \mathrm{Nov}$ 12. 


The urinary bladder is controlled by both the central nervous system in combination with spinal cord reflexes. In addition, there is an intrinsic control mechanism within the bladder wall ${ }^{1}$. In this thesis, the study of local control mechanisms of the bladder has been the focus. More specifically, the role of prostaglandins (PGs), phosphodiesterases (PDEs) and intramural ganglia has been discussed. Both morphological investigations, and ex vivo experiments were designed to elucidate the role of the prostanoid system in the modulation of muscarinically induced contractions. In this chapter, the obtained results are discussed in view of new insights into bladder function and their potential role as targets in bladder pharmacotherapy.

\section{Intramural ganglia - the link between autonomy and central regulation?}

Intramural ganglia are detected in the bladder wall of several species, i.e. human, pig and guinea pig $^{2-4}$ and it is likely that the network of intramural ganglia in the urinary bladder is part of a motor-sensory system and receives afferent input. In the human bladder, the ganglia have been shown to receive multiple synaptic contacts ${ }^{2}$. Intramural ganglia are assumed to relay activity of the parasympathetic nerves to the smooth muscle in order to initiate the micturition contraction ${ }^{5}$.

The intramural ganglia of the guinea pig urinary bladder are discussed in chapter 2 . We found immune reactivity for two $\mathrm{PGE}_{2}$-specific receptors, prostaglandin E type receptor 1 (EP1) and 2 (EP2), in the cytoplasm of intramural ganglia, closely surrounded by interstitial cells and PGproducing cyclooxygenase-1 (COX-1)-positive cells. Interstitial cells with processes originating near the urothelium are likely to send collateral axons to the intramural ganglia and might therefore be responsible for sensory modulation ${ }^{6}$. Furthermore, it has been suggested that the intramural ganglia are interconnected ${ }^{5}$, and they might be influenced by messenger molecules, such as prostaglandins. This hypothesis was strengthened by data obtained in our study ${ }^{6}$. Outputs generated in the intramural ganglia are most likely to target the detrusor muscle. Moreover, we hypothesised that ganglia might interconnect two different regulatory systems which were present within the bladder wall. These systems are the cholinergic neuronal system and the complex network of suburothelial and intramural interstitial cells, which can pick up sensory signals carried by messenger molecules such as adenosine triphosphate (ATP), cyclic guanosine monophosphate (cGMP), and prostaglandins. Ganglia receive information from both systems, making interconnection likely. In this way, sensory information is processed and regulated within the bladder wall. Data from previous studies support the assumption that ganglia form the interconnection between a molecular sensory system arranged by interstitial cells, to a cholinergic neuronal system ${ }^{5,7}$, involving the urothelium. The urothelium can produce 
and release various substances, e.g. ATP, nitric oxide (NO) ${ }^{8-11}$ and prostaglandins, ${ }^{12}$ and these substances have been shown to influence afferent nerves ${ }^{8-11}$. Any of these agents, released during rapid bladder emptying, can activate the interstitial cells and through ganglia, activation of sensory fibres results in inhibition. Therefore, chemical stimulation of afferents by substances released from the urothelium can influence local motor activity with or without information being processed to the central nervous system, depending on complex processing of the ganglia within the bladder wall. Hence, ganglia located within the bladder wall can be considered to be the link between autonomous and central regulation of bladder activity.

\section{PDEs and bladder contraction}

The urothelium is capable of producing a great variety of substances in response to chemical or mechanical stimuli. One of these substances is $\mathrm{NO}^{13}$. In this thesis, we presented a study on the NO/cGMP system. As described in chapter $3, \mathrm{NO}$ is produced by the urothelium ${ }^{10}$, and could have its effects on suburothelial interstitial cells ${ }^{13}$. cGMP is produced from GTP under NO stimulation. Phosphodiesterases are involved in the cyclic nucleotide metabolism and catalyse the reaction from cyclic adenosine monophosphate (CAMP) and cGMP to AMP and GMP, both playing a role in non-micturition activity. While cGMP activates phasic activity, cAMP has an inhibitory effect ${ }^{14,15}$. Inappropriate regulation of autonomous activity is considered to lead to bladder overactivity ${ }^{16}$. PDE1 and PDE5 inhibitors have been studied clinically for their effect on bladder relaxation and as a potential treatment for overactive bladder syndrome (OAB). However, the reported success was limited ${ }^{17,18}$.

The PDE1 inhibitor vinpocetin relaxed pre-contracted strips of human detrusor muscle ${ }^{19,20}$, and reduced clinical symptoms in patients with urgency and urgency incontinence ${ }^{17}$. Inhibition of PDE5 by zaprinast had minor effects on human bladder smooth muscle tone ${ }^{19}$ but high doses of several PDE5 inhibitors were able to relax pre-contracted bladder strips ${ }^{21-25}$. PDE5 inhibition had no effect on contractile responses on electric field stimulation, ATP and potassium chloride, but supresses contractions induced by carbachol administration ${ }^{26}$. In anaesthetised rats, PDE5 inhibition prolonged the inter-micturition interval ${ }^{22}$, and chronic treatment reduced nonvoiding contractions in a bladder outlet obstruction model ${ }^{21}$. PDE5 is as PDE2 a cGMP-dependent PDE. This raises the possibility that PDE2 could influence bladder contraction as well.

The results presented in chapter 3, provided the first evidence for the presence of PDE2 activity in the guinea pig urinary bladder. In the urothelium, PDE2 activity was detected at the level of the umbrella cells. Intermediate and basal urothelial cells showed a significant lower PDE2 activity. In the lamina propria, PDE2 activity was found in the interstitial cells of the 
suburothelium, forming a network which was distributed throughout the muscle layers. In addition, PDE2 activity was shown in nerve fibres located within the lamina propria and muscle layer.

The different expression pattern of PDE2 activity and the localisation in different layers of the urothelium, suggests different functions of these layers. The difference in function of the different urothelial layers has been described before, and a sensory function of the umbrella cells has been suggested ${ }^{27}$. This indicates that PDE2 might have a role in initiating contraction by the breakdown of cGMP once stretch is sensed by the mechanosensors of the urothelium.

In the lamina propria, PDE2 activity has been detected in interstitial cells and nerve fibres. Following bladder outlet obstruction, changes in the proliferation of the networks of NOresponsive interstitial cells have been demonstrated in the guinea pig urinary bladder ${ }^{28}$. In isolated mouse bladders, it has been shown that the only cells responding to NO are the interstitial cells on the outer muscle bundles. After exposure to a muscarinic agonist, phasic activity developed, which was abolished by exogenous $\mathrm{NO}^{29}$. This suggests a role for NOresponsive interstitial cells in phasic activity. NO stimulates the production of cGMP, which is broken down by PDE2. Therefore, inhibition of PDE2 could have a similar effect compared to NO on phasic activity and would therefore be an interesting target for new treatment modalities for detrusor overactivity.

We also detected PDE2 activity in nerves within the lamina propria and muscle layer. This can be associated with the fact that the pathophysiologic mechanisms underlying $O A B$ have been shown to involve at least partly alterations in bladder afferent fibre activity. Hence, we can hypothesise that PDE2 could play a role in these pathological changes. The bladder is innervated by two types of afferent nerves: the myelinated A-delta and unmyelinated C-fibres ${ }^{30}$. In normal conditions, mechano-sensitive A-delta fibres are activated by distension and urothelial stretching resulting from a progressive increase in stored urine. Subsequently, these fibres convey sensations of bladder fullness during the bladder filling phase to spinal and supraspinal centres coordinating the micturition reflex. In contrast, the usually silent C-fibres have been shown to get activated in a prominent role under pathophysiological conditions, where they become hyperexcitable and therefore are responsible for inducing detrusor hyperactivity ${ }^{31}$. In our study, nerves which were stained for calcitonin gene related peptide (cGRP), synaptic vesicle protein 2 (SV2), neurofilament and the general neuronal marker protein gene product 9.5 (PGP 9.5) also showed PDE2 activity. This suggests that PDE2 could play a role in signal transduction through the nervous system. Both neurofilament and cGRP-positive nerve fibres are considered afferent fibres and co-stained with cGMP after PDE2 inhibition. The 
concept of urothelial and suburothelial cells releasing chemical mediators which consequently affect neural activity and ultimately the threshold for bladder afferent nerve activation has been proven before ${ }^{32}$. This implies that modulation of PDE2 activity could modulate the sensory signal processing.

Furthermore, our data also showed the efferent nerve marker SV2 co-staining with PDE2 activity, pointing to a possible modulatory effect on the motor signal transmission. Therefore, it seems likely, that modulation of PDE2 could modulate the nervous signal transduction of the urinary bladder. In conclusion, PDE2 could modulate bladder activity at several levels urothelium, interstitial cells, afferent and efferent nerves - and could therefore be promising in the search for treatment targets OAB.

\section{PGE2 and bladder control}

Another local regulatory mechanism of the bladder is the prostanoid system. PGE 2 is released by the urothelium in response to mechanical and chemical stimuli ${ }^{33}$, and PGE 2 -specific receptors are expressed by different structures throughout the bladder wall ${ }^{27,34}$. Prostaglandins (PGs) are widely known as substances playing a key role in inflammation ${ }^{35}$. PGE 2 exerts its effects by binding to one of its specific receptors, which are classified into four subtypes (EP1 - EP4) ${ }^{36}$. Recent research from our group in Maastricht revealed the EP1 and EP2 expression in different layers of the urinary bladder 27,34 . In chapter 4 of this thesis a study on the expression of the EP3 receptor revealed presence of the EP3 receptor in the urinary bladder of the guinea pig. More specifically, it has been located in neuronal structures within the muscle layer, suburothelium and urothelium. In addition, suburothelial interstitial cells and urothelial cells expressed the EP3 receptor. Increased levels of $\mathrm{PGE}_{2}$ have been found in the urine samples of patients suffering from the overactive bladder syndrome ${ }^{37,38}$, and administration of $\mathrm{PGE}_{2}$ directly into the human urinary bladder has been shown to cause strong sensations of urgency ${ }^{39}$. In animals, intravesical instillation of $\mathrm{PGE}_{2}$ has been shown to provoke detrusor overactivity, probably through activation of sensory bladder afferent neurons ${ }^{40-43}$. Inhibition of EP1 and EP2 reduced the effect of $P G E_{2}$ dose-dependently in isolated guinea pig bladders ${ }^{12}$. Intravesical administration of $P_{G} E_{2}$ itself or an EP1 agonist reduced significantly the inter-micturition interval ${ }^{44}$ in an in vivo mouse model. Inhibition of the $\mathrm{PGE}_{2}$-producing COX enzymes inhibited the micturition reflex in rats with bladder overactivity, which was less distinctive in control rats ${ }^{45}$.

On a molecular level, $\mathrm{PGE}_{2}$ induces the release of acetylcholine $(\mathrm{ACh})^{46}$. Moreover, stimulation with the muscarinic agonist arecaidine induces $P G E_{2}$ release ${ }^{46}$. Hence, $P_{G E}$ could be an interesting target to modulate muscarinically induced contractions. Thereby, modulation could 
reduce possible side effects of antimuscarinic medication by being able to lower the dose or by local instead of systemic administration.

The studies described in this thesis point out that stimulation with $\mathrm{PGE}_{2}$ prior to muscarinic stimulations induced an amplifying effect on muscarinically induced contractions. Assuming that a positive feedback mechanism, as it has been shown on a molecular level ${ }^{46}$, is also present in whole bladder preparations, it can be hypothesised that endogenous PGE2, produced through this positive feedback, has the same effect as exogenously administered PGE 2 . Hence, PGE 2 seems to amplify muscarinically induced contractions. Furthermore, we showed that inhibition of the $\mathrm{PGE}_{2}$-producing enzymes prior to arecaidine stimulation decreased the amplitude during the initial phase of the response. Again, this supports the theory of a positive feedback mechanism between $\mathrm{PGE}_{2}$ and $\mathrm{ACh}$ on a whole bladder/functional level.

A combined EP1/EP2 blocking agent reduced the effect of $\mathrm{PGE}_{2}$ dose-dependently in isolated guinea pig bladders ${ }^{12}$ and intravesical administration of an EP1 had a significant effect on the inter-micturition interval ${ }^{44}$. Therefore, we added an EP1 antagonist to isolated bladders and investigated the effect on arecaidine-induced responses. Inhibition of EP1 resulted in a decreased frequency of contractions during the second phase. However, this effect was not comparable to the effect which was seen after inhibition of the PGE2-producing COX enzymes by acetylsalicylic acid. This may reflect that other subtypes of $\mathrm{PGE}_{2}$-specific receptors (EP2-4) are involved in the signal transduction between $\mathrm{PGE}_{2}$ and $\mathrm{ACh}$. We also showed immune reactivity for EP3 predominantly in the urothelial and suburothelial layers. Within the muscle layer, the EP3 receptor immune reactivity was merely present in neuronal structures. In the urothelium, M3- and EP3-positive cells were in close proximity to each other. Therefore, a study was designed to investigate whether EP3 activation modulates muscarinically induced contractions in addition to the EP1 receptor. When EP3 was stimulated prior to muscarinic stimulations, the frequency of bladder contractions was reduced during the second phase of the arecaidine response. These findings were in conflict with existing literature about EP3 and bladder activity. In general, EP3 agonists have a stimulating, bladder activity enhancing effect ${ }^{47,48}$. The study on EP3 presented in this thesis has been conducted in an ex vivo setting. All available literature on EP3 and bladder activity was based on in vivo studies. It has been shown that EP3 had an effect on the central nervous system, thereby regulating bladder activity ${ }^{49}$. This supports the assumption that the stimulating effect of EP3 in in vivo studies is based on its central effects. In addition, it has to be taken into account that the effect on muscarinic agonistinduced contractions was measured in this study and not baseline bladder activity. Our studies showed that the prostanoid system is a potentially useful target to treat detrusor overactivity 
by indirect modulation of muscarinically induced contractions. Especially, the COX-enzymes, and the EP1 and EP3 receptors could be interesting targets to modulate muscarinically induced contractions. However, the mechanism via which this modulation works, still needs to be elucidated further.

\section{Interaction of PDE's, the prostanoid and the cholinergic systems in the urinary bladder}

The prostanoid system and the PDE control system as described above, are not independent systems, but have an interaction both with each other and the cholinergic system. Studies presented in this thesis investigated directly the interaction between the prostanoid and the cholinergic system. However, at the bladder level more interaction takes place, involving also PDEs. Bladder smooth muscle relaxation is substantially mediated by increased levels of CAMP $^{19,20,26}$. Increased levels of CAMP lead to the activation of Protein kinase $A$ and subsequently decrease calcium $\left(\mathrm{Ca}^{2+}\right)$ influx (Figure 1). An increase of cAMP levels can be achieved or by increasing its production via stimulation of adenylyl cyclase or by inhibition of its breakdown, which is mediated by cAMP- dependent PDEs. Inhibitors of the CAMP-dependent PDE4 induced relaxation on isolated bladder strips from various species, including humans ${ }^{19,20,26,50}$. In our study, the distribution of PDE2 was investigated in the guinea pig urinary bladder. PDE2 is both CAMP- and cGMP-dependent and inhibition of PDE2 could therefore also play a role in bladder relaxation due to increased cAMP levels. Activation of the muscarinic M2 receptor leads to inhibition of adenylyl cyclase ${ }^{51}$. However, even while the majority of muscarinic receptors in the urinary bladder is of the $M 2$ subtype, bladder function has been found to be mainly regulated by $M 3$ receptors ${ }^{52,53}$. Activation of the $M 3$ receptor induces bladder contraction in a direct way. Therefore, even if the effect on $M 2$ receptors may be minor, antimuscarinic drugs have a double effect on bladder contractions. First, inhibition of the $M 2$ receptor leads to an increase of cAMP in an indirect way. Second, inhibition of the M3 receptor prohibits its contractile effect. The effect of a PDE4 inhibitor and the muscarinic antagonist tolterodine, and its selectivity on non-voiding contractions versus voiding bladder contractions were compared in a $\mathrm{BOO}$ rat model ${ }^{54}$. The PDE4 inhibitor has been found to be more selective for non-voiding contractions ${ }^{54}$. Therefore, PDE4 or CAMP-dependent PDEs, in general, are interesting targets to investigate further, as new treatment modalities for detrusor overactivity. PDE2 degrades both, CAMP and cGMP. An increase of cGMP results in an increased activity of protein kinase $\mathrm{G}(\mathrm{PKG})$, resulting in a decrease of intracellular $\mathrm{Ca}^{2+}$ and therefore relaxation of bladder smooth muscle. In afferent nerves, this decrease in $\mathrm{Ca}^{2+}$ resulted in decreased neuropeptide release ${ }^{55}$. After exposure to NO, maximal levels of cGMP were detected in lamina propria and interstitial cells of the urinary bladder ${ }^{29,56-60}$. However, only a 
small amount of guanylyl cyclase is present in detrusor smooth muscle cells and therefore the effect of NO and cGMP-dependent PDEs, as PDE5, on bladder relaxation is limited ${ }^{61}$. Higher amounts of guanylyl cyclase have been found in afferent nerves and interstitial cells. Using the example of a PDE5 inhibitor, it has been shown that inhibition of a cGMP-dependent PDE leads to direct decrease in neuropeptide release in afferent nerves and reduced afferent firing rates ${ }^{61}$. In interstitial cells, inhibition of PDE5 resulted in decreased $\mathrm{Ca}^{2+}$ sparks and intrinsic contractions. These alterations can indirectly lead to a decrease in afferent firing ${ }^{61}$. As both mechanisms lead to decreased sensation, it can be concluded that cGMP-dependent PDEs exert their effects mainly on a bladder sensory level.

Besides the PDEs and the muscarinic system, the modulatory effect of the prostanoid system on muscarinically induced contractions is discussed in this thesis. PGE 2 is able to reinforce muscarinically induced contractions and this enhancement is, at least partly, mediated by the $\mathrm{PGE}_{2-}$ producing enzyme COX-1. However, how this enhancement is mediated in detail needs to be investigated further as it may influence several receptors and signalling systems. We investigated the role of two PGE 2 -specific receptors in more detail, EP1 and EP3. EP1 is able to directly induce contraction via activation of protein kinase $\mathrm{C}(\mathrm{PKC})$ and increasing $\mathrm{Ca}^{2+}$ influx. The EP3 receptor inhibits adenylyl cyclase, thereby decreasing the amount of cAMP. 


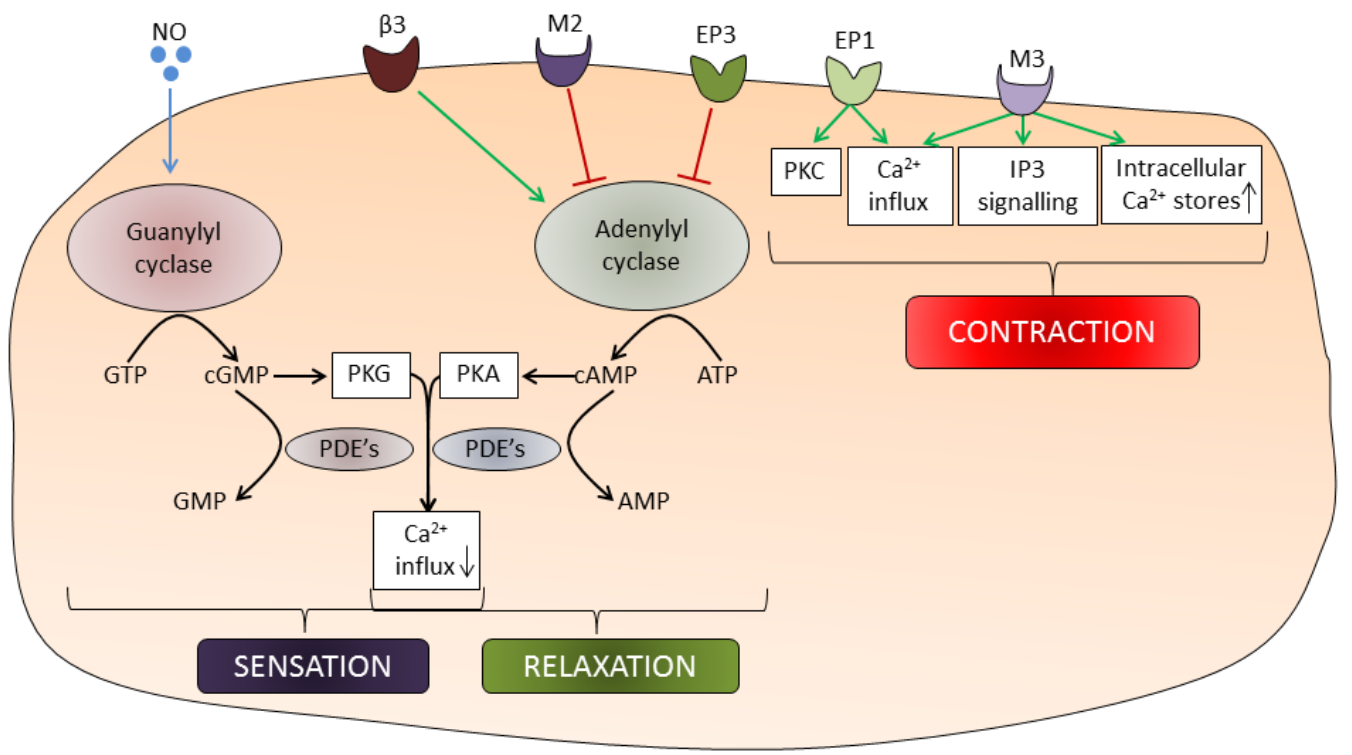

Figure 1. Interaction of signalling systems of the urinary bladder

Recently, a specific $\beta 3$-receptor agonist has been introduced as a treatment for OAB patients. Activation of the adrenergic $\beta 3$-receptor results in stimulation of adenylyl cyclase, thereby increasing the amount of cAMP in bladder smooth muscle cells. In physiological conditions, noradrenaline is released from sympathetic bladder efferent nerves during bladder filling and subsequently induces bladder relaxation due to activation of adenylyl cyclase ${ }^{62}$.

Direct modulation of bladder contraction can be roughly divided into two mechanisms.

1. One mechanism deals with direct induction of contraction, as it can be induced by EP1 or M3 activation.

2. The second mechanism plays a role in bladder contraction by influencing relaxation, where cAMP levels are of central importance.

In addition, bladder sensation plays a role in modulation of bladder contraction. While sensation and CAMP-dependent relaxation are of interest for $O A B$, sensation and direct induction of contraction could be attractive topics when searching for new treatment targets for detrusor underactivity. 


\section{Future research perspectives}

It is of both clinical and scientific interest to investigate alternative targets involved in bladder regulation in order to identify new treatment modalities for $O A B$ and detrusor underactivity (DU). The presented data in this thesis offer some potential targets for future (translational) research. We could demonstrate in this thesis that not only the appreciation of each separate regulatory system on bladder function is important, but that their complex interactions should be understood as well. Our ex vivo experiments showed a strong interaction between the prostanoid and the cholinergic systems. While PDE2 can potentially modulate sensation and relaxation by changes in CAMP or cGMP levels, the prostanoid system is likely to affect contraction and relaxation. Future research is needed to translate these findings into an in vivo situation. Especially for the effects of stimulation and inhibition of EP3, it is of most importance to determine which way of administration leads to which effect. It could very well be, that direct administration of drugs to the bladder by instillation evokes the opposite effect compared to systemic administration. The role of COX-1 inhibition in modulation of muscarinic induced contractions is an additional interesting approach to investigate in vivo. An interesting link that should be explored is towards the purinergic system. The purinergic system is an important signalling system in the urinary bladder, and interactions with the prostanoid and the cholinergic system have been shown. These aspects of bladder physiology need further elucidation. 


\section{References}

1. Drake MJ. The integrative physiology of the bladder. Ann R Coll Surg Engl. 2007 Sep;89(6):580-5.

2. Gilpin CJ, Dixon JS, Gilpin SA, Gosling JA. The fine structure of autonomic neurons in the wall of the human urinary bladder. J Anat. 1983 Dec;137 ( Pt 4):705-13.

3. Dixon JS, Gilpin SA, Gilpin CJ, Gosling JA. Intramural ganglia of the human urinary bladder. Br J Urol. 1983 Apr;55(2):195-8.

4. Pirker ME, Montedonico S, Rolle U, Austvoll H, Puri P. Regional differences in nitrergic neuronal density in the developing porcine urinary bladder. Pediatr Surg Int. 2005 Mar;21(3):161-8.

5. Gillespie JI, Markerink-van Ittersum M, de Vente J. Sensory collaterals, intramural ganglia and motor nerves in the guinea-pig bladder: evidence for intramural neural circuits. Cell Tissue Res. 2006 Jul;325(1):33-45.

6. Rahnama'i MS, Hohnen R, van Kerrebroeck PE, van Koeveringe GA. Evidence for prostaglandin E2 receptor expression in the intramural ganglia of the guinea pig urinary bladder. J Chem Neuroanat. 2015 Mar 23.

7. Drake MJ, Mills IW, Gillespie JI. Model of peripheral autonomous modules and a myovesical plexus in normal and overactive bladder function. Lancet. 2001 Aug 4;358(9279):401-3.

8. Birder LA, Apodaca G, De Groat WC, Kanai AJ. Adrenergic- and capsaicin-evoked nitric oxide release from urothelium and afferent nerves in urinary bladder. Am J Physiol. 1998 Aug;275(2 Pt 2):F226-9.

9. Birder LA. Involvement of the urinary bladder urothelium in signaling in the lower urinary tract. Proc West Pharmacol Soc. 2001;44:85-6.

10. Birder LA, Nealen ML, Kiss S, de Groat WC, Caterina MJ, Wang E, et al. Beta-adrenoceptor agonists stimulate endothelial nitric oxide synthase in rat urinary bladder urothelial cells. J Neurosci. 2002 Sep 15;22(18):806370.

11. Ferguson DR, Kennedy I, Burton TJ. ATP is released from rabbit urinary bladder epithelial cells by hydrostatic pressure changes--a possible sensory mechanism? J Physiol. 1997 Dec 1;505 ( Pt 2):503-11.

12. de Jongh $\mathrm{R}$, van Koeveringe GA, van Kerrebroeck PE, Markerink-van Ittersum M, de Vente J, Gillespie JI. The effects of exogenous prostaglandins and the identification of constitutive cyclooxygenase I and II immunoreactivity in the normal guinea pig bladder. BJU Int. 2007 Aug;100(2):419-29.

13. Birder LA. Urothelial signaling. Auton Neurosci. 2009 Feb 16;153(1-2):33-40.

14. Gillespie JI, Drake MJ. The actions of sodium nitroprusside and the phosphodiesterase inhibitor dipyridamole on phasic activity in the isolated guinea-pig bladder. BJU Int. 2004 Apr;93(6):851-8.

15. Gillespie Jl. Phosphodiesterase-linked inhibition of nonmicturition activity in the isolated bladder. BJU Int. 2004 Jun;93(9):1325-32.

16. Gillespie JI. The autonomous bladder: a view of the origin of bladder overactivity and sensory urge. BJU Int. 2004 Mar;93(4):478-83.

17. Truss MC, Stief CG, Uckert S, Becker AJ, Schultheiss D, Machtens S, et al. Initial clinical experience with the selective phosphodiesterase-I isoenzyme inhibitor vinpocetine in the treatment of urge incontinence and low compliance bladder. World J Urol. 2000 Dec;18(6):439-43.

18. Dmochowski R, Roehrborn C, Klise S, Xu L, Kaminetsky J, Kraus S. Urodynamic effects of once daily tadalafil in men with lower urinary tract symptoms secondary to clinical benign prostatic hyperplasia: a randomized, placebo controlled 12-week clinical trial. J Urol. 2010 Mar;183(3):1092-7.

19. Truss MC, Uckert S, Stief CG, Forssmann WG, Jonas U. Cyclic nucleotide phosphodiesterase (PDE) isoenzymes in the human detrusor smooth muscle. II. Effect of various PDE inhibitors on smooth muscle tone and cyclic nucleotide levels in vitro. Urol Res. 1996;24(3):129-34.

20. Truss MC, Uckert S, Stief CG, Kuczyk M, Jonas U. Cyclic nucleotide phosphodiesterase (PDE) isoenzymes in the human detrusor smooth muscle. I. Identification and characterization. Urol Res. 1996;24(3):123-8.

21. Filippi S, Morelli A, Sandner P, Fibbi B, Mancina R, Marini M, et al. Characterization and functional role of androgen-dependent PDE5 activity in the bladder. Endocrinology. 2007 Mar;148(3):1019-29.

22. Lee JG, Moon du G, Kang SH, Cho DY, Park HS, Bae JH. Relaxation effect of phosphodiesterase-5 inhibitor on the animal bladder and prostatic urethra: in vitro and in vivo study. Urol Int. 2010;84(2):231-5. 
23.

24.

25.

26.

27.

28.

29.

30.

31.

32.

33.

34.

35.

36.

37.

38.

39.

40.

41.

42.

43.

44.

45.

Tinel H, Stelte-Ludwig B, Hutter J, Sandner P. Pre-clinical evidence for the use of phosphodiesterase-5 inhibitors for treating benign prostatic hyperplasia and lower urinary tract symptoms. BJU Int. 2006 Dec;98(6):1259-63.

Werkstrom V, Hedlund P, Lee T, Andersson KE. Vardenafil-induced relaxation and cyclic nucleotide levels in normal and obstructed rat urinary bladder. BJU Int. 2009 Dec;104(11):1740-5.

Yanai $Y$, Hashitani H, Hayase M, Sasaki S, Suzuki H, Kohri K. Role of nitric oxide/cyclic GMP pathway in regulating spontaneous excitations in detrusor smooth muscle of the guinea-pig bladder. Neurourol Urodyn. 2008;27(5):446-53.

Longhurst PA, Briscoe JA, Rosenberg DJ, Leggett RE. The role of cyclic nucleotides in guinea-pig bladder contractility. Br J Pharmacol. 1997 Aug;121(8):1665-72.

7 Rahnama'i MS, van Koeveringe GA, Essers PB, de Wachter SG, de Vente J, van Kerrebroeck PE, et al. Prostaglandin receptor EP1 and EP2 site in guinea pig bladder urothelium and lamina propria. J Urol. 2010 Mar;183(3):1241-7.

de Jongh R, van Koeveringe GA, van Kerrebroeck PE, Markerink-van Ittersum M, de Vente J, Gillespie Jl. Alterations to network of NO/cGMP-responsive interstitial cells induced by outlet obstruction in guinea-pig bladder. Cell Tissue Res. 2007 Oct;330(1):147-60.

Lagou M, Drake MJ, Markerink VANIM, J DEV, Gillespie JI. Interstitial cells and phasic activity in the isolated mouse bladder. BJU Int. 2006 Sep;98(3):643-50.

Park $\mathrm{H}$, Clark E, Conklin JL. Effects of phosphodiesterase inhibitors on oesophageal neuromuscular functions. Neurogastroenterol Motil. 2003 Dec;15(6):625-33.

de Groat WC, Yoshimura N. Afferent nerve regulation of bladder function in health and disease. Handbook of experimental pharmacology. 2009 (194):91-138.

Birder LA. Urinary bladder urothelium: molecular sensors of chemical/thermal/mechanical stimuli. Vascul Pharmacol. 2006 Oct;45(4):221-6.

Birder LA. More than just a barrier: urothelium as a drug target for urinary bladder pain. Am J Physiol Renal Physiol. 2005 Sep;289(3):F489-95.

Rahnama'i MS, de Wachter SG, van Koeveringe GA, van Kerrebroeck PE, de Vente J, Gillespie JI. The relationship between prostaglandin E receptor 1 and cyclooxygenase I expression in guinea pig bladder interstitial cells: proposition of a signal propagation system. J Urol. 2011 Jan;185(1):315-22.

Ricciotti E, FitzGerald GA. Prostaglandins and inflammation. Arterioscler Thromb Vasc Biol. 2011 May;31(5):986-1000.

Narumiya S, Sugimoto $\mathrm{Y}$, Ushikubi F. Prostanoid receptors: structures, properties, and functions. Physiol Rev. 1999 Oct;79(4):1193-226.

Kim JC, Park EY, Hong SH, Seo Sl, Park YH, Hwang TK. Changes of urinary nerve growth factor and prostaglandins in male patients with overactive bladder symptom. Int J Urol. 2005 Oct;12(10):875-80.

Kim JC, Park EY, Seo SI, Park YH, Hwang TK. Nerve growth factor and prostaglandins in the urine of female patients with overactive bladder. J Urol. 2006 May;175(5):1773-6; discussion 6.

Schussler B. Comparison of the mode of action of prostaglandin E2 (PGE2) and sulprostone, a PGE2derivative, on the lower urinary tract in healthy women. A urodynamic study. Urol Res. 1990;18(5):349-52.

Ishizuka O, Mattiasson A, Andersson KE. Prostaglandin E2-induced bladder hyperactivity in normal, conscious rats: involvement of tachykinins? J Urol. 1995 Jun;153(6):2034-8.

Maggi CA, Giuliani S, Conte B, Furio M, Santicioli P, Meli P, et al. Prostanoids modulate reflex micturition by acting through capsaicin-sensitive afferents. Eur J Pharmacol. 1988 Jan 12;145(2):105-12.

Schroder A, Newgreen D, Andersson KE. Detrusor responses to prostaglandin E2 and bladder outlet obstruction in wild-type and Ep1 receptor knockout mice. J Urol. 2004 Sep;172(3):1166-70.

de Groat WC. Mechanisms underlying the recovery of lower urinary tract function following spinal cord injury. Paraplegia. 1995 Sep;33(9):493-505.

Wang X, Momota Y, Yanase H, Narumiya S, Maruyama T, Kawatani M. Urothelium EP1 receptor facilitates the micturition reflex in mice. Biomed Res. 2008 Apr;29(2):105-11.

Angelico P, Guarneri L, Velasco C, Cova R, Leonardi A, Clarke DE, et al. Effect of cyclooxygenase inhibitors on the micturition reflex in rats: correlation with inhibition of cyclooxygenase isozymes. BJU Int. 2006 Apr;97(4):837-46. 
46. Nile CJ, Gillespie JI. Interactions between cholinergic and prostaglandin signaling elements in the urothelium: role for muscarinic type 2 receptors. Urology. 2012 Jan;79(1):240 e17-23.

47. McCafferty GP, Misajet BA, Laping NJ, Edwards RM, Thorneloe KS. Enhanced bladder capacity and reduced prostaglandin E2-mediated bladder hyperactivity in EP3 receptor knockout mice. Am J Physiol Renal Physiol. 2008 Aug;295(2):F507-14.

48. Jugus MJ, Jaworski JP, Patra PB, Jin J, Morrow DM, Laping NJ, et al. Dual modulation of urinary bladder activity and urine flow by prostanoid EP3 receptors in the conscious rat. Br J Pharmacol. 2009 Sep;158(1):372-81.

49. Su X, Leon LA, Wu CW, Morrow DM, Jaworski JP, Hieble JP, et al. Modulation of bladder function by prostaglandin EP3 receptors in the central nervous system. Am J Physiol Renal Physiol. 2008 Oct;295(4):F98494.

50. Oger S, Behr-Roussel D, Gorny D, Denys P, Lebret T, Alexandre L, et al. Relaxation of phasic contractile activity of human detrusor strips by cyclic nucleotide phosphodiesterase type 4 inhibition. Eur Urol. 2007 Mar;51(3):772-80; discussion 80-1.

51. Eglen RM, Hegde SS, Watson N. Muscarinic receptor subtypes and smooth muscle function. Pharmacol Rev. 1996 Dec;48(4):531-65.

52. Hegde SS, Choppin A, Bonhaus D, Briaud S, Loeb M, Moy TM, et al. Functional role of M2 and M3 muscarinic receptors in the urinary bladder of rats in vitro and in vivo. Br J Pharmacol. $1997 \mathrm{Apr}$;120(8):1409-18.

53. Longhurst PA, Leggett RE, Briscoe JA. Characterization of the functional muscarinic receptors in the rat urinary bladder. Br J Pharmacol. 1995 Oct;116(4):2279-85.

54. Kaiho Y, Nishiguchi J, Kwon DD, Chancellor MB, Arai Y, Snyder PB, et al. The effects of a type 4 phosphodiesterase inhibitor and the muscarinic cholinergic antagonist tolterodine tartrate on detrusor overactivity in female rats with bladder outlet obstruction. BJU Int. 2008 Mar;101(5):615-20.

55. Yoshimura N, Seki S, de Groat WC. Nitric oxide modulates $\mathrm{Ca}(2+)$ channels in dorsal root ganglion neurons innervating rat urinary bladder. J Neurophysiol. 2001 Jul;86(1):304-11.

56. Gillespie JI, Markerink-van Ittersum M, de Vente J. cGMP-generating cells in the bladder wall: identification of distinct networks of interstitial cells. BJU Int. 2004 Nov;94(7):1114-24.

57. Gillespie JI, Markerink-van Ittersum M, de Vente J. Expression of neuronal nitric oxide synthase (nNOS) and nitric-oxide-induced changes in cGMP in the urothelial layer of the guinea pig bladder. Cell Tissue Res. 2005 Sep;321(3):341-51.

58. Gillespie Jl, Markerink-van Ittersum M, De Vente J. Endogenous nitric oxide/cGMP signalling in the guinea pig bladder: evidence for distinct populations of sub-urothelial interstitial cells. Cell Tissue Res. 2006 Aug;325(2):325-32.

59. Gillespie JI, Markerink-van Ittersum M, De Vente J. Interstitial cells and cholinergic signalling in the outer muscle layers of the guinea-pig bladder. BJU Int. 2006 Feb;97(2):379-85.

60. Lagou M, De Vente J, Kirkwood TB, Hedlund P, Andersson KE, Gillespie JI, et al. Location of interstitial cells and neurotransmitters in the mouse bladder. BJU Int. 2006 Jun;97(6):1332-7.

61. Kanai A, Zabbarova I, Oefelein M, Radziszewski P, Ikeda Y, Andersson KE. Mechanisms of action of botulinum neurotoxins, beta3-adrenergic receptor agonists, and PDE5 inhibitors in modulating detrusor function in overactive bladders: ICI-RS 2011. Neurourol Urodyn. 2012 Mar;31(3):300-8.

62. Andersson KE. Changes in bladder tone during filling: pharmacological aspects. Scand J Urol Nephrol Suppl. 1999;201:67-72; discussion 76-99. 

In the studies presented in this thesis, peripheral pharmacological targets that are able to modify bladder function, are discussed. More specifically, interactions of the prostanoid system, the cholinergic system and the NO/cGMP system have been the focus of interest.

In a general introduction (chapter 1), two functional bladder dysfunctions overactive bladder syndrome and detrusor underactivity are described especially with respect to bladder histology, central control and peripheral control mechanisms are described.

In chapter 2, the distribution of phosphodiesterase type 2 (PDE2) in the guinea pig urinary bladder is shown. Treatment with anticholinergics, the first line treatment in the overactive bladder syndrome $(O A B)$, is characterized by a poor effect size and high prevalence of side effects, resulting in poor treatment compliance. Therefore, new and alternative therapy modalities for detrusor overactivity (DO) are needed. We focussed on the PDE2 selective inhibitors that might offer an interesting approach and investigated its presence in the guinea pig bladder wall morphologically. PDE2 inhibited cGMP breakdown mostly in urothelial and suburothelial layers as well as on nerve fibres. In the outer muscle layers of the lateral wall, cGMP is mainly expressed by intermuscle interstitial cells and nerve fibres, indicating the presence of PDE2 enzyme activity in these structures. This study is the first to show the distribution of PDE2 in the bladder. Due to its presence in both, neuronal and non-neuronal structures, which are important in regulation of bladder function, it can be hypothesized that PDE2 plays a role in signal transduction throughout the whole bladder wall. To gain more insight into potential treatment modalities using PDE2 inhibitors, physiological experiments are required to study the possible role of PDE2 inhibition in modulating bladder activity.

Another possible target for treatment is the prostanoid system. The expression of two prostaglandin E2 (PGE2) specific receptors, EP1 and EP2 in the intramural ganglia of guinea pig bladders is presented in chapter 3. Intramural ganglia have been shown in the bladder wall of several species including human, pig, and guinea-pig. A network of intramural ganglia in the bladder of these species might be part of a motor-sensory system and receive afferent input. Prostaglandins (PG) have been suggested to play a role in this afferent signalling mechanism. The distribution of EP1 and EP2 in and around intramural ganglia of the guinea pig was investigated morphologically. Immune reactivity for EP1 and EP2 was found in intramural ganglion cells. These cells were observed in between muscle bundles and on, or close to the serosal surface of the bladder. In addition, COX I was present in interstitial cells close to ganglion cells, indicating the possibility of a local synthesis of prostaglandins near the ganglia. The co-staining of EP1 or EP2 with vimentin showed that processes of interstitial cells run through the ganglia, often encircling or ensheathing cells. 
Thus, a close relationship is shown between the intramural ganglia and the network of interstitial cells in the muscular layers of the bladder. As EP1 and EP2 receptors are expressed on the ganglia, it can be suggested that intramural ganglia are involved in (pre)processing afferent information. Therefore, intramural ganglia might function as a connection between neuronal structures containing information from the central nervous system, and non-neuronal regulatory structures within the bladder wall.

The interaction of the prostanoid and the cholinergic system and its potential role in modifying bladder contractions are discussed in chapter 4 and chapter 5 . The urothelium releases several substances in response to mechanical and physical stimuli i.e. $\mathrm{PGE}_{2}, \mathrm{NO}$, acetylcholine (ACh) and adenosine triphosphate (ATP). PGE 2 and $A C h$ have been shown to interact in a positive feedback manner on a molecular level. In these functional studies, the role of PGE2 and two of its receptor, EP1 and EP3, on muscarinic induced contractions was investigated. In addition, the morphological distribution of the EP3 receptor was studied. Adding $\mathrm{PGE}_{2}$ before muscarinic stimulations induced an amplifying effect on muscarinically induced contractions. After inhibition of the $\mathrm{PGE}_{2}$ producing enzyme COX-1, a decreased amplitude during the initial phase of the muscarinic response was recorded. Inhibition of EP1 decreased the frequency during the second phase of the arecaidine response. To investigate the role of EP3 in this feedback mechanism, the distribution and function of EP3 in the guinea pig bladder were studied. EP3 immune reactivity had been found to be present in neuronal structures in the urothelial/ suburothelial and muscle layer as well as by suburothelial interstitial cells and urothelial cells. Activation of EP3 receptors in the urinary bladder decreased the frequency of muscarinic induced contractions. In summary, both studies provide evidence that the cholinergic and prostanoid systems in the urinary bladder act in a positive feedback loop and that the EP1 and EP3 receptor play a subtle role in this process. Due to the amplifying effect of the cholinergic and the prostanoid system, targets belonging to the prostanoid system are promising when searching for potential new modalities for the treatment bladder dysfunctions. In order to identify new treatment targets, the location of the different steps in the cascade and the targets for modulation of this process need to be determined in the near future.

New potential treatment modalities for detrusor underactivity are reviewed in chapter 6 . Detrusor underactivity, compared to detrusor overactivity, gained less attention in functional urological research until four years ago. However, there is only limited knowledge on the pathophysiological and molecular background of detrusor underactivity. In this chapter, treatment targets of all levels involved in physiological bladder function are discussed: targets involved in urethral- and bladder sensation, targets involved in afferent signalling, targets 
involved in the central processing of afferent information, and targets involved in efferent signalling and local regulatory processes of bladder contractility. At all different levels, new potential therapeutic targets have been identified. Usually, targets which modulate bladder contractility in a direct way would be under focus when searching for new treatment modalities. In this chapter, it is shown that these targets can be found at all different levels: from sensation to contractility.

A general discussion of all findings presented in this thesis can be found in chapter 7. If each signalling system of the urinary bladder is examined separately, important information will get lost. It is of utmost importance to investigate interactions and effects on other systems. In this thesis, it has been shown directly that the prostanoid system and the cholinergic system interact on each other. Furthermore, the NO/cGMP system can interact and influence muscarinic induced contractions also. Possible interactions of the different systems of peripheral pharmacological targets presented in this thesis are discussed in this last chapter of the thesis with respect to their involvement in the modulation of bladder function. 


In dit proefschrift werden perifere farmacologische aangrijpingspunten onderzocht, die gebruikt kunnen worden om de activiteit van de urineblaas te beïnvloeden. De activiteit van de urineblaas wordt gereguleerd door centrale, de hersenen en ruggenmerg betreffende, en perifere, het eind orgaan de blaas betreffende, mechanismen. Meerdere regelsystemen zijn betrokken bij deze perifere regulatie. In dit proefschrift werd de betrokkenheid onderzocht van het prostanoïde, het cholinerge en het NO/cGMP regelsysteem naast de interacties tussen deze systemen.

In de algemene inleiding beschreven in hoofdstuk 1, werden de fenomenen overactieve blaas en detrusor onderactiviteit besproken, dit zijn beide functionele blaasdisfuncties. Hierbij werd in het bijzonder ingegaan op de blaas histologie en de controle door de centrale en perifere regelsystemen.

In hoofdstuk 2 werd de aanwezigheid van fosfodiësterase type 2 (PDE2) in de urineblaas van de cavia beschreven. Fosfodiësterases zouden een mogelijk nieuw aangrijpingspunt voor de behandeling van de overactieve blaas kunnen bieden. Momenteel behoort het gebruik van antimuscarinica tot de eerstelijns behandeling van het overactieve blaas syndroom. Deze behandeling gaat echter dikwijls gepaard met hinderlijke bijwerkingen en heeft vaak slechts een matig afzwakkend effect op de klachten. Hetgeen resulteerde in een lage therapietrouw. Daarom zijn andere, meer effectievere therapiemogelijkheden voor patiënten met overactieve blaas van belang. In dit kader vormden PDE2 specifieke inhibitoren een mogelijk interessant aangrijpingspunt voor nieuwe therapieën. Om te onderzoeken of PDE2 inhibitoren een rol kunnen spelen in de behandeling van overactieve blaas, werd de aanwezigheid van het enzym in een morfologische studie van de blaaswand bestudeerd. De aanwezigheid van PDE2 werd aangetoond in zowel zenuwen als andere structuren die van belang zijn bij het reguleren van de blaasfunctie. Deze specifieke aanwezigheid gaf aanleiding tot de hypothese dat PDE2 een rol speelt in de signaalgeleiding van de blaaswand. Om verder inzicht te verkrijgen in eventuele behandelingsopties gebaseerd op PDE2 inhibitoren, zijn in de toekomst fysiologische experimenten rondom de modulatie van blaasactiviteit met PDE2 aangewezen.

Een ander potentieel aangrijpingspunt voor de behandeling van blaasdisfuncties is het prostanoïde systeem. De aanwezigheid van twee prostaglandine E2 (PGE2) specifieke receptoren, EP1 en EP2 in ganglion cellen in de spierwand werd beschreven in hoofdstuk 3. De aanwezigheid van ganglion cellen in de spierwand (intramurale ganglia) is aangetoond in verschillende diersoorten, varkens en cavia's, en in de mens. Een netwerk van intramurale ganglia in de blaaswand van deze dieren zou deel uit kunnen maken van de koppeling tussen motorische- en sensorische activiteit en in deze rol dan ook de nodige informatie ontvangen 
vanuit de hersenen (zogenaamde afferente informatie). Prostaglandines spelen mogelijkerwijs een rol in deze afferente signaleringsmechanismen. De aanwezigheid van de twee specifieke receptoren, EP1 en EP2, in en rond de intramurale ganglia van de cavia werd in deze studie morfologisch aangetoond. Immuunreactiviteit voor EP1 en EP2 werd gevonden in de intramurale ganglia. De intramurale ganglion cellen werden gedetecteerd tussen de spierbundels en dichtbij de serosa. Het enzym, dat voor de productie van PGE2 verantwoordelijk is, cyclooxygenase type 1 (COX-1), werd aangetoond in de interstitiële cellen die rondom de ganglion cellen gelokaliseerd waren. Dit duidde op de mogelijkheid van lokale productie van prostaglandines in de directe omgeving van de ganglia. De kleuring van de receptoren EP1 en EP2 samen met een marker voor interstitiële cellen, had laten zien dat uitlopers van deze interstitiële cellen door de ganglia heen passeerden. Vaak werd een groep van ganglia ook helemaal omgeven gezien door deze uitlopers. Hiermee werd een sterk verband aangetoond tussen de intramurale ganglia en het netwerk van interstitiële cellen in de spierlaag van de blaas. Aangezien EP1 en EP2 receptoren aanwezig waren in de ganglia, kon de hypothese gevormd worden dat intramurale ganglia een rol speelden in de (voor)verwerking van afferente informatie. Bovenstaande bevinding wijst erop dat intramurale ganglia de connectie vormen tussen de neuronale structuren, die informatie vanuit het centrale zenuwstelsel ontvangen, en de niet-neuronale, regulerende structuren binnen de blaaswand.

De interactie van het prostanoïde en cholinerge systeem werd besproken in hoofdstuk 4 en 5 . In het bijzonder werd ingegaan op de potentiële rol van het prostanoïde systeem bij de modificatie van blaascontracties. Als reactie op mechanische of fysische stimuli geeft het urotheel een groot repertoire aan stoffen af. Deze stoffen zijn onder andere, PGE2, NO, acetylcholine (ACh) en adenosine trifosfaat (ATP). Een eerdere studie liet op moleculair niveau zien, dat PGE2 en ACh elkaar via positieve feedback versterkten. In de studies, die in dit proefschrift beschreven werden, werd het effect van PGE2 en twee van zijn specifieke receptoren, EP1 en EP3, op muscarine geïnduceerde contracties onderzocht. Daarnaast werd morfologisch het voorkomen van de EP3 receptor in de blaas onderzocht. Het werd aangetoond dat PGE2 de muscarine geïnduceerde respons versterkt. Na remming van het COX-1 enzym, dat voor de aanmaak van PGE2 verantwoordelijk was, werd een zwakkere muscarine geïnduceerd respons gemeten. Het kon dus worden vastgesteld, dat PGE2 en ACh elkaar versterkten en dus volgens een soort positief feedback mechanisme elkaar beïnvloedden. Hierna werd de rol van de twee PGE2 specifieke receptoren, EP1 en EP3, in dit versterkingsmechanisme onderzocht. Inhibitie van de EP1 receptor resulteerde in een lagere frequentie van de fasische samentrekkingen tijdens een latere fase van de muscarine geïnduceerde respons op het blaasspierweefsel. Om de rol van EP3 in dit feedback mechanisme te onderzoeken, werd zowel 
de aanwezigheid als ook de functie van EP3 in de caviablaas bestudeerd. EP3 immuunreactiviteit werd in neuronale structuren gelegen in het urotheel, het suburotheel en de spierlaag gevonden. Daarnaast was EP3 ook in sub-urotheliale interstitiële cellen en urotheelcellen aanwezig. Activatie van de EP3 receptoren in de blaas verlaagde de frequentie van muscarine geïnduceerde contracties. Samenvattend kan worden gezegd, dat beide studies een positieve feedback tussen het prostanoïde en het muscarine systeem in de urineblaas hebben laten zien. Verder werd aangetoond, dat zowel de EP1 als de EP3 receptor betrokken zijn in dit verband. Terwijl activatie van EP3 in een zwakkere muscarine geïnduceerde respons resulteerde, moest EP1 geïnhibeerd worden om hetzelfde effect te laten zien. Door het versterkende effect van het prostanoïde op het cholinerge systeem, kunnen receptoren of enzymen van het prostanoïde systeem als interessante, potentiële nieuwe aangrijpingspunten voor de behandeling van blaasdisfunctie worden gezien. Om specifieke nieuwe aangrijpingspunten te identificeren, moet de rol van de verschillende stappen in de signaalcascade en de locatie van de potentiële spelers die betrokken zijn bij de regulatie van deze processen, in de toekomst bepaald worden.

Potentiële nieuwe behandelingsmogelijkheden voor detrusor onderactiviteit werden besproken in hoofdstuk 6. Detrusor onderactiviteit - in vergelijking met detrusor overactiviteit - kreeg lange tijd minder aandacht binnen het functioneel georiënteerde urologisch onderzoek, maar dit is een aantal jaren geleden veranderd. Er was slechts beperkte kennis beschikbaar over de pathofysiologische en moleculaire achtergrond van detrusor onderactiviteit. In dit hoofdstuk werden nieuwe aangrijpingspunten voor de behandeling op alle niveaus besproken die een rol speelden in fysiologische controle van de urineblaas: aangrijpingspunten die een rol speelden in urethrale- en blaassensaties, aangrijpingspunten die een rol speelden in afferente signalering, aangrijpingspunten die betrokken waren in de centrale verwerking van de afferente informatie, aangrijpingspunten welke een rol spelden in efferente signalering en aangrijpingspunten die geassocieerd waren met lokale regulerende processen van blaascontractiliteit. In dit hoofdstuk lieten wij zien dat aangrijpingspunten voor de behandeling van detrusor onderactiviteit op alle verschillende niveaus van regulatie aanwezig zijn: van sensatie tot contractiliteit.

In de algemene discussie (hoofdstuk 7) werden alle bevindingen besproken die beschreven staan in dit proefschrift. Als ieder signaalsysteem apart onderzocht werd, zou belangrijke informatie verloren gaan. Het was daarom uitermate belangrijk om de interacties tussen verschillende systemen die een rol spelen in de controle van de urineblaas te onderzoeken. In dit proefschrift werden onderzoeken beschreven, waarin direct een interactie tussen het prostanoïde en het cholinerge systeem aangetoond werd. Daarnaast is het mogelijk dat het 
NO/cGMP systeem muscarine geïnduceerde contractiest. Mogelijke interacties tussen de verschillende systemen en hun perifere farmacologische aangrijpingspunten, die in dit proefschrift behandeld zijn, zijn besproken in dit laatste hoofdstuk met betrekking tot hun rol in de modulatie van blaasfunctie.

In dit proefschrift werden een aantal onderzoeken beschreven, die aantonen dat nieuwe aangrijpingspunten voor de behandeling van functionele blaasdysfuncties mogelijkerwijs gevonden kunnen worden in de interactie van verschillende signaalsystemen. Vooral het prostanoïde systeem, maar ook het NO/cGMP systeem blijken hiervoor interessante kandidaten. Verder onderzoek is noodzakelijk om specifieke aangrijpingspunten te identificeeren en nieuwe, hierop gebaseerde therapieën, te ontwikkelen. 


\section{Valorisation}

Lower urinary tract dysfunctions are a major global health issue. The studies presented in this thesis have aimed to identify new treatment targets. Detailed knowledge of urinary bladder signalling is of utmost importance when new treatment targets have to be identified. Until now, it is not fully known how the different signalling systems, involved in regulation of micturition and continence, interact with each other. Two important bladder dysfunctions have been discussed in this thesis i.e. the overactive bladder syndrome and detrusor underactivity. These two dysfunctions will be elaborated to elucidate the societal impact of the presented research.

The overactive bladder syndrome $(O A B)$ is defined as urgency, usually with frequency and nocturia, with or without urgency urinary incontinence ${ }^{1,2}$. It is a highly prevalent condition with almost 100 million people affected in the western world, 33 million in the United States ${ }^{3}$ and 66 million in the European Union ${ }^{4}$. The impact on patients' quality of life is enormous and even higher than the impact on quality of life associated with diabetes ${ }^{5-8}$. Furthermore, the economic costs and burden of $O A B$ are comparable to those of rheumatoid arthritis and asthma ${ }^{9}$. The pathophysiology is multifactorial and the patient group shows a high heterogeneity. Therefore, optimal therapy remains challenging. To optimize bladder function in those patients, two aspects are of importance: the heterogeneity of $O A B$ needs to be taken into account. Furthermore we need to more knowledge about symptomatology-related physiological processes taking place at bladder level. Concerning the heterogeneity of $O A B$, patient subgroups have to be identified and the pathological functional and morphological derivatives have to be investigated for each subgroup. Concerning the aspect on bladder physiology, the question to put forward is: How do the different signalling systems interact with each other and what will be the effect of bladder dysfunction on those interactions? Answering these questions will enable us to identify new, more specific treatment targets for OAB.

Currently, antimuscarinic drugs are widely used to treat patients suffering from OAB. However, the effect has been shown to be small compared to placebo, with a high prevalence of side effects $^{10}$. This signifies the need for new pharmacological treatment targets. The question is: Can we use other signalling systems, which are active in the bladder to modify excitationcontraction coupling? In studies presented in chapter 4 and 5 , the prostanoid system was identified to be a potential candidate for the modulation of muscarinic induced contractions. 
Future research can elaborate on our data and might help to identify new treatment targets with less side effects for the patients.

The second bladder dysfunction that may benefit from the results of this thesis, is detrusor underactivity. In older women, the prevalence of detrusor underactivity ranges from $12 \%-45 \%$. In males, a prevalence between $9 \%$ and $45 \%$ has been identified dependent on population and diagnostic criteria ${ }^{11}$. One of the causes of detrusor underactivity is bladder outlet obstruction, which will induce a cascade of morphological and functional changes within the bladder wall. At a later stage, these changes can lead to detrusor underactivity. The most frequently occurring cause of bladder outlet obstruction in men, is prostate enlargement due to Benign Prostatic Hyperplasia. In addition, functional neurogenic and even psychogenic causes may also underlie the detrusor underactivity ${ }^{12}$. Detrusor underactivity and the subsequent bladder distension give rise to residual urine after voiding in males and females resulting, in a significant burden: Chronic urinary tract infections, increased antibiotic resistance of microorganisms, reduced quality of life and high costs for care, especially in the institutionalised elderly.

Currently, there is no treatment option for detrusor underactivity with good long-term results. The current management includes life-long intermittent catheterisation, which is the only option to prevent urinary tract morbidity. Unfortunately, performing intermittent catheterisation has a large impact on the quality of life ${ }^{13}$. It is of utmost importance to understand the pathophysiological processes, which lead to detrusor underactivity. This thesis contains a literature review on detrusor underactivity, that identifies potentially new treatment targets and could serve as a base for future research. Current knowledge is presented, on possible changes in physiological processes that may lead to detrusor underactivity. To find new treatment modalities, more basic and clinical research is needed. Patient subgroups have to be identified, and pathophysiological processes involved in the development of detrusor underactivity have to be elucidated. Hereby, novel treatment strategies can be developed, improving patients' quality of life.

The studies presented in this thesis focussed on the interaction of signalling systems. The prostanoid system was identified as a potential target system when searching for new therapeutical strategies. Therefore, a first step was provided towards new therapeutical approaches using pharmacological modulators of the prostanoid system for the treatment of bladder dysfunctions. 


\section{References}

1. Abrams P, Cardozo L, Fall M, Griffiths D, Rosier P, Ulmsten U, et al. The standardisation of terminology of lower urinary tract function: report from the Standardisation Sub-committee of the International Continence Society. Neurourol Urodyn. 2002;21(2):167-78.

2. Haylen BT, de Ridder D, Freeman RM, Swift SE, Berghmans B, Lee J, et al. An International Urogynecological Association (IUGA)/International Continence Society (ICS) joint report on the terminology for female pelvic floor dysfunction. Neurourol Urodyn. 2010;29(1):4-20.

3. Hu TW, Wagner TH, Bentkover JD, Leblanc K, Zhou SZ, Hunt T. Costs of urinary incontinence and overactive bladder in the United States: a comparative study. Urology. 2004 Mar;63(3):461-5.

4. Milsom I, Abrams P, Cardozo L, Roberts RG, Thuroff J, Wein AJ. How widespread are the symptoms of an overactive bladder and how are they managed? A population-based prevalence study. BJU Int. 2001 Jun;87(9):760-6.

5. Abrams P, Kelleher CJ, Kerr LA, Rogers RG. Overactive bladder significantly affects quality of life. The American journal of managed care. 2000 Jul;6(11 Suppl):S580-90.

6. Hashim H, Abrams P. Overactive bladder: an update. Curr Opin Urol. 2007 Jul;17(4):231-6.

7. Komaroff AL, Fagioli LR, Doolittle TH, Gandek B, Gleit MA, Guerriero RT, et al. Health status in patients with chronic fatigue syndrome and in general population and disease comparison groups. Am J Med. 1996 Sep;101(3):281-90.

8. Liberman JN, Hunt TL, Stewart WF, Wein A, Zhou Z, Herzog AR, et al. Health-related quality of life among adults with symptoms of overactive bladder: results from a U.S. community-based survey. Urology. 2001 Jun;57(6):1044-50.

9. Coyne KS, Sexton CC, Thompson CL, Clemens JQ, Chen Cl, Bavendam T, et al. Impact of overactive bladder on work productivity. Urology. 2012 Jul;80(1):97-103.

10. Cardozo L. The overactive bladder syndrome: treating patients on an individual basis. BJU Int. 2007 Jun;99 Suppl 3:1-7.

11. Osman NI, Chapple CR, Abrams P, Dmochowski R, Haab F, Nitti V, et al. Detrusor underactivity and the underactive bladder: a new clinical entity? A review of current terminology, definitions, epidemiology, aetiology, and diagnosis. Eur Urol. 2014 Feb;65(2):389-98.

12. van Koeveringe GA, Rademakers KL, Birder LA, Korstanje C, Daneshgari F, Ruggieri MR, et al. Detrusor underactivity: Pathophysiological considerations, models and proposals for future research. ICI-RS 2013. Neurourol Urodyn. 2014 Jun;33(5):591-6.

13. Shaw C, Logan K, Webber I, Broome L, Samuel S. Effect of clean intermittent self-catheterization on quality of life: a qualitative study. J Adv Nurs. 2008 Mar;61(6):641-50. 



\section{Abbreviations}

ACh Acetylcholine

AMP Adenosine monophosphate

ATP Adenosine triphosphate

Bax Bcl-2-associated $X$ protein

Bcl-2 B-cell lymphoma 2

BK large conductance $\mathrm{KCa}$

BOO Bladder outlet obstruction

CaM Ca2+/calmodulin-dependent protein

CAMP Cyclic adenosine monophosphate

CB1 Cannabinoid receptor type 1

CB2 Cannabinoid receptor type 2

cGMP Cyclic guanosine monophosphate

cGRP Calcitonin gene related peptide

COX Cyclooxygenase

COX-1 Cyclooxygenase type 1

COX-2 Cyclooxygenase type 2

D1 D1-type dopaminergic receptor

D2 D2-type dopaminergic receptor

D3 D3-type dopaminergic receptor

D4 D4-type dopaminergic receptor

D5 D5-type dopaminergic receptor

DO Detrusor Overactivity

DU Detrusor underactivity

EHNA Erythro-9-(2-hydroxy-3-nonyl)adenine

EP1 Prostaglandin E receptor type 1

EP2 Prostaglandin E receptor type 2 
EP3 Prostaglandin E receptor type 3

EP4 Prostaglandin E receptor type 4

GABA Gamma-aminobutyric acid

$\mathrm{GABA}_{\mathrm{A}} \quad$ Gamma-aminobutyric acid receptor type A

$\mathrm{GABA}_{B} \quad$ Gamma-aminobutyric acid receptor type $B$

GlyT1 Glycine transporter 1

GlyT2 Glycine transporter 2

GMP Guanosine monophosphate

GTP Guanosine triphoshate

IC Interstitial cell

ICS International Continence Society

IP3 Inositol triphosphate

KO Knock-out

LU Bladder lumen

M1 Muscarinic receptor type 1

M2 Muscarinic receptor type 2

M3 Muscarinic receptor type 3

MAP Microtubule-associated protein

MIF Macrophage migration inhibitory factor

MLCK Myosin light chain kinase

MLCP Myosin light chain phosphatase

MnSOD Manganese superoxide dismutase

MU Muscle layer

nNOS Neuronal nitric oxide synthase

NO Nitric oxide

NOS Nitric oxide synthase

$O A B \quad$ Overactive bladder syndrome

PAK p21-activated kinase

PARP poly (ADP-ribose) polymerase

PDE Phosphodiesterase 
PDE1 Phosphodiesterase type 1

PDE2 Phosphodiesterase type 2

PDE4 Phosphodiesterase type 4

PDE5 Phosphodiesterase type 5

PG Prostaglandin

PGE2 Prostaglandin E2

PGP $9.5 \quad$ Protein gene product 9.5

PKC Protein kinase $\mathrm{C}$

PKG Protein kinase $G$

PKN Protein kinase $\mathrm{N}$

ROK Roh Kinase

ROS Reactive oxygen species

SK small-conductance

SU Suburothelial layer

SV2 Synaptic vesicle protein 2

TBS Tris-buffered saline

TBS-T Tris-buffered saline containing $0.3 \%(v / v)$ Triton X-100

TRP Transient receptor potential

TRPA1 Transient receptor potential cation channel, member A1

TRPM Transient receptor potential melastin

TRPM4 Transient receptor potential melastin type 4

TRPV Transient receptor potential vanilloid

TRPV1 Transient receptor potential vanilloid channel type 1

TRPV4 Transient receptor potential vanilloid channel type 4

UR Urothelium

UUI Urgency urinary incontinence 



\section{List of Publications}

Hohnen R, Rahnama'i MS, van Gink K, Meriaux C, van Koeveringe GA. Ex vivo modulation of muscarinically induced contractions by PGE2 and an EP1 receptor antagonist in the guinea pig urinary bladder. Submitted

Hohnen R, Meriaux C, Raven F, van Koeveringe GA. Distribution and function of the EP3 receptor in the guinea pig urinary bladder. Submitted

Hohnen R, Rahnama'i MS, van Kerrebroeck PE, van Koeveringe GA. Evidence for prostaglandin E2 receptor expression in the intramural ganglia of the guinea pig urinary bladder. J Chem Neuroanat. 2015 Mar-Apr;64-65:43-7.

Hohnen R, Rahnama'i MS, Van Kerrebroeck PE, van Koeveringe GA. Phosphodiesterase type 2 distribution in the guinea pig urinary bladder. World J Urol. 2014 Dec 6.

Rahnama'i MS, Uckert S, Hohnen R, van Koeveringe GA. The role of phosphodiesterases in bladder pathophysiology. Nat Rev Urol. 2013 Jul;10(7):414-24.

Rahnama'i MS, van Koeveringe GA, Hohnen R, Ona S, van Kerrebroeck PE, de Wachter SG. Distribution of phosphodiesterase type 5 (PDE5) in the lateral wall of the guinea pig urinary bladder. BJU Int. 2013 Jul;112(2):246-57. 



\section{Acknowledgements}

Here it is - the last part of my PhD thesis. After three years of work and lots of writing, I am proud to write this last piece of text: The acknowledgements. I believe, this part will be the one which will be read most. I was looking forward to writing this section for a long time. However, a certain risk was always in my mind... The risk of forgetting important people. Hence, if you are not mentioned in this acknowledgements, I did not forget you at all, you were just hidden in all the stress of finishing this booklet. I am wholeheartedly grateful to all people who supported me to put the project "PhD" into practice!

First of all, I would like to thank my promotion team. All of you were of high importance during the last three years.

Beste Prof. van Kerrebroek, toen het niet duidelijk was, wie mijn promotor kon zijn, stond u er onmiddelijk voor klaar. Ik wil u hiervoor, maar ook voor uw uitzonderlijk snelle commentaar, op mijn introductie, discussie en stellingen hartelijk danken.

Gommert, er zijn veel dingen, waarvoor ik jou kan danken. Allereerst, wil ik je ervoor danken, dat je mij de mogelijkheid hebt gegeven, om bij jou mijn promotieonderzoek te kunnen doen. Binnen dit onderzoek heb ik dan ook onzettend veel van jou geleerd. Planning en flexibiliteit, geduld en, waar nodig, nadrukkelijke ongeduld, teamgeest en zelfstandig werken, assertiviteit en de kritische reflectie van mijzelf, het omgaan met succes en mislukking. Ondanks dat je het onzettend druk had, kon ik altijd op je inzet en advies vertrouwen. Hartelijk dank voor alles!

Beste Sajjad, je hebt mij ooit bij de urologie gebracht. Tijdens mijn bachelorstage met jou als begeleider, heb ik mijn passie voor dit onderzoeksveld ontdekt. Je hebt mij altijd gesteund en mede dankzij jou, zijn op mijn bachelorstage niet alleen twee master stages, maar ook dit promotie onderzoek gevolgd.

Dear Celine, I learned enormously much from you during the last years. Even in busy times, I knew that I could count on you and your expertise. For almost every challenge, a discussion with you provided possible solutions! Thank you for all of this! I enjoyed working together with you over the last 3 years and I am extremely grateful that you are part of my promotion team! 
Furthermore, I would like to thank the members of the reading committee of my thesis, especially Prof. Steinbusch as the head of the committee, for putting their effort on the evaluation and judgement of my thesis.

Jamie en Kevin, mijn Paranimfen, jullie hebben de afgelopen drie jaar mijn PhD van zeer nauw meegevolgd. Wij hebben drukke tijden, maar ook ontzettend leuke uren op congres met elkaar gedeeld. Jullie zijn ontzettend van belang voor mij geweest binnen de urologie groep. Mede door jullie heb ik geleerd, altijd de klinische implicatie te achtervragen. Of er nu privé of werkgerelateerd iets te bespreken was, ik wist dat ik op jullie kon vertrouwen. Mijn hartelijk dank ervoor! Ik ben ontzettend blij, dat jullie op deze bijzondere dag als mijn paranimfen achter mij zullen staan!

Anna, danke für all die kreativen und gesellingen „Gedanken-ordnen-Kaffepausen”! Ohne diese wäre so manche Schreib- und Denkblockade länger mein Begleiter gewesen! Ich freue mich, dass ich dein Paranimf sein darf und wünsche dir jetzt schon alles erdenktlich Gute für deinen neuen Job!

Ranjana, de laatste weken mocht ik bij jou op kantoor komen zitten. Ik wil je graag danken voor de vele gezellige en productieve uren. Ik kijk nu al uit naar onze nog komende onderzoeks-tijd en de vele pickwick vragen, die nog beantwoord moeten worden;)

It was a pleasure to work in such an enthusiastic research team as the functional urology team in Maastricht. Daisy, Aryo and Martijn, I would like to thank you for the good team atmosphere and fruitful and interesting team meetings.

One important person outside the urology research team was Romina Gentier. Romina, wij hebben onze hele PhD samen doorleefd, met alle up's and down's. Je stond altijd voor mij klaar als ik weer eens iets over de ziekte van Alzheimer moest weten. Ik heb ontzettend genoten van onze lunch-pauzes!

I would like to thank Sandra and Yuan for the great time together at our office. I deeply enjoyed our cultural and scientific discussions or a short chat in between the busy schedule.

Of course, lots of other people from the neuroscience laboratory were important to me during my PhD. Working at the $1^{\text {st }}$ floor, UNS 50, was (and is) a pleasant adventure, characterized by a friendly and helpful atmosphere. Working long days would not have been that successful without the colleagues around me! Thank you, all! 
Several people are indispensable, at the laboratories, at the CPV or at the secretaries. Hartelijk dank, Marjan, Denise, Marcella en Hellen voor jullie inzet op de verschillende labs. Zonder jullie zouden er heel veel dingen misgaan of niet werken! Jullie zijn enorm belangrijk voor onze afdeling!

Ook wil ik de medewerkers van het CPV bedanken: Richard en Saskia voor alle organisatorische hulp, maar ook de dierverzorgers die mij enorm ondersteund hebben tijdens de afgelopen drie jaar. Bedankt Clarice, Rik, Harry, Inger en Paul!

Administrative organisation can be challenging. It was much less challenging due to the commitment of Nancy Logjes, Anja Dullens, and Rachelle Capponi. Dank jullie wel voor jullie inzet en om altijd het onmogelijke mogelijk te maken.

During the three years of laboratory work, which resulted in this thesis, I received lots of help by students. Frank, Christopher, Eugene, Matthijs and Charelle, thanks for your hard work and the good scientific discussions. Your motivation and dedication made it a great experience to supervise you. I wish you all the best for your future!

Besides the people in my direct working environment, several other people supported me during the last years.

Beste Jean, zonder jou zou het boekje er nu absoluut niet zo uitzien als het er uitziet! Je hebt mij last minute geleerd, hoe ik netjes een opmaak doe en mij ontzettend geholpen met het design van mijn kaft! Ook wil ik je danken omdat ik weet dat je altijd wel een luisterend oor voor mij hebt en klaar staat, als ik even voor een koffie moet ontsnappen.

Working hard without any compensation would be impossible. This compensation I found in latin and ballroom dancing. Markus, ich möchte dir danken für die entspannten Stunden beim Tanzen, dein immer offenes Ohr, aber auch für dein nie endendes Verständnis, wenn ich mal wieder aus irgendeinem Grund gerade keine Zeit zum Tanzen hatte!

Schwesterherz, liebe Alex, ohne dich wäre das Buch, welches du gerade in deinen Händen hälst, nicht das, was es nun ist. Ob es nun die Besuche in Nijmegen waren, das Korrekturlesen oder das Zeichnen des Covers, ich konnte immer auf dich zählen. Wenn ich gerade mal keine Zeit habe, weil es zu "druk” ist, hast du immer Verständnis. Ich hoffe, wir werden noch ganz viele lustige Momente erleben, wenn andere Familienmitglieder oder Freunde unserem Kaudawelsch aus Niederländisch, Deutsch und Englisch nicht folgen können ;). Ich wünsche dir viel Erfolg für 
deine Zukunft; ich bin mir sicher, dass du deinen Weg gehen wirst! Schön dich in Maastricht zu haben, Frau buurvrouw ;)!

Auch wenn ihr euch dessen nicht bewusst seid, liebe Omi, lieber Opi, ihr habt einen enorm großen Anteil an diesem Buch geleistet: Ihr habt mit den Grundstock gelegt! Danke für all die Stunden, die du mit mir gelernt hast, liebe Omi! Danke für die geschnittenen Äpfelchen, den Fencheltee, den Grillageboden, der mit etwas Glück in der Blechdose zu finden war, der ich mich als Erstes widmete, als ich bei euch war! Lieber Opi, auch du warst imens wichtig in dieser Zeit! Ja, du warst immer für mich da, wenn ich dich brauchte...aber da ist noch etwas: Vielleicht hast du dich einmal gefragt, wo all deine Büroutensilien hin verschwinden, die in der Schublade im Wohnzimmer gelagert wurden. Nun, diverse Tintenkiller, Lineale, Bleistifte oder Radiergummis landeten regelmäßig in den Schulmäppchen deiner Enkelkinder. Genaueres hierzu wird Omi dir sicher gerne erklären!

Natürlich möchte ich mich auch bei dem Rest meiner Familie bedanken! Gabi, Klaus und Angelika - auch ihr ward immer zur Stelle wenn ich gerade mal eure Hilfe benötigte, seit ab und an gerne mal nach Maastricht gekommen und hattet immer Verständnis, wenn ich gerade mal nicht zu der ein oder anderen Geburtstagsfeier kommen konnte. Lieber Schirra-EnkelkinderKlan: Auch euch habe ich zu danken: für all die ausgelassenen, lustigen Momente, die wir auf so manch einer Familienfeier hatten...Auf dass noch viele weitere folgen werden!

Großer Dank gilt auch meinen Eltern! Ihr habt es mir ermöglicht, meinen Weg zu gehen, auch wenn es nicht immer ganz einfach war. Aber wie ihr seht, es ist alles gut geworden! Danke für alles!

In der „heißen, letzten Phase“ meines PhD's warst du an meiner Seite, lieber Lucky! Danke, für die kurze Zeit, die wir miteinander hatten und für all die Kraft und Energie die du mir geschenkt hast!

Lieber Anan, du hast die letzten 1.5 Jahre des Projekts „PhD“ miterlebt, mich unterstützt und hattest immer ein offenes Ohr. Was aber noch viel wichtiger ist, du hast dafür gesorgt, dass meine ,work-life balance‘ wirklich ein Gleichgewicht wurde. Danke für die vielen gemeinsamen Stunden, Entspannung und Ablenkung wenn eine Pause dringend benötigt wurde und Motivation und Zuspruch, wenn diese zur Neige ging. 


\section{Curriculum Vitae}

Ramona Hohnen was born on February 5th 1988 in Willich (Germany). In 2007, she graduated from the St. Bernhard Gymnasium in Willich, and started her bachelor program in biomedical sciences at Maastricht University in The Netherlands. She received her bachelor's degree in 2010. Already during her bachelor internship, she became interested in urological research. Subsequently, she started her 2 years master program on clinical molecular sciences in Maastricht. After the first year of her master she was awarded with the top $3 \%$ award. There was a growing interest in functional urological research, which made her continue in this research field during both, the junior and senior internship of her master phase. In both internships, she performed her research in the laboratory of the school for Mental Health and Neuroscience (MHeNs) and focused on the autonomous regulation of the urinary bladder. From 2012 on, she started her PhD trajectory at the department of urology under supervision of Prof. Dr. Gommert Van Koeveringe, Dr. Sajjad Rahnama'i and Dr. Celine Meriaux. Her research on peripheral pharmacological targets involved in bladder signalling, is presented in this thesis. 


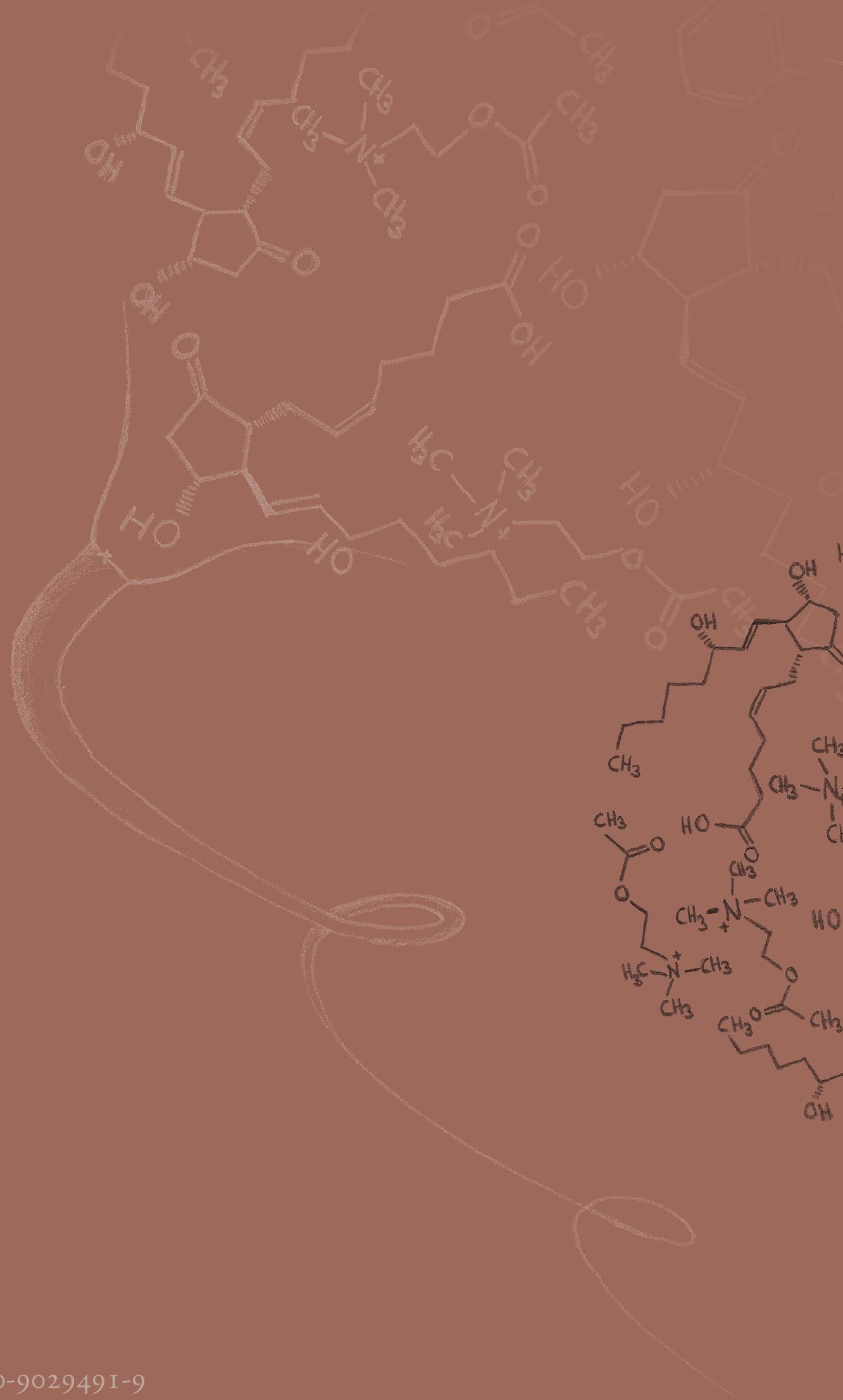

